\title{
COMPOSITION AND PHYSICOCHEMICAL PROPERTIES \\ OF OAT STARCHES
}

CENTRE FOR NEWFOUNDLAND STUDIES

\section{TOTAL OF 10 PAGES ONLY MAY BE XEROXED}

(Without Author's Permission)

S.PJ. NAMAL SENANAYAKE 




\title{
COMPOSITION AND PHYSICOCHEMICAL, PROPERTIES OF OAT STARCHES
}

\author{
BY \\ S. P.J. NAMAL, SENANAYAKE, B.Sc. (Agric.)
}

A thesis submitted to the School of Graduate Sududies in partial fulfilment of the requirements for the degree of the Master of S'sience

Department of Biochemistry

Memorial University of Newfoundland

September, 1995

St. John's

Newfoundland

Canacla 


\begin{abstract}
Starches from two new oat varietics namely AC Stewart (A'cha sativa $L_{n}$ ) and NO 753-2 (Avena mula L.) were isolated and some of their charatereristies determined. The total amount of starch lipids (TSL) extracted hy acid hydrolysis was $1.60 \%(w / w)$ in both starches. The free lipid content (extracted by chloroformmethanol (CM) $2: 1$ v/v at $25^{\circ} \mathrm{C}$ ) was 0.36 and $(0.3(0 \%(\mathrm{w} / \mathrm{w})$ in $\mathrm{N}()$ 7.5. -2 and $\mathrm{AC}$ Stewart starches, respectively. The bound lipid content (extracted by hot n-propanolwater $3: 1 \mathrm{v} / \mathrm{v}$ from the residue left after CM extraction) was 1.27 and I..37\% (w/w) in NO 753-2 and AC Stewart starches, respectively. The total amylose contents were nearly the same ( 23\%, w/w) in both starches, of which 14.1 (No $75.3-2)$ and $15.3 \%$ (AC Stewart) were complexed by native lipids. The starches differed widely in their degree of swelling. gelatinization transition temperateres and enthalpy, susceptibility towards acid and enzyme hydrolysis, gel strength, paste viscosity. thermal stability and retrogradation characteristics. The results suggest that the extent of interaction of starch chains within the amorphous and crystalline regions of the granule wats stronger in NO 753-2 than in AC Stewart.
\end{abstract}




\section{ACKNOWLEDGEMENTS}

I wish (o) express my sincere thanks to the Vice Chancellor. University of Peradeniya, Sri Lanka, for granting me study leave to pursue graduate studies at Memorial University of Newfoundland, St. John's, Canada. Thanks are also extended to the Rotary Foundation. USA, for providing me an opportunity and financial assistance to undertake this degree program at Memorial University. I would also like to acknowledge linancial support from the School of Graduate Studies, Memorial University of Newfoundland (August I - October 31, 1995).

I would like to express my sincere appreciation for the invaluable guidance and advice of my supervisors, Dr. R. Hoover and Dr. A.M. Martin. Thanks to Dr. A. M. Martin for providing me access to his laboratory facilities. The suggestions provided by Drs. F. Shahidi and D. Heeley, as supervisory committee members, are also greatly appreciated. Assistance provided by Dr. S. Ghazala, with texture analyses is gratefully acknowledged.

I am very grateful to my friends, Chandani Perera and Fábio Diniz, for helping me to succeed in all possible ways. Finally. I want to thank all others at Memorial University for their many help in different ways. 


\section{TABLE OF CONTENTS}

ABSTRACT

ACKNOWLEDGEMENTS iii

TABLE OF CONTENTS iv

LIST OF FIGURES viii

LIST OF TABLES X x

LIST OF ABBREVIATIONS X xi

CHAPTER 1. INTRODUCTION 1

CHAPTER 2. LITERATURE REVIEW 3

2.1 Starch-General considerations $\quad 3$

2.1.1 Occurrence 3

2.1.2 Characteristics of the starch granule

2.2 Components of starch

2.2.1 Carbohydrate components

2.2.1.1 Amylose 6

2.2.1.2 Amylopectin $\quad 12$

2.2.2 Nencarbohydrate components

2.2.2.1 Proteins 20)

2.2.2.2 Lipids 21

2.3 The amylose-lipid complex $\quad 22$

2.3.1 Structure 23

2.3.2 Formation of the complex $\quad 25$

2.3.3 Thermal behavior of the complex $\quad 27$

2.4 The amylopectin-lipid complex $\quad 27$

2.5 The crystalline nature of starch 28

2.6 Swelling and solubility of starch 34

2.7 Enzyme digestibility of starch 36

2.7.1 Mode of action of $\alpha$-amylase $\quad 37$ 
2.8 Starch gelatinization

2.8.1 Factors affecting gelatinization $\quad 43$

2.8.1.1 Water

2.8.1.2 Lipids

44

2.8.1.3 Protein

45

2.8. I.4 Sugars

2.9 Starch retrogradation

2.9.1 Amylose gelation

2.9.2 Amylopectin crystallization

53

2.9.3 Factors affecting starch retrogradation

2.9.3.1 Source of starch

54

2.9.3.2 Concentration

55

2.9.3.3 Storage temperature

56

2.9.3.4 Lipids

57

2.9.3.5 Sugars

57

2.10 The oat grain

59

2.11 Oat starch

CHAPTER 3. MATERIALS AND METHODS

3.1 Cereal grain

3.2 Starch isolation and purification

3.3 Chemical composition of starch

3.3.1 Moisture content

3.3.2 Asil content

68

3.3.3 Total protein content

69

3.3.4 Lipid content

69

3.4 Granule morphology

70

3.5 Pasting behavior

3.6 Swelling factor

3.7 Extent of amylose leaching 
3.9 Enzymatic digestibility

3.10 Light transmittance of starch pastes $7+4$

3.11 Amylose content $\quad 75$

3.11.1 Preparation of starch dispersions $\quad 75$

3.11.2 Chrastil's method of amylose determination 76

3.12 X-ray diffraction 76

3.13 Differential scanning calorimetry $\quad 77$

$3.14 \mathrm{Gel}$ prepatation $\quad 77$

$3.15 \mathrm{Gel}$ powder preparation 78

3.16 Freeze-thaw stability 78

$3.17 \mathrm{Gel}$ texture determination 79

$\begin{array}{ll}3.18 \text { Statistical analysis } & 70)\end{array}$

CHAPTER 4. RESULTS AND DISCUSSIONS

4.1 Morphological granular characteristics of the starch

4.2 Chemical composition of the starch 8()

4.3 Amylose content 81

$4.4 \mathrm{X}$-ray diffraction $\quad 82$

4.5 Swelling factor and amylose leaching $\quad 82$

$\begin{array}{ll}4.6 \text { Pasting propertics } & 87\end{array}$

4.7 Gelatinization temperatures gl

4.8 Light transmittance 94

4.9 In vitro digestibility of native starches by porcine pancreatic $\alpha$-amylase $\quad$ (94

4.10 Acid hydrolysis $9 \mathrm{~K}$

4.11 Retrogradation of oat starch gels $\quad$ [()] 
4.11.I Frecre-thaw stability

4.I I.2 Differential scanning calorimetry

4.11 .3 X-ray diffraction

4.11.4 Gel firmness

CONCIUUSIONS

112

REFERINCES

114

PUBLICATIONS

140 


\section{LIST OF FIGURES}

Fig. 2.1 Schematic representation of the arrangement of amylopectin molecules within a growth ring of a starch gramule.

Fig. 2.2 Schematic of the organization (structure) of a starch granule.

Fig. 2.3 Structure of the amylose and amylopectin components of starch.

Fig. 2.4 Segment of a hypothetical branched $(1-4)-\alpha-1)-$-glucan.

Fig. 2.5 Cluster model of innylopectin.

Fig. 2.6 Schematic illustration of monostearin-amylose helical complex with the whole chain inside the heicial space.

Fig. 2.7 Typical diffactometer pattens for starches giving A-, B-, and C-type X-ray spectra.

Fig. 2.8 Double-helix packing arrangements it, A- and B-type unit cell structures of erystalline amylese.

Fig. 2.9 A schematic representation of the processes and structures observed during heating and storage of aqueous suspensions of granular starch.

Fig. 2.10 Double helix formation and association.

Fig. 2.11 The oat caryopsis.

Fig. 4.1 Scanning electron micrographs of native vat starches.

Fig. 4.2 X-ray diffraction patterns of native oat starches.

Fig. 4.3 Freeze-thaw stability of native oat starches. 
Fig. 4.4 X-ray diffraction patterns of retrograded NO 753-2 starch gels us a function of storage time (at $25^{\circ} \mathrm{C}$ ).

Fig. 4.5 Gel strength of oat starches as a function of storage time (at $\left.25^{\circ} \mathrm{C}\right)$. 


\section{LIST OF TABLES}

Table 2.1 Structure and physicochemical properties of starch polymets.

Table 4. I Chemical composition (\%) of uat starches.

Table $4.2 \mathrm{X}$-ray diftraction spacings and intensitics of the major peaks of oat starches.

Table 4.3 Effect of temperature on swelling lictor of oat starclecs.

Table 4.4 Effect of temperature on amylose leaching of oat stanches.

Table 4.5 Pasting characteristics of oat starches.

Table 4.6 Differential scanning calorimetry of oat starches.

Table 4.7 Effect of $\mathrm{pH}$ on light transmittance $(\%)$ of native wat starches.

Table 4.8 Time course of hydrolysis of native oat starches by porcine pancreatic $\alpha$-amylase.

Table 4.9 DSC gelatinization parameters of enzyme treated granular residues following hydrolysis with porcine pancreatic $\alpha$-amylase.

Toble 4.10 Heteiogenous acid hydrolysis of native oat starehes in $2.2 \mathrm{~N} \mathrm{HCl}$ at $35^{\prime \prime} \mathrm{C}$.

Table 4.11 The enthalpy of retrogradation of native oat starch gels.

Table $4.12 \mathrm{X}$-ray diftaction spacings and intensitics of the major peaks of retrograded oat starch gels. 


\section{I.IST OF ABBREVIATIONS}

$\begin{array}{ll}\text { BU } & \text {-Branender units } \\ \text { CL } & \text {-Choin length } \\ \text { CTAB } & \text {-Cetyltrimethylammonium bromide } \\ \text { CM } & \text {-Chlorolom-methanol } \\ \text { DP } & \text {-Degree of polymerization } \\ \text { ISSC } & \text {-Differential scanning calorimetry } \\ \text { IDMSO } & \text {-Dimethylsulfoxide } \\ \text { IECL } & \text {-Exterior chain length } \\ \text { ESR } & \text {-Flectron spin resontance } \\ \text { GMP } & \text {-Monopalmitin } \\ \text { GME } & \text {-Monoclaidin } \\ \text { GMO } & \text {-Monoolein } \\ \text { GML } & \text {-Monolinolein } \\ \text { GMS } & \text {-Monostearin } \\ \text { GMM } & \text {-Monomyristin } \\ \text { ICL } & \text {-Interior chain length } \\ \text { PW } & \text {-n-Propanol-water } \\ \text { SSL } & \text {-Sodium stearoyl-2-lactylate } \\ \text { SDS } & \text {-Sodium dodecyl sulfate } \\ \text { SEM } & \text {-Seanning electron microscopy } \\ \text { SEL } & \text {-Solvent extracted lipids } \\ \text { TSL } & \text {-Total starch lipids } \\ \end{array}$




\section{DEDICATED TO MY LOVING PARENTS}




\section{CHAPTER 1 \\ INTRODUCTION}

Oats have been grown for thousands of years as a forage crop and a feed grain rather than for use as human food. Unlike other world cereal crops such as wheat, corn, barley, and rice, oats have received little attention as a subject of major scientific or industrial study.

Oats are unique in their uses and attributes in comparison to most other cereal grains. Most oats used as food are consumed as whole grain products so that the nutritional quality characteristics of the oat are reflected in the food product. The major food uses of oats are in hot and cold cereals. bread products, cookies, and infant foods. Oat products are often used in bakery items to pri duce desired texture or to increase moisture retention (Paton, 1986). A specially fine-ground oat flour was marketed for antioxidant purposes and found to be very effective to some extent in milk and milk powder, butter, ice-cream, cereals and other products that are sensitive to lipid oxidation during storage (Paton, 1979).

Due to increased awareness regarding the nutritional value of oats, considerable attention has been paid to this cereal grain in recent years (Paton, 1986). Nonetheless, it is difficult to obtain any commercial oat starch as a food ingredient since the starch industry utilizes primarily wheat, potato, maize and rice as raw material. 
Many researchers have investigated physicochemical properties of out starch including pasting, swelling. gelatinization, X-ray diffraction and granular characteristics (Paton, 1977, 1979. 1987; MacArthur and D'Appolonia. 1979): Doublier et al.. 1987a.b). Considerable difference has been observed between the physicochemical properties of oat starch and that from other cereal grains and also between oat starch cultivars (P'atton. 1977,1987; Gudmundsson and Eliasson, 1989; Hoover and Vasanthan, 1992; Sowa and White, 1992). Oat starch has been shown to differ from other cereal starches in several ways: 1) Starch gels are less susceptible to retrogradation during storage than olher cereal starch gels, e.g. maize and barley (Gudmundsson and Eliasson, 1989). 2) During heatting of oat starch suspensions, both anylose and amylopectin are coleached from the granules (Doublier et al., 1987a,b). 3) Starch granules have a marked tendency to aggregate into clusters (Hoover and Vasanthan, 1992). However, there is a dearth of information on the variation in crystallinity, digestibility and retrogradation properties between oat starches isolated from different cultivars.

The objectives of this study were to compare the thermal, digestibility, rheological and retrogradation properties of oat starches extracted from two new varictics, NO 75.3-2 (hull-free oat) and AC Stewart (hulled oat). These properties were investigated by differential scanning calorimetry (DSC), X-ray diffractometry, rheology, scanning electron microscopy (SEM), freeze-thaw stability and paste clarity. 


\section{CHAPTER 2}

\section{LITERATURE REVIEW}

\subsection{Starch-General considerations}

Starch is a potential carbohydrate polymer with widespread use in foods as well as in technical applications. It is not only available at relatively low cost, but is also convertible to versatile products through biological or physicochemical modifications of the molecular or granular structure. Besides its technical uses, mainly in paper, textile, and chemical industries, starch is of importance in food applications for improving quality of food because of its unique physicochemical properties.

\subsubsection{Occurrence}

Starch is the major energy reserve carbohydrate in the plant kingdom (Manners, $198.5 \mathrm{c})$. It is synthesized in the form of granules irrespective of whether energy storage is transient (e.g. in leaves) or longterm (e.g. in seeds). The storige of starch in the form of granules is a convenient method since starch is an insoluble source of energy that can be gradually made available through the action of enzymes.

Starch can be found in all organs of most higher plants and their modifications (Imberty et al.. 1991). It is metabolically easily accessible, in contrast to cellulose, and therefore, is an excellent source of energy. In all cases, it is produced in plastids. In fact, 
the ability to produce starch is a characteristic feature of the plastids of higher plants (Badenhuizen, 1965).

Starches can be deposited in tubers, bulbs, seeds, mizomes, stems, and unripe fruits. The most important starches of commerce are from seds of cereal gatins (maiz. rice, wheat, etc.) and from underground storage organs (potato, sweet potato, cassaval) (French, 1975).

\subsubsection{Characteristics of the starch granule}

The starch granule is a densely packed, semi crystalline malterial, and it is not soluble in cold water. The size, morphology and chemical composition of the starch granules are plant specilic, and are also influenced by the growing conditions of the plant (Shannon and Garwood, 1984). In the cereal or legume seed endosperm, potato tuber, and other plant reserve organs, starch is deposited in the form of granules that range in sire between $\mathrm{I}$ and $100 \mu \mathrm{m}$ and have a variety of shapes depending on their botitical source. Potato starch granules, for example, are large (perhaps $100 / 1 \mathrm{~m}$ in diamete') and oval, whereas rice starch granules are smaller (at most $10 \mu \mathrm{m}$ in diameter) and much more angular (Jenkins et al., 1993). In cach case, an examination of these granules under optical or electron microscopy reveals pronounced concentric rings (French, 1984). These rings are alternately of semi-crystalline and amorphous composition as shown by their differing 
susceptibility to $\alpha$-amyluse attack. These rings are referred to as "growth rings", and are generally observed to be between $J 200$ and $4000 \AA$ in size (Manners, 1985 c; Jenkins et al., 1993).

At a higher level of organisation, the semi-crystalline rings are composed of stacks of alternating crystalline and amorphous lamellae. The combined repeat distance of crystalline and amorphous lamellae accounts for the peak observed in small angle X-ray and neutron scattering experiments. The crystallinity is associated with the branched amylopectin component of the starch granule. The currently accepted crystalline structure consists of a radial arrangement of clusters of amylopectin (Jenkins et al., 1993). Each cluster contains a region high in branch points (the amorphous lamella) and a region where short chain segments of amylopectin have formed double helix structures (the crystalline lamella) (Fig. 2. 1 a and b). Lineback (1984) proposed a typical and plausible model for the overall distribution of amylose and amylopectin within the granule (Fig. 2.2).

Cameron and Donald (1992) have developed a model which allows quantification of the various parameters needed to describe this complex structure. The starch granule structure is modelled as a finite number of lamellae of alternating electron density (crystalline regions $\mathrm{C}$ with high electron density, and amorphous regions $\mathrm{A}$ with low electron density) embedded in a background region (B) of a third electron density, assumed to correspond to the amorphous growth rings (Fig. 2.1c). 


\subsection{Components of starch}

\subsubsection{Carbohydrate components}

Starch contains two mijor high molecular weight earbohydrate components. Amylose has traditionally been considered to be a linew polymer composed of glucopyranose units linked through $\alpha$-D-( $1 \rightarrow 4)$ glycosidic linkages (l'ig. 2.3A). Although there is now evidence that amylose is not completely linear (llizukuri et al., 1981), its behaviour is that of a linear polymer. Amylopectin is a branched polymer (Fig. 2.3k) containing short (degree of polymerization (DP)= 20)-25 glucopyranose residues) chatiss linked to the C-6 hydroxymethyl position of certain glucose moietiss vial $\alpha-1)-(1$ p() linkages. In addition to the line structure, amylose and amylopectin difler in matly respects, as shown in Table 2.1 (Biliaderis, 1991).

\subsubsection{Amylose}

Amylose is found with molecular weights ranging from $100^{5}-10^{\prime \prime}$ and with the number of glucose residues per molecule, DP, ranging from 500 w $500(0)$. Although considered to be an essentially linear $\alpha-(1-4)$-glucan, amylose extricted from starches is not completely hydrolysed by the $\alpha-(1 \rightarrow 4)$-specilic, $\alpha$-amylase, unless an $\alpha-(1 \quad$ (1) glucan hydrolase (c.g. pullulanase) is also) added (Manners, 198.0). That a certain 
Fig. 2.I Schematic representation of the arrangement of amylopectin molecules within a growth ring of a starch granule. (a) A single amylopectin cluster with double helix formation. (b) Schematic representation of the arrangement of amylopectin molecules within a semi-crystalline growth ring. (c) The structure may be modelled in terms of a stack of lamellae alternating in electron density (crystalline regions $\mathrm{C}$ and amorphous regions $A$ ), embedded in a background region (B) of a different electron density. Adopted from Jenkins et al. (1993). 


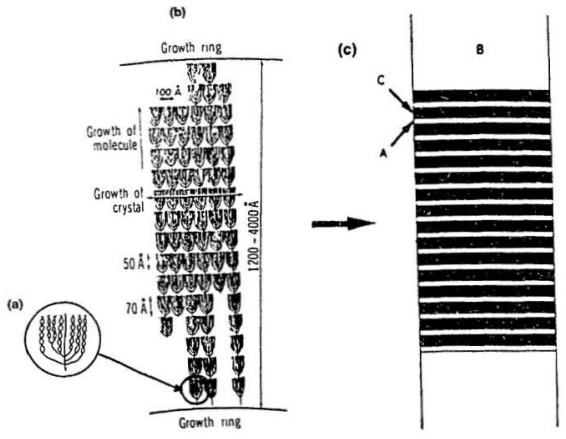


Fig. 2.2 Schematic of the organization (structure) of a starch granule. Adopted from Lincback (1984). 


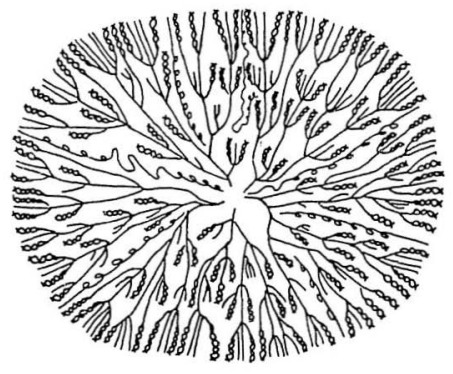


Fig. 2.3 Structure of the amylose and amylopectin components of starch. A, diagram of a portion of an amylose molecule; B, enlarged view of the shaded section of A, showing the chemical formula: $C$, diagram of a portion of an amylopectin molecule; $D$, enlarged view of the shaded section of $\mathrm{C}$, showing the chemical formula. Adopted from Pataur (1965). 


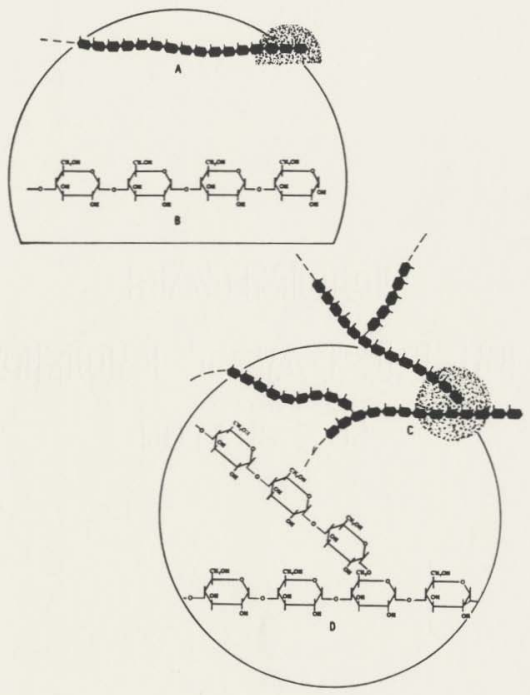


Table 2.1 Structure and physicochemical properties of starch polymers .

\begin{tabular}{|c|c|c|}
\hline Property & Amylose & Amylopectin \\
\hline Molecular structure & $\begin{array}{l}\text { Essentially linear. } \\
\alpha-(1 \rightarrow 4)\end{array}$ & $\begin{array}{l}\text { Branched. } \\
\alpha-(1 \rightarrow 4) \text { and } \alpha-(1 \rightarrow 6)\end{array}$ \\
\hline Degree of polymerization & $-10^{3}$ & $-10^{4-1}-10^{5}$ \\
\hline Molecular weight & $1.5 \times 10^{5}-10^{6}$ & $(50-500) \times 10^{6}$ \\
\hline Average chain length & $\sim 10^{3}$ & $\sim 20-25$ \\
\hline $\begin{array}{l}\text { (color) } \\
\text { Iodine complex }\end{array} \lambda_{\max }$ & $\begin{array}{l}\text { 600-640 } \mathrm{nm} \\
\text { (blue) }\end{array}$ & $\begin{array}{l}530-550 \mathrm{~nm} \\
\text { (purple) }\end{array}$ \\
\hline $\begin{array}{l}\text { Digestibility (\%) } \\
\text { \$-Amylase } \\
\beta \text {-Amylase and debranching enzyme }\end{array}$ & $\begin{array}{l}-70 \\
\sim 100\end{array}$ & $\begin{array}{l}\sim 55 \\
\sim 100\end{array}$ \\
\hline Stability of dilute aqueous solutions & Unstable (retrogrades) & Stable \\
\hline Gel texture & $\begin{array}{l}\text { Stiff, irreversible } \\
\left(T_{m}>100^{\circ} \mathrm{C}\right)\end{array}$ & $\begin{array}{l}\text { Soft (thermally reversible } \\
\text { at }<100^{\circ} \mathrm{C} \text { ) }\end{array}$ \\
\hline Film properties & Strong. coherent & Brittle \\
\hline
\end{tabular}

Adopted from Biliaderis (1991). 
degree of branching is present in amylose has been confirmed recently by Hizukuri at al. (1981), who have demonstrited that amylose from different sources contains, on average, $2-8$ branch points per molecule, the side-chains ranging in chain-length from 4 to $=100$ glucose units. In a recent study it wis found that $1.6 \%$ of the glucose in amylose was in fact found in an $\alpha(1 \rightarrow 6)$ branching point (Curà and Krisman, 1990).

The solution behaviour of amylose has been interpreted as heing that of a random coil, with no marked helical content in agueous solution in the absence of eomplexing agents (Ring ot al.. 1985). Small-angle X-ray scattering data suggest that the amylose chain is highly disordered but that short-range helical structures might exist (Braga et al.. 1985). These helical structures are both irregular and labile. Although amylose is slightly branched, as described above, the branching does not inlluence its behaviour in solution; amylose behaves as a linear polymer.

There are two features of amylose in solution that are of special interest in relation to baking. The first is the great tendency to form intramolecular hydrogen bonds, which means a strong tendency toward crystallization (also referred to as retrogradation). An amylose solution is therefore, not very stable. For a $2.4 \%$ amylose solution, turbidity is observed only a few minutes after cooling to $32^{\circ} \mathrm{C}$ (Miles et al., 19855). The development of crystallinity can be followed by the $\mathrm{X}$-ray powder technique, and it is found that crystallinity develops at a slower rate than turbidity. Moreover, the crystallinity develops 
in the polymer-rich phase. 'The second feature of interest concerning amylose in solution is its ability to form helical inclusion complexes. When the proper ligand is present, anylose forms a helix with the ligand in the cavity. The formation of a complex between amylose and iodine causes the typical blue colour, as this complex has an absorption maximum at $\lambda=640 \mathrm{~nm}$ (Williams ef al.. 1970).

\subsubsection{Amylopectin}

Amylopectin is an $\alpha-(1 \rightarrow 4)$-D-glucan containing $4-5 \% \alpha-(1 \rightarrow 6)-D$-glycosidic linkages (branch points) (Imberty et al., 1991). This highly branched polymer has one of the highest molecular weights (greater than $10^{*}$ ) known among naturally occurring polymers. Because of the short length of the exterior chains, amylopectin does not form strong complexes with icdine.

A number of terms are now frequently used to describe the structural parameters of amylopectin-type molecules. Exterior chains are those parts of a chain between the non-reducing end-group and the outermost branch point, whilst interior chains represent parts of a chain hetween branch points in the interior of the molecule (Fig. 2.4). A-Chains are linked to the molecule only by the potential reducing group, whilst B-chains are similarly linked, but also carry one or more A-chains. The C-chain carries the sole reducing group in the molecule. although for some purposes, the possible presence of a 
reducing group is not significant. and the C-chain can be regarded als a B-chain (Meyer and Bernfeld. 194()).

It must be emphasised that analytical methods for measurements of the chatin length (CL), exterior chain length (ECL) and interior chain length (ICL) give average values, and that individual chains can vary considerably in length. From the above definitions and ligg. 2.4 , it can be seen that an amylopectin molecule contains roughly eyual numbers of exterior and interior chains. If the molecule has an A:B chain ratio of $1: 1$, then each $A$ chain is also an exterior chain, and each B-chain, on the average, consists of one exterior and two interior chains (Robin et al., 1975). In fact, many B-chains anc known fo consist of one exterior and only one interior chain. Other B-chains contain one exterior and three or mc.e interior chairs. The proportion of very Iong B-chains will decrease as their C.L. increases. Nevertheless there is now evidence for a small proportion of B-chuins containing perhaps 50 or more glucose residues which play a key role in the overall molecular structure.

Although the main structural leatures of amylopectin have been known for sime 50 years, details of the fine structure are still lacking. Indeed, there is still some uncertainty about the detailed arrangements of the constituent linear chains of (1 +4)linked $\alpha$-D-glucose residues, and during the period 1970-81, three different molecular structures for amylopectin were proposed (French, 1972; Robin et al., 1974; Manners 
Fig. 2.4 Segment of a hypothetical branched $(1 \rightarrow 4)-\alpha$-D-glucan. In amylopectins, the exterior chains may contain 12-16 glucose residues, but in phytoglycogen and animal glycogens, they are about hall this length, ${ }^{\circ-}$ a $(1 \rightarrow 4)$-linked $\alpha$-D-glucose residue; $0^{+}$, il $(1-r 6)$-linked $\alpha$-D)-glucose residue; $R$, a free reducing group; A,B and C, types of chain. Adopted from Manners (1989). 


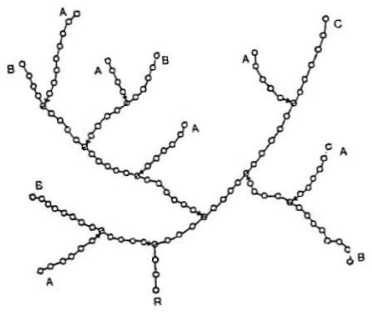


and Matheson, 1981). One of these molecular structures, the so called cluster model, has emerged as the most probable structure, although there are some variations of the cluster model, and it is not yet clear whether it applies to all amylopectins, irrespective of the botanical source of the starch (Manners, 1989).

The fine structure of amylopectin represents something of a paradox (Manners, 1989). In purcly chemical terms, it could scarcely be simpler. It is composed of only one monosaccharide residue, the great majority of which are joined together by $(1 \rightarrow 4)-\alpha-D$ glycosidic linkages to form chains of varying lengths. Amylopectin also contains about 4 $5 \%$ of $(1 \rightarrow 6)-\alpha$-D-glycosidic linkages which interlink the chains to form a three dimensional macromolecule. The problems arise from the very high molecular weight of amylopectin $\left(\sim 10^{7}\right)$ giving a DP of $\sim 10^{5}$. Since the average length is usually $20-25$ glucose nesidues, it follows that each macromolecule contains several thousand individual chains (Manners, 1985c).

From a chemical point of view, three types of glucose residues can be described. There are $4-5 \%$ of non-reducing end-groups, which lead to tetra-o-methyl-D-glucose on methylation analysis. There are an equal number of branch point residues which are triply linked by two $(1 \rightarrow 4)$ - and one $(1 \rightarrow 6)-\alpha$-D-glycosidic linkages to adjacent residues. These give rise to di-o-methyl-D-glucose on methylation analysis. However, some $90 \%$ of the glucose residues are indistinguishable from each other by chemical-analytical techniques 
(Manners, 1989).

Substantial progress in investigating the fine structure of amylopectin has hecome possible by the use of highly purified debranching enzymes. These enrymes specilically hydrolyse the $(1 \rightarrow 6)-\alpha-D$-glyeosidic inter-chain linkages in anylopectin and derived dextrins, but have no action on the major $(1-4)-\alpha$-D-glycosidic linkages (Manners, 1974). Their specificity is therefore opposite to that of the conventional $\alpha$ - and $\beta$ amylases.

Four classes of enzymes have been widely used in studies of the fine structure of amylopectin. $\alpha$-Amylases hydrolyse non-teminal $(1 \rightarrow 4)-\alpha-1)$-glycosidic linkages liy a partly random action to give eventually a mixture of maltose. branched oligosaceharides ( $\alpha$-dextrins) and either maltotriose or glucose depending on the rolative concentrations of enzyme and substrate (Manners, 1989). The $\alpha$-dextrins contain the originat ( interchain linkages and two or more adjacent $(1 \rightarrow 4)-\alpha-1)$-glyeosidic linkages. The $\alpha$ dextrins are a heterogeneous mixture with DPs ranging from 4 to more than 10, and individual $\alpha$-dextrins may contain one, two or even three ( 1 - (1) inter-chain linkages, depending on their proximity to each other in the original macromolecule, and whether the enzyme can hydrolyse $(I \rightarrow 4)-\alpha$-D-glycosidic linkages in very short interior chains containing perhaps only two, three or four glucose residues. There is some evidence that $\alpha$-amylases require a linear segment of at least five glucose residaes for rapid hydrolysis. 
$\beta$-Amylases hydrolyse, in stepwise fashion, alternate linkages in their substrates, so that linear molecules are completely converted into maltose (French, 1975; Manners, 1985c). It should be noted that chains containing an odd number of residues will give one molecule of maltotriose or glucose, depending on the concentration of enzyme, along with the many molecules of maltose.

With branched substrates, enzyme action is confined to the exterior chains, since $\beta$-amylase cannot hydrolyse or bypass $(1 \rightarrow 6)$ inter-chain linkages. Enzyme action ceases leaving 'stubs' containing an average of two glucose residues per chain. With A-chains, the stubs actually contain either two or three residues per chain, whilst with B-chains, either one or two residues are present in the stub (French, 1975).

Amylopectins are also degraded by plant and animal phosphorylases (Manners, 1985c). In the presence of inorganic phosphate, enzyme action results in a stepwise cleavage of adjacent linkages in the exterior chains to give about $40 \%$ of $\alpha$-D-glucose 1phosphate. Like $\beta$-amylase, the phosphorylases cannot degrade or by-pass the inter-chain linkages, and enzyme action ceases giving 'stubs' of about four glucose residues.

The structure of amylopectin has been investigated extensively, and a number of molecular models have been proposed (Manners, 1989). The gerieral view that has emerged during the last 15 years or so is that amylopectin has a cluster type structure (see Fig. 2.5). In this structure, only a small portion of an amylopectin molecule is shown to demonstrate the concept of "clusters" of interchain branching points (French, 1972; 
Fig. 2.5 Cluster model of amylopectin. Adopted from Robin et al. (19)74). 


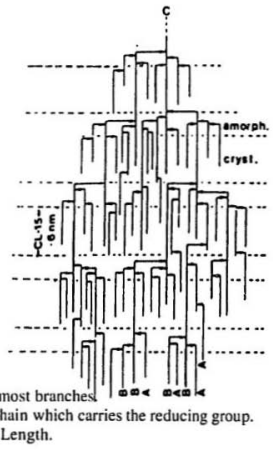


Robin et al. 1974: Manners and Matheson, 1981).

\subsubsection{Noncarbohydrate components}

A number of minor noncarbohydrate constituents, particularly lipids, proteins, phospholipids and plant cell-wall materials may also be present in starch (Gracza, 1965). These occur in such small amounts that is not clear whether they are trace components of the starch granule or are contaminants that are not completely removed during isolation of the starch. Although they are present in small amounts, they can, nevertheless, affect the functional properties and behaviour of the starch (Lincbuck and Rasper, 1988).

The minor components of starches may be considered in three categorics, aceording to their location: (I) Particulate material- fragments of non-starch substances (e.g. insoluble proteins and cell-wall material) that separate with starch (2) Surface components- material associated with the surface of granules (e.g. residues of amyloplast membranes, water soluble proteins and inorganic material) and that may be removed by extraction procedures which do not cause disruption of the granule internal structure (3) Internal components- material buried within the granule matrix (e.g. lipids that appear to be associated with the amylose fraction, nitrogenous phospholipids and internal proteins) and inaccessible to extraction without granule disruption (Galliard and Bowler, 1987). 


\subsubsection{Proteins}

Grac/a (1965) reported the presence of $0.24 \%$ protein (N X 6.25, dry basis) in oat starch. The nitrogen is generally considered to be present as protein, but it may also be part of lipids (e.g. lysophosphatidylcholine in wheat starch). In general, as the purity of isolated starch increases, the amount of protein present decreases. The protein present is of different types, depending on, among other things, the starch preparation procedure.

Other proteins present might be enzymes, either remaining from the starch synthesis or those necessary for the hydrolysis of starch when the seed germinates. Two types of amylases are present: $\alpha$-amylases and $\beta$-amylases. $\alpha$-Amylase is an endoenzyme, meaning that it breaks $\alpha(\mathrm{I} \rightarrow 4)$ bonds randomly (more or less). The size of the starch molecules will quickly be reduced owing to the action of $\alpha$-amylase, and consequently the viscosity of a starch suspension rapidly decreases when $\alpha$-amylase is present (Robyt and Whelan, 1968a). $\beta$-Amylase is an exoenzyme, meaning that the $\alpha(1 \rightarrow 4)$ glycosidic bonds are hydrolyzed from the nonreducing end during the release of maltose. However, when the enzyme meets an $\alpha(1 \rightarrow 6)$ linkage, its action is stopped, and the $\beta$-amylase leaves $\beta$-limit dextrins as a result of its action (Robyt and Whelan, 1968b; Manners, 1974). 


\subsubsection{Lipids}

Lipids are among the minor components of starth granules that have received most attention, particularly those from within the granule matrix. These ane distinguished clearly from other lipids associated with starch granules on the hasis of selective extraction methods. Morrison et al. (1975) have used cold and hot solutions of walersaturated butanol to separate 'non-starch' lipids (removed by cold solvent fiom ungelatinized granules) from the 'starch' lipids that are released only slowly with cold solvents and that require gelatinization of starch for efficient extraction.

The way in which lipids are distributed at the surface of starch gramules is not known. The surface lipid content of well-washed starch granules of wheat is sulficient to form a bimolecular lipid layer on the surface of granules of average diameter of

$10 \mu \mathrm{m}$ (Galliard and Bowler, 1987). However, there is no evidence of an intact 'membrane' around granules of isolated starch. It is more likely that lipid matcrial is distributed unevenly at the granule surface. Whether an uneven distrilution of lipid and other materials on the surface of granules contributes to the ohserved resistance of parts of the granule surface to attack by $\alpha$-amylase remains to be determined.

Lipids associated with native ecreal starches have heen differentiated ats non-starch, surface and internal lipids the last being true starch lipids inside the granules. Non-sitarch lipids can reside either in a free state or they are bound together with proteins to the 
surface of granules. This fraction of lipids is composed of triacylglycerols, diacylglycerols, diacylglucolipids, phospholipids, tocopherols, sterols and carotenoids constituting aleurone lityer and germ (Gibinski et al., 1993). Free fatty acids as well as monoacylglycerols resulting from lypolysis on isolation and storage of starch (Liukkonen and Lilakso, 1992) are also present. Monoacyl lipids, penetrated into interior of granules on isolation of starch, are considered as surface lipids (Liukkonen and Laakso, 1992). Internal lipids of cereal starch are composed exclusively of monoac ylglycerols, free fatty acids, and lysuphospholipids. Such lipids reside either inside the cavity of the amylose helix or in the spaces between anylose and amylopectin. Therefore, rigorous conditions are needed to swell the starch granules sufficiently to permit complete lipid extraction.

\subsection{The amylose-lipid complex}

Amylose forms crystalline complexes with a variety of polar and non-polar organic compounds. These complexes play an essential role in every process associated with the utilization of starch-containing materials. Thus, texture and structural stability of cereals and starch-based products are greatly influenced by complex formation of linear starch components with varioas ligands (Krog and Lauridsen, 1976; Lund, 1984). 


\subsubsection{Structure}

There is now ample evidence from a range of physical and chemical studies about the nature and structure of amylose-lipid complexes, as represented in Fig. 2.6. The amylose molecule forms a single helix and its hydrophobic cavity is occupied by a ligand. For a polar lipid such as a monoacylglycerol, each turn of the helix consists of six glucose residues, and on the average there are two to three turns for each monoacylglycerol molecule. On the average, about two-thirds of the hydrocarbon chatin is involved in the complex (Carlson et al., 1979). Each amylose molecule may contain several helices with ligands. When the ligand is more bulky than a fatty acid chain, the turn in the helix can consist of seven or eight glucose residues (Yamishita et al., 1973; French and Murphy, 1977). The list of ligands that complex with amylose is long and includes fatty acids, monoacylglycerols, surfactants such as sodium dodecyt stiphatc (SDS), cetyltrimethylammonium bromide (CTAB), lecithin, alcohols, carhoxylic acids, and even cyclic compounds such as cyclohexanol (Mikus at al., 1946; Osman et al.. 1961: Lagendijk and Pennings, 1970; Eberstein et al., 1980; Gough et al., 1985; Eliasson and Krog, 1985; Kowblansky, 1985; Eliatsson, 1986b; Evans, 1986; Eliasson, 1988).

One of the strongest pieces of evidence for the structure of amylose-lipid complexes is the characteristic ' $\mathrm{V}$ ' pattern in X-ray diffraction studies (Osman ef al., 1961; Zobel et al., 1967). The ' $\mathrm{V}$ ' type pattern is readily observed in cereal starches. The complex is not 
Fig. 2.6 Schematic illustration of monostearin-amylose helical complex with the whole chain inside the helical space. Adopted from Carlson et al. (1979). 


\section{LIPID POLAR GROUP}

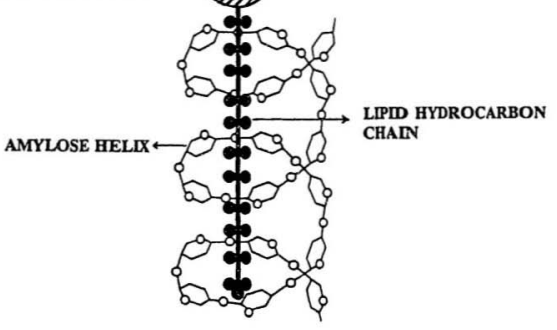


formed only by monoacyl lipids; lecithin also gives the 'V' pattern (Osman et al., 1961). The unit cell of the complex is orthorhombic with the dimensions $a=13.0 \AA \AA, b=23.0 \AA$, and $c=8.05 \AA$ (Mikus $d$ al., 1946). The packing of the helices is the same; the ligand is either a fatty acyl or iodine, although some variations in d-spacing due to the ligand in the complex have heen reported (Osman ct al., 1961). Moreover, the d-spacings observed were also related to the tratment of the complex- to whether it was extracted with carbon tetrachloride or methanol. The amylose chains in the crystals are folded and form a lamellar structure (Manley, 1964).

The circumstance that native starch does not show the 'V' pattern (except in a few special cases (Zobel, 1988:1)) has been taken as evidence that the amylose complex does not exist in the native starch but is formed during starch gelatinization. However, the absence of the ' $\mathrm{V}$ ' pattern cloes not prove the absence of the amylose-lipid complex, it merely proves that the complex is not arranged in crystalline domains that we can detect by the X-ray diffaction technicue.

\subsubsection{Formation of the complex}

To achieve the best conditions for the formation of a complex between amylose and monoucyl lipids. both should be in solution. If a solution of monoacyl lipids is added to a solution of anylose, the complex forms as a white precipitate, which can be collected 
by centrifugation for further studies. The presence of uneomplexed lipid can he checked by DSC if the chain melting temperature is suitable. It has boen noted that the existence of uncomplexed lipid is common when dimethylsulphoxide (DMSO) is used as solvent. perhaps because the monoucyl lipids and DMSO compete for the same site in the helieil cavity (Raphaelides and Karkalas. 1988).

Complex-forming ability differs among the monocylglycerols (() sman (') al.. I)(1): Lagendijk and Pennings, 1970): Krog. 1971; Hoover and Hadriyev, (981). Monomal lipids with a large polar group, or diacyl lipids such as lecithin, were shown to have poor amylose-complexing ability (Osman ot al., 196); Krog, 1971). To form a precipitale, a higher amount is required for a diacylglycerol than for a monoacylglycerol (O)sman of al., 1961).

When the complex-forming abilities of monopalmitin (GMP), monoclaidin (CiMI:), monoolein (GMO), and monolinolein (GML) were compared, GMI: was found to be the best when the monoacylglycerols were added as acqueous clispersions al 30 ) C ( Riisom et al., 1984). At these conditions GMP forms $\beta$-crystals, the cis-unsituratled monoacylglycerols form a cubic phase, and GME is in the border region between the $\beta$ crystalline form and the lamellar phase. If all monoacylglyecrols were added as liposimes (liposomes prepared with the aid of sodium cholate), their complexing ability was increased. 


\subsubsection{Thermal behaviour of the complex}

Differential scanning calorimetric studies of Kugimiya ef al. (1980) have shown that the presence of an endothermal transition typical of cereal starches near $100^{\circ} \mathrm{C}$ was due to the melting of amylose-lipid complexes. Formation of these complexes can be observed as an exothermal transition at a temperature range of 60 to $80^{\circ} \mathrm{C}$ when starch free of lipid is gelatinized with a water-soluble lipid. However, the melting temperatures depend on the water content (Biliaderis et al., 1985: Eliasson. 1986b). The size of the melting endotherm of the amylose-lipid complex can be used to calculate the amylose content of starch (Roos, 1992).

\subsection{The amylopectin-lipid complex}

It has been assumed that amylopectin molecules do not form complex with polar lipids. When emulsifiers are added to an amylopectin solution, no precipitate is formed, as it would with amylose (Krog, 1971). However, a slight decrease in iodine absorption is olserved. On the other hand, when amylopectin and monoacylglycerols were suspended in water at $60^{\circ} \mathrm{C}$ for several hours, a precipitate was formed (Batres and White, 1986). The least amount of complex was formed with monostearin (GMS), whereas GMP gave the highest amount and monomyristin (GMM) produced a moderate amount. The iodine aftinity of these complexes was lower than that of amylopectin. 
DSC studies have shown that retrogradation of starch decreases when monoacyl lipids are added to the starch (Russell, 1983). This effect has been explained by the formation of amylose-lipid complex. It should be remembered. however. that these DSC measurements show the retrogralation of amylopectin. It is not evident how the amyloselipid complex can affect the retrogradation of amylopectin. The simplest explanation may be that the amylose-lipid complex does not affect the retrogradation of amylopectin and that it is the polar lipid that directly affects the amylopectin. This explanation is supported by the fact that it is possible to decrase the retrogradation of waxy maize starch or amylopectin by the addition of monoacyl lipids (Eliasson and Ljunger, 1988).

Several indirect measurements have indicated the existaned of an amylopectin-lipid complex. As described above, the retrogradation of waxy maize starch and anylopectin is affected by monoacyl lipids but not by triacylglycerols (Fliasson and Ljunger. 1988). Equilibrium dialysis indicates that stearic acid is bound to waxy maize starch; $0.76 \mathrm{~g}$ stearic acid/g amylopectin was bound (Hahn and Hood. 1987). The corresponding value for amylose was $5.25 \mathrm{~g}$ stearic acid $/ \mathrm{g}$ amylose.

\subsection{The crystalline nature of starch}

Classic work of Katz and his collaborators (Katy and Van Itallic, 193()) has shown that starch is a semi-crystalline material. Using $X$-ray diffraction techniques these authors 
have distinguished three types of erystalline structure in intact starch granules, giving diffraction patterns which were designated as A-, B-, and C-patterns (Fig. 2.7). The structural type depends on the botanical source of the starch: the A-type pattern is given by most starches of cereal origin (rice, wheat. and corn); the B-type pattern is shown by luber, fruit, and high amylose con (>40\%) starches as well as by retrograded starch; and C-type pattern, which is intermediate between A and B-type, is observed for legume seed starches (pea and bean). The reasons for these differences are not properly understood. Slight differences in the chain length and chain profile of amylopectin molecules may be responsible for existing differences in X-ray patterns (Hizukuri, 1985).

Recent studies with low molecular weight monodisperse oligosaccharides have suggested that the A-type crystal is the most themodynamically stable form, while the Btype is the kinetically favoured polymorph (Gidley, 1987; Gidley and Bulpin, 1987). All other factors being equal, the A-type structure is preferred over the B-type under conditions of (a) higher crystallization temperature, (b) higher polymer concentration, and (c) shorter chain lengths. The work of Hizukuri (Hizukuri, 1986; Hizukuri et al., 1983) on the structure of amylopectins from a variety of starch sources also concurs with the view that the average chain length of the branched starch molecules is the major determinant of erystalline polymorphism observed among native starches; amylopectins of B-type starches have longer chain lengths than those of the A-type (Hizukuri et al., 
1983).

According to the modelling studies of Wu and Sarko (1978a,b), using diffraction powder data of oriented amylose A- and B-type fihers, crystillinity in starch is due to packing of double helices. The arrangement of duplexes into the crystal lattice is mearly the same in both structures, except that the unit edl of B amylose contains 36 water molecules in a channel formed by the hexagonally packed double helices: in $A$ amylose this channel is occupied by another double helix and the water molecules (eight / unit cell) are distributed in interstitial spaces between strands (Fig. 2.8). Recent studies by Imberty et al. (1987) have established that the A-type polymorph is characterized by packing of left-handed parallel-stranded duplexes. This arrangement is consistent with the overall architecture of the amylopectin molecule and chain polarity requirements arising from biosynthetic considerations (French, 1972). There still exists a controversy whether the C-type is a distinct structure of simply a mixture of A- and B-lype crystallites (Sarko and Wu, 1978; Zobel, 1988a).

Only a small portion of the starch granule is believed to be erystalline and the concept of the partially crystalline nature of starch is now widely accepted (Biliaderis, 1991). Kainuma and French (1971) have visualized the granule as at gel matrix in which the crystalline regions are embedded. These crystallites exhibit the $\mathrm{X}$-ray pattern and optical birefringence and are relatively resistant to chemical and enrymic attack. In 
lig. 2.7 Typical dilfractometer patterns for starches giving A-, B-, and C-type X-ray spectra. Adopted from Banks and Greenwood (1975). 


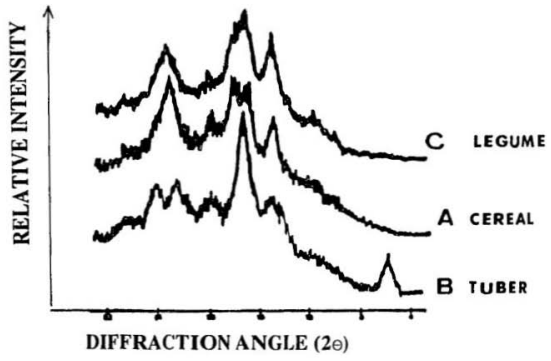


Fig. 2.8 Double-helix packing arrangements in A- and B-type unit cell structures of crystalline amylose. Adopted from Wu and Sarko $(1978 a, b)$. 

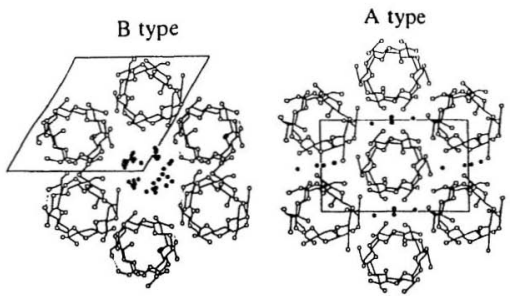
cintrast, the gel phase (amorphous regions) is less dense and more susceptible to chemical and en\%ymatic modifications and absorbs water more readily at temperatures below the gelatinization temperature. Diffusion of small molecules within the starch granule and swelling upon hydration are properties also associated with the gel or amorphous phase (French. 1972). It is a i interest to note that as a result of the fine structure of amylopectin. there is no sharp demareation between crystallites and amorphous regions in starch. Instead, a range of structures is expected between well-developed crystallites and fully disordered regions. In this type of supermolecular structure, the amorphous and crystalline phises are interdependent. Levels of crystallinity, determined by integration of the areas under the crystalline diffraction peaks, range between 15 and $45 \%$, depending on the sturce of starch (Zohel, 1988b). Another intriguing question regarding starch structure is the degree to which amylose and amylopectin are separated or mixed within the granule. \%ohel (1988b) presented several arguments to support the notion that amylose is more closely associated with amylopectin in potato than in cereal starches. Viewed under polarized light, starch granules also show birefringence (the well-known Maltese cross), which indicate chain orientation of some sort (Biliaderis, 1991).

Another crystallographically distinct structure, typically observed when linear starch molecules form complexes with various ligands, is the V-form. The V-pattern is evident when lipid-containing cereal starches are subjected to hent-moisture treatments 
at temperatures below the gelatinization temperature or in their freshly cooked gels. The V-polymorph is believed to consist of closely packed single helices of amylose in which the complexing ligand molecules reside within the helix (Zobel of al.. 1967). Native cereal starches do not exhibit the V-pattern in X-ray allalysis. Nevertheless, there is circumstantial evidence that internal granular monoacyl lipids (lysophospholipids, frec fatty acids) are associated somehow with the glucan molecules in sim (Galliard and Bowler, 1987). It is likely that some form of complexing between lipids and starch chain exists in the granule but of insufficient perfection and/or limited extent of Iong-range ordering to demonstrate a well-defined V-diffraction palturn (Biliaderis, I(9)1).

\subsection{Swelling and solubility of starch}

Starches show different patterns of swelling and solubility when heated at different temperatures (Hashim et al, 1992). Cereal starches show a two stage swelling and solubility pattern (Blanshard, 1978; Doublier et col, 1987a,b; Hoover and Vasanthan, 1994). In the region of the gelatinization temperature, there is limited swelling and only a small amount of carbohydrate is solubilised. At around 9()$^{\circ} \mathrm{C}$ there is a large increase in the extent of swelling and a more substantial loss of starch from the granule. Normally, amylose leaves the granule first and it is only at the higher iemperature stage of the pasting process that the amylopectin is lost (Doublicr, 1981). However, for oat starch both 
amylose and amylopectin are leached out together when held in the 90 to $100^{\circ} \mathrm{C}$ temperature range (Launay et al., 1986).

The swelling power is defined as the swollen sediment weight $(\mathrm{g})$ per $\mathrm{g}$ of dry starch while the solubility is expressed as the percentage (by weight) of the starch sample that is dissolved after heating in water at $95^{\circ} \mathrm{C}$ (Soni et al., 1993). The swelling power test is one of a number of closely related tests (also known as water-holding capacity or water-retention capacity tests) which measure the uptake of water during gelatinization of starch (Leach et al., 1959); Medcalf and Gilles, 1965; Freeman and Verr, 1972; Sollars, 1973; Kulp and Loren\%, 1981; Konik et al., 1993). The swelling power test has several advantages over the conventional viscograph procedure. It utilises only one gram of starch, is relatively easy to carry out with simple laboratory equipment and can be performed on large numbers of samples simultaneously (Konik et al., 1993).

Tester and Morrison (1990) developed a method for measuring the volume of water absorbed by starch granules heated in excess water, based on the observation that blue dextran dye (molecular weight $2 \times 10^{6}$ ) will dissolve in supernatant and interestitial water but not in the intragranular water. This method measures only intragranular water and hence the true swelling factor at a given temperature. The swelling factor is reported as the ratio of the volume of swollen starch granules to the volume of the dry starch. 


\subsection{Enzyme digestibility of starch}

Digestibility of carbohydrates is very important in diabetics and in hyperlipidaemia. The rate and extent of starch degradation in the small intestine affect glucosc absorption and the corresponding insulin response (Wolever, 1991). In ruminants, ingestion of large amounts of highly degradable carbohydrates may result in rumen acidesis and depression of feed intake. Knowledge of starch degradability is also important for beer brewing and bread baking technology.

Degradation of starch by ruminants can be determined in vitro using rumen fluid from fistulated cows. Starch degradability can also be determined in vitro using $\alpha$ amylase. However, it is not possible to predict accurately the degradation of starch in feedstuffs by ruminal thuid with $\alpha$-amylase (Wolters and Cone, 1992).

The digestibility of starch by $\alpha$-amylases has heen the subject of numerous investig:tions (Greenwood and Milne, 1968a; Thoma et al., 1971; Leegwater et cl., 1971; Wootton and Chaudhry, 1979; Preiss and Levi, 1980); Rohy1, 1984; Dreher et cl., 1984; Wolters and Cone, 1992; Tsuge et al., 1992; Sreenath, I992; Gorinstcin, I993; Wootton and Mahdar, 1993; Camire and Camire, 1994; Coma et al., 1995; Lee ef el.. 1995). ^ wide variation in digestibility of native, gelatinized, and chemically modified starches under in vivo and in vitro conditions, depending on the souree of starch and fiosd processing and storage conditions, has been reported (Björck et al.. 1989). 
It is gencrally accepted that intact granular (raw) starches are less digestible than their gelatinized counterparts (McBurney, 1991; Sreenath, 1992) and that cereal starches (A-type) are more easily digested than root or tuber starches (B-type) (Dreher ef al., 1984). Cooking greatly improves the digestibility of poorly digested starches, presumably owing to granular disorganization and changes in crystallinity of starch materials. Similarly, glucose and insulin responses are significantly higher after intake of conked versus raw starches (Vaaler et al.. 1984). The in vitro digestibility of legume starches and seeds is generally lower than those of cereals (Hoover and Sosulski, 1985). With increasing degree of gelatinization, there is a concomitant improvement in the in vitro digestibility of baked products (Wootton and Chaudhry, 1980). Incompletely gelatinized products (as assessed by calorimetry) made from whole wheat by various industrial processes also exhibited reduced rates of $\alpha$-amylosis (Holm et al., 1988).

\subsubsection{Mode of action of $\alpha$-amylase}

Amylose is often used as a substrate for studies of $\alpha$-amylase action patterns because the linear dextrins formed can be identified and quantitated more easily than the complex mixture of linear and branched dextrins formed during hydrolysis of amylopectin or solubilized stnrch (Manners, 1985b). $\alpha$-Amylosis of amylose can be 
considered to take place in two stages (Myrbäck and Neumuller. 195()). Initially, rapid breakdown of macromolecules to short-chain dextrins is accompanicd by a large decrease in viscosity, loss in iodine staining power, and limied formation of reducing sugars. Three mechanisms can be postulated to describe dextrinization, this initial phase of amylose hydrolysis (Robyt. 1984). In the single-chain mechanism, the enzyme forms an active complex with the substrate and hydrolyzes it completely in one direction in a "zipper"-type manner to form large amounts of small dextrins throughout hydrolysis. This mechanism is not found with cereal $\alpha$-amylases. In the multiple (or repetitive) attack mechanism, the enzyme cattalyzes a number of bond scissions per encounter with the substrate before diffusing away and forming an active complex with another substrate molecule. This type of attalck would produce less dextrin than the single-chain mechanism during early stages of hydrolysis. There is also no evidence that cereal $\alpha$-amylases react in this way (Banks et al., 1970), although it is difficult to eliminate the possibility of a small amount occurring. Strong evidence shows, however, that $\alpha$-amylases from other sources may utilize this mechanism (Rohyl and french. 1967; Thoma, 1976). Completely random hydrolysis of internal bonds of amylose is achieved in the multichain process, in which the enzyme hydrolyzes one bond per encounter with a substrate molecule. This mechanism best describes the behaviuur of cereal $\alpha$-amylases. 
A large amylose molecule (approximately 500,000 molecular weight) has about $3,000) \alpha-(1-4)$ bonds, of which six $(0.2 \%$ of the total) are more resistant than the others to hydrolysis by cereal $\alpha$-amylases because of their position at the ends of the molecule. There is little impediment, therefore, to rapid hydrolysis by the enzyme, but the proportion of less susceptible bonds increases surprisingly rapidly during hydrolysis. After hydrolysis of only $5 \%$ of the total amylose bonds, the less susceptible bonds represent $30 \%$ of the remainder, and this doubles to $60 \%$ after $10 \%$ of the amylose bonds have been hydrolyzed. Obviously, enzyme hydrolysis slows down markedly after only limited amylose degradation (Hill and MacGregor, 1987).

Amylopectin is a highly branched molecule in which relatively short unit chains of $\alpha-(1 \rightarrow 4)$-linked glucose residues (average chain length. 20-26) are joined by $\alpha-(1 \rightarrow 6)$ bonds (Manners, 1985a). These $\alpha-(1 \rightarrow 6)$ bonds are resistant to hydrolysis by $\alpha$-imylase, and they also inhibit hydrolysis of $\alpha-(1 \rightarrow 4)$ bonds in their vicinity (Manners, 1962). Therelore, amylopectin has a higher proportion of $\alpha$-amylase-resistant bonds than amylose.

\subsection{Starch gelatinization}

Starch gelatinization is one of the most important phase transitions in foods. A. group of starch scientists and technologists recently defined starch gelatinization 
(Atwell et al.. 1988) as " the collapse (disruption) of molecular orders within the starch granule manifested by irreversible changes in properties such as granular swelling. crystallite melting. loss of biretringence, viscosity development. and starch solubilization. The point of the initial gelatinization and the range over which it occurs is goverted by starch concentration, methods of observation and granule type, and heterogeneties within the granule population under observation."

Starch granules are insoluble in cold water but swell when heited in an acueous medium. Initially, the swelling is reversible and the optical propertics of the granule are retained(e.g.. birefringence). But when a certain temperature is reached, the swelling becomes irreversible and the structure of the granule is altered significintly. The process is called "gelatinization" and the temperature at which gelatinization oceurs is called the "gelatinization temperature". At this temperature the granule looses its birefringence and material from the granule diffuses into the water (Lund, 1984).

Aside from the swelling during gelatinization, the viscosity of the medium also increases (Bornet, 1993). Both the molecular and granular structures contribute to the increase in viscosity. Initially, gelatinization occurs in the more accessible an amorphous regions. As the temperature is raised above that for iniliation of gelatinization, intermolecular hydrogen bonds which maintain the structural integrity of the granule continue to be disrupted. Water molecules solvate the liberaled hydroxyl 
groups and the granule continues to swell. As a consequence of severe disruption of hydrogen bonds, the granule will be fully hydrated and finally the micellar network separates and diffuses into the aqueous medium. After disruption of the granules, the viscosity decreases. The increase and decrease in viscosity during gelatinization can be followed by a Brabender Amylograph. The increase in viscosity in the early heating stages is due mainly to the release of amylose while, in later stages, the continued viscosity increase is due to interaction of extragranular material and swelling of the granules.

Based on changes in characteristics of starch granules (using a Brabender Amylograph) during and alter heating in aqueous medium, Olkku and Rha (1978) summarized the steps of gelatinization: (1) granules hydrate and swell to several times their original size.(2) granules lose their birefringence. (3) clarity of the mixture increases. (4) marked, rapid increase in consistency occurs and reaches a maximum. (5) linear molecules dissolve and diffuse from ruptured granules. (6) upon cooling, uniformly dispersed matrix forms a gel or paste-like mass.

Marchant and Blanshard (1978) postulated three constituent processes for starch gelatinization based on nonequilibrium thermodynamics:(1) diffusion of water into the starch granules, (2) a hydration-facilitated helix-coil transition which is a melting process, and (3) swelling as a result of crystallite melting. 
The detection of a glass transition endoherm just prior to the gelatinization endotherm led Slade and Levine (1988) to postulate that the process of stareh gelatinization is inherently non-equilibrim in character, in that it occurs when starch granules are subjected to heat in the presence of plasticizing water in which crystallite melting is indirectly controlled by the kinctically constrained continuous amorphous environment, which was in a glassy state prior to gelatinization.

Because gelatinization is of great importance to many ford processing operations, several analytical technicues have been employed to probe this phenomenon and determine quantitatively the amount of gelatinired starch in processed foods. These include light microscopy, scanning electron microsenpy, light transmission, viscometry, swelling and solubility measurements, $X$-ray diffraction, nuclear magnetic resonance, and enzymic methods (Zobel, 1984). Because gelatinization is an endothermic process, thermal analysis methods, and dillerential scanning calorimetry (DSC) in particular, have attracted most interest during the last decade in studies of phase transitions of aqueous starch systems (Biliaderis et al, 1986). DSC can provide the characteristic temperatures and enthalpies of the various transitions as well as allowing measurements over a wide range of starch concentrations. 


\subsubsection{Factors affecting gelatinization}

\subsubsection{Water}

The effect of water on starch gelatinization has been extensively studied (Collison and Chilton, 1974; Wootton and Bamunuarachchi, 1979; Donovan, 1979; Eberstein et al., 1980); Burt and Russell, 1983; Maurice et al., 1985; Biliaderis et al.. 1986; Eliasson, 1986a; Huang et al., 1994). In DSC studies of wheat starch suspensions with water contents ranging from 32 to $67 \%$, a minimum moisture content of $32 \%$ was necessary for gelatinization (Wootton and Bamunuarachchi, 1979). This finding is in good agreement with the results for mixtures of wheat starch and water heated in an oven, in which the minimum moisture content for gelatinization was $30 \%$ (Collison and Chilton, 1974). Thus, these authors concluded that gelatinization did not occur when the water content was less than $30 \%$. Eberstein et al. (1980) used DSC to study gelatinization in systems with low water content and found that an enthalpy change was no longer observed at about $20 \%$ water content, indicating that gelatinization could no longer occur in such a system. In systems with higher water contents, the enthalpy change was inclependent of starch concentration, but in systems with a water content of about $60 \%$ or less, it decreased strongly. This result indicated that only a portion of the gelatinization process, namely swelling up to the absorption of 1.5 times the amount of water, is calorimetrically detected. However, later work with rice starches showed that melting does occur in 
systems with less than $30 \%$ water content, but at higher temperatures (Maurice et al.. 1985; Biliaderis et al., 1986). In a normal rice starch at $10 \%$ water content, the onset temperature appears to be above $140{ }^{\circ} \mathrm{C}$. In systems with water contents below $30 \%$. witter was reported to act as a plasticizer, decreasing the glass transition temperature of the amorphous parts of the granule. This behaviour assists the melting or reorganization of starch crystallites and amylose-lipid complexes to occur at lower temperatures. A threephase model, proposed to explain the thermal behaviour of mixtures of granular starch and water. included two distinct types of amorphous material and the crystallites formed by the clusters of amylopectin.

\subsubsection{Lipids}

Effect of the lipid on starch gelatinization is related to hydrocarbon chain lengh. While short chain polar lipids may actually accelerate the rate of gelatinization, medium and long chain compounds inhibit the swelling of granules and uptake of water (Camire ef al., 1990). Polar lipids have long been known to affect the behaviour of starch pastes and are thought to interact with linear amylose chains to inhibit swelling and hydration (Gray and Schoch, 1962).

Monoacyl lipids present during gelatinization of starch affect the swelling power, the solubility, and the size and shape of the starch granules (Eliasson, I986b; Tester 
and Morrison, 1990). Most monoacyl lipids cause a decrease or delay in swelling and solubility. The sediment volume of wheat starch heated to $70^{\circ} \mathrm{C}$ is lower when monoacylglycerols are present. However, if the monoacylglycerols are added after the heating they do not affect the sediment volume (Van Lonkhuysen and Blankestijn, 1976). Monoacylglycerols decrease the solubility more than, for example, sodium stearoyl-2lactylate (SSL) (Ghiasi ef al.. 1982a). The swelling power is also lower in the presence of monoacylglycerols than with SSL. The morphological changes that occur during gelatinization of wheat starch are the same in the presence of monoacyl lipids as without such additives. However, the changes in the size and shape of the granules occur at a somewhat higher temperature in the presence of added lipids.

\subsubsection{Protein}

Gelatinization of starch from some sources may be influenced by the presence of protein. Chandrashekar and Kirleis (1988) found that water absorption of sorghum at 70 and $80^{\circ} \mathrm{C}$ was reduced, and gelatinization was decreased when the kafirin fraction was increased from 46 to $70 \%$ of the total protein content. Kafirin is an alcohol-soluble prolamine that forms a capsule around sorghum starch granules, preventing their rapid gelatinization under ordinary cooking conditions. 


\subsubsection{Sugars}

Effects of sugars on the gelatinization of starches have heen extensively studied (D'Appolonia, 1972: Derby of al.. 1975: Hoseney it al.. 1977: Savage and ()sman. 1978: Bean and Yamazaki. 1978a,b; Koepsel and Hosency. 1980): Wooton and Bamunuarachchi. 1980: Spies and Hoseney, 1982: Chungcharoen and Lund. 1987: Slade and Levine, 1987; Hansen et al., 1989; Paredes-Loper, and Ilerninder-Lope\%, |90)1; Tomasik et al., 1995). It has been reported that sugars increase the oniset temperature of gelatinization of starches, and disaccharides returd the start of gelatinization process more than monosacchurides.

The precise mechanism, by which salcharrides delay statch gelatinization, is still unclear. Hansen et al. (1989) classified the mechanism into thre types; (a) competition between the saccharides and starch for available water and associated changes in free volume ( Derby et al.. 1975; Hoseney et al., 1977); (b) the ability of saccharicles in water system to retard gelatinization by inhibiting the swelling of the starch granules (Savige and Osman, 1978; Wootton and Bamuntarachehi, 1980); and (c) the ahility of saccharides to penetrate the starch granule and interact in the amorphous areass, thus stabilizing this region and increasing onset temperature of gelatinization (O)sten, 1984: Johnson it al., 1990b). 


\section{9) Starch retrogradation}

Retrogradation is an important property of starch gels. It has been defined as "a process which occurs when the molecules comprising gelatinized starch begin to reassociate in an ordered structure" (Atwell et al.. 1988).

After gelatinization or pasting of starch, the amylose and amylopectin molecules may be consiclered to be "dissolved". The entangled amylose molecules have a strong tudency to assuciate through the formation of hydrogen bonds with adjacent amylose chains when the solution (sol) is cooled or upon standing for long periods of time (Fig. 2.9). This phenomenon is known as retrogradation and manifests itself through the formation of precipitates or gels. If the original starch solution is diluted and cooled slonvly, the amylowe molecules have sufficient time to align themselves in such a way that several hydrogen bonds can be formed between adjacent parallel chains. The resulting hundles of parallel chains are insoluble aggregates, which precipitate. If the starch paste is relatively concentrated. a gel is produced almost immediately upon cooling. This gelation is interpreted as being due to an inability of the amylose chains to form insoluble aggregaltes. Hydrogen bonds are formed where possible between the entangled chains, resulting in junction zones (points) and yielding the elastic network of a gel. As the starch gel stands. additional hydrugen bonds form slowly. causing the gel to shrink and some of the water we separate (the process of syneresis). Areas where chains or portions of them 
are associated through hydrogen bonding are crystalline and are called micelles. Thus the process of retrogradation is accompanied by an increase in crystallinity. although it is not the crystallinity of the original granule.

A considerable amount of experimentai data is available (differential stanning calorimetry and X-ray diffraction) to suggest that the main underlying ciase of bread staling is retrogradation (Kulp and Ponte. 1981). Although numerous investigattions have been undertaken on this phenomenon. the exact mechanism of retrogradation, particularly at a molecular level. is not clear (Biliaderis, 199)1).

The molecular structures and transformations that oceur during gelation and retrogradation of starch and its components have been the subject of several investigations recently (Miles et al.. 1984. 1985ab: Ring. 1985: Ring et al. 1987: Leloup. et al.. 1992; Sievert and Wursch. 1993: Svegmark and Hermansson. '993: ('ameron, et al., 1994). As shown by Miles et al. (1985a,h), retrogradation consists of two separable processes: (1) gelation of amylose molecules exuded from the granules during gelatinization and (2) recrystallization of amylopectin. In order to isolate the roles played hy amylose and amylopectin, it is convenient on discuss amylose gelation and amylopectin recrystillization separately. 


\subsubsection{Amylose gelation}

Amylose, becuuse of its linear nature, is considered primarily responsible for gelation of starch (Biliaderis, 1991). Amylose forms opaque, partially crystalline, thermoirreversible gels. It is a flexible molecule that adopts a near spherical shape in aqueous solution (Miles et al., 1985b). In dilute solution, the average intermolecular separation will be much greater than the molecular size. However, if the concentration is increased, a critical concentration $\left(\mathrm{C}^{+}\right)$is reached where the intermolecular separation is similar to the molecular size and the molecules interpenetrate. The concentration $\mathrm{C}^{+}$may be regarded as the so-called overlap or entanglement concentration. For amylose preparations, it was noted (Miles et al., 1985b) that $\mathrm{C} \sim 1.5 \%(\mathrm{w} / \mathrm{w})$, which was very close to the critical concentration for gelation $\left(\mathrm{C}_{\mathrm{v}}\right)$. Thus, the gelation process involves converting the weak, temporary network into a strong permanent network.

Characteristic features of gelation include the formation of a permanent elastic network and the development of opacity (Ring, 1987). Miles et al.(1985b) have shown that amylose solutions of low concentration (1.6-2.4\%) become turbid during the early stages of amylose gelation. For normal polydisperse amylose, the increase in turbidity mly slightly preceded network formation. In this case, gelation was envisaged as a separation of amylose into a coarse network of a polymer-rich phase interspersed with a solvent- rich phase (Miles (t al.. 1985a). Subsequently, an increase in elasticity was 
recorded followed by a slow increase in crystallinity in the polymer-rich phase (Hoover. 1995). The level of crystallinity within the gel was shown to be concentration dependent. but the rate of crystallization was concentration independent (Miles 'l al., 1984). This suggests that the local polymer concentration is constant in the phase-separated network. Miles et al. (1985a) showed that stiffening of amylose gels is accompanied by the formation of B-type crystals.

The above discussion suggests that an amorphous amylose network containing crystallites provides permunency to the structure. Development of crystallinity can be measured by X-ray diffraction (Miles et al., 1984). Unfortunately, the exposure times with conventional X-ray sources are too large to permit time-dependent studies of crystallization during the very early stages of network formation (Morris, 1900).

In hot aqueous solution, amylose molecules are flexible (Ellis and Ring, 198.5), whereas within the amylose gel at least some regions of the amylosic molecules are present as stiff double helices within the crystallite junction wones. This double helix formation may occur between the ends of molecules, favouring chatin clongation (Hig. 2. 10:a). (nnce helix formation has occurred, lateral association may occur through crystallization (Fïg. 2.10b). For high molecular weights, poor matching of chains during helix formation maty initially favor fibrillar network formation, whercas low molecular weights may initially favor lateral association, due to better matching of chains upon 
Fig. 2.) A schematic representation of the processes and structures observed during heating and stonge of alpleous suspensions of granular starch. Adopted from Biliaderis (|0)|). 


\section{GELATINIZATION}

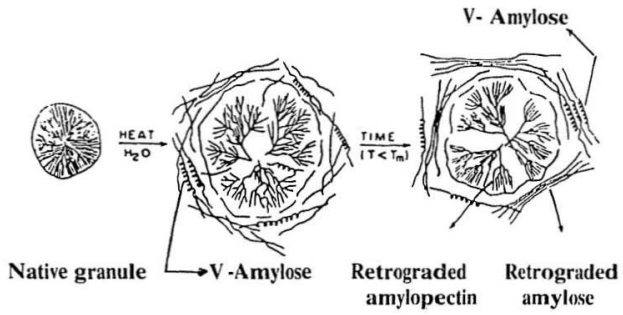


Fïg. 2.10 Double helix formation and association: (a) helix formation and chain clongation; (b) lateral association of helical regions. Adopted from Morris (1990). 
(a)
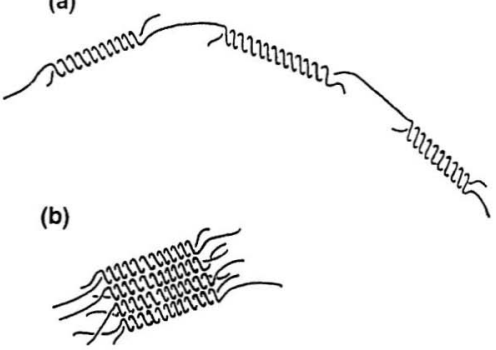
helix formation, and the conversion of fibrils to thicker fibres (Morris, 1990).

\subsubsection{Amylopectin crystallization}

In contrast with amylose, amylopectin gelation is a much slower process and requires much higher polysaccharide concentrations (usually $\geq 15 \%$ ), well above the $\mathrm{C}^{*}$ $(\because 0.9 \%)$ of this polymer (Biliaderis, 1091). In this respect, the gelation kinetics of amylopectin is different than that of amylose and is believed to reflect network formation vil crystallization of the outer short chains of the molecule (Ring et al.. 1987). The slow crystallization rate of amylopectin corresponds kinetically with the staling events of ageing baked items (Kulp and Ponte, 1981).

Kalichevsky et al. (1990) studied the relationship between the fine structure of anylopectins from various botanical sources and their gelation behaviour. Amylopectins from pea, potato, and canna were found to exhibit higher rates of retrogradation (monitored by development of shear modulus) than those from wheat, barley and maize starches. However, there was no simple relationship between shear modulus and molecular structure of amylopectin.

\subsubsection{Faciors affecting starch retrogradation}

Retrogradation affects the texture and acceptability of many starch-containing 
foods. How this process is affected by interactions between stath and other food components needs to be understood to better control the keeping quality of starchy food products. Extent of retrogradation, and the nature of the crystallites formed, may be affected by: starch source (Orford ot al.. 1987): concentration (Zeleznak and Hosency. 1986; Orford et al.. 1987: Slade and Levine. 1987): storage temperature (Slade and Levine, 1987; Eliasson and Ljunger, 1988); acids (Muhrbeck and Eliasson, 1987; Russell and Oliver, 1989); salts (Ciacco and Fernandes, 1979); lipids and surlictants (Germani et al., 1983; Russell, 1983; Evans, 1986; Eliasson and Ljunger, 1988: Krog ('t al., 1989); and sugars (Maxwell and Zobel, 1978; Hase et al., 1981; Germani et al., 1983; Slade and Levine, 1987; l'anson et al., 1990; Ward of al., 1994; Eerlingen et al.. 1904; Bello-Péres. and Paredes-Lopez, 1995; Botlan and Desbois, 1995).

\subsubsection{Source of starch}

The retrogradation differs among starches from different sources (Rosario and Pontiveros, 1983; Gudmundsson and Eliasson, 1992; Ward el al., 1994). (Orford at al. (1987) investigated the extent of retrogradation of wheat, corn, potato and pea starchus. Gels from all sources showed substantial increases in shear modulus over 7 days. Pea starch showed the highest increase, followed by potato, corn and whetil. Crystallinity (Xray and DSC) paralleled the long term development of shear modulus, indiciting 
that this Iong term development was because of a crystallization process. All gels exhibited a B-type X-ray pattern. However, the above authors made no attempt to explain the differences in recrystallization between various starch sources. The $G$ value of wheat was found to increase very slowly during storage compared to that of barley (Kalichevsky et al., 1990). Gudmundsson and Eliasson (1989, 1991) have used DSC to investigate several cereal starches and found the following order in the extent of retrogradation: oat $<$ rye $<$ wheat.

\subsubsection{Concentration}

Starch concentration influences the extent of retrogradation. The most intense Bpattern is obtained for wheat starch gels with a water content of $47-50 \%(w / w)$ [Hellman et al., 1954). For al starch gel with $6.3 \%(w / w)$ water stored 8 days at $24^{\circ} \mathrm{C}$, the intensity of the B-pattern is only one-fifth the intensity observed for a starch gel with $50 \%$ water treated in the same way. Measurements by DSC have confirmed earlier X-ray results. The maximum $\Delta H$ value is obtained in a starch concentration of about $60 \%(w / w)$ (Longton and LeGrys, 1981; Eliasson, 1983; Zeleznak and Hoseney, 1986). Also the increase in storage modulus during storage is related to the starch concentration (Biliaderis and Zawistowski, 1990). 


\subsubsection{Storage temperature}

The retrogradation process is very sensitive to temperature (Colvell et al.. i (9)6; Eliasson, 1985; Biliaderis and Zawistowski. 1990). This is evident from using DSC and X-ray diffraction as well as rheological measurements. These results are easily understood from classic knowledge about crystallization. The higher the degree of supereooling, the more crystals will be formed, but the growth of the crystals is favored at a higher temperature. However, in the case of starch gel the superooling cannot be brought too far; at some temperature, the glass transition temperature $\left(T_{f}\right)$ of the starch as well as the freezing point of water will be passed, and during these conditions no erystallization will occur at all. The best conditions for crystallization of amylopectin therefore seem to be just above $0^{\circ} \mathrm{C}$. The retrogradation process might then be avoided or delayed by storage at the correct temperature.

In order to bring about as much starch retrogradation as possible, the correct treatment would be to store the starch gel first at a low temperature (e.g. $4^{\prime \prime} \mathrm{C}$ ) to promote nucleation and then at a higher temperature (c.g. $40^{\prime \prime} \mathrm{C}$ ) to promote crystal growth. Such experiments have been performed, and after $24 \mathrm{~h}$ al $4^{\prime} \mathrm{C}$ starch gels were stord for another $24 \mathrm{~h}$ at $4,12,25$, or $40^{\prime \prime} \mathrm{C}$. The highest values of $\Delta \mathrm{H}_{\mathrm{r}}$ were obtained alter storage at 12 and $25^{\circ} \mathrm{C}$ (Zeleznak and Hoseney, 1987). 


\subsubsection{Lipids}

Many researchers have demonstrated that lipids retard retrogradation. The effects of lipids have been reported by several investigators (Krog and Jenson, 1970; Kulp and Ponte, 1981). It is well known that amylose forms inclusion complexes with lipids (Krog, 1971: Birnbaum, 1977). Amylopectin also lorms complexes with lipids (Gray and Schoch, 1962; Batres and White, 1986). It has been suggested that complex formation between lipids and the starch components could hinder crystallization during gel storage (Batres and white, I986; Slade and Levine, 1987). However, it is also possible that reduced retrogradation in the presence of lipids could also correspond to a decrease in the mobility (due to water-water interaction and/or to an increase in the local viscosity of the starch suspension) of those starch chains which are involved in double helix formation and lateral alssociations during recrystallization (Hoover, 1995).

DSC studies have shown that lipids decrease crystallization of amylopectin and increase the amount of amylose-lipid complex (Eliasson, 1983; Russell, 1983). But how lipids or the amylose-lipid complexes retard recrystallization of amylopectin is still not clear.

\subsubsection{Sugars}

Results of several studies agree that sugars do affect meiting temperatures of 
retrograded starch as well as the extent to which retrogradation occurs. However, the literature is replete with conflicting information about the effect of individual sugars on retrogradation. Futhermore, the mechanism by which sugars influence retrogradation still remains unclear (Hoover, 1995).

Sugars are believed to penetrate the melted erystalline region of starch. Hence. "sugar-bridges" (a term coined by Spies and Hoseney. 1982) are formed in both crystalline and amorphous regions during gelatinization. When starch gels are cooled, the starch chains become less energetic and the hydrogen bonds become stronger. Retrogradation involves, among others, recrystallization of starch chain in the gels. In starch-water-sugar systems, sugars interfere with the hydrogen bonds between starch chains. Thus, stabilized starch gels retard retrogradation. i.e., the rate of retrogradation is reduced. by sugars (Miura et al., 1992).

Katsuta et al. (1992a) reported that sucrose stabilized the starch get matrix and impeded retrogradation more than glucose and fructose. They suggested that the ability of saccharides to stabilize the starch-water system might be inlluenced by the conformation of saccharides, i.e. the number of equatorial ()H (c-C)H) groups in saccharide molecules might play an important role in maintaining the water structure surrounding the saccharides and starch molecules.

Katsuta et al. (1992b,c) studied the eflects of mono-, di- and oligusaccharides 
on stabilitics of rice starch gels. In this study, they applied retrogradation kinetics on the basis of viscoelastic properties to starch-water-saccharide systems in order to investigate the effects of conformation of saccharides on stabilities of rice starch gels and water structure. The above authors showed that hexoses (with the exception of galactose) decreased the extent of retrogradation to a greater extent than pentose (ribose and xylose). While disaccharides, (maltose and sucrose) were more effective than monusaccharides in reducing retrogradation. Furthermore, among maltooligosaccharides, the effectiveness in reducing retrogradation followed the order: maltotriose $>$ maltotetraose $>$ branched oligosaccharides. Similar findings were reported by Miura el al. (1992).

\subsection{The oat grain}

The oat kernel or caryopsis is usually longer and more slender than wheat or barley kernels, and mosi domestic cultivirs are more extensively covered by hairs, or trichomes (Fig. 2.11), which often obscure other surlace details (Fulcher, 1986). At maturity the caryopsis, usually called the groit. is tightly enclosed within the fibrous lemma and palea, which persist after threshing during harvesting operations and form the hull except in the cilse of hull-less oats. The caryopsis usually accounts for $65-75 \%$ and the hull $25-35 \%$ of the whole oat (McMullen, 1991). 
The wall of the caryopsis consists of several eell linyers derived from three different sources: the pericarp, from the ovary wall; the testa, from the inner integument; and the epidermis, from the nucellus (Bonne. 1961). The endosperm is located inside the wall layers of the caryopsis and is composed of the alcurone cells and the starchy endosperm (Fig. 2.11). The layer or two of eells which comprise the aleurone layer are more rectangular in shape and thicker walled than the starchy endesperm cells and contain aleurone grains. The aleurone cells secrete a variety of hydrolytic enzymes during germination which digest and mobilize the starchy endespem reserves (McMlullen, |90|). The wall and the aleurone layers from milling fiaction referred to as the baul.

The starchy endosperm is composed of large thin-walled parenchyma cells filled with starch contributing approximately $55.8-68.3 \%$ of the weight of the matture kernel (Youngs, 1972) and comprises the conmercial fraction called the starchy endesperm. The starchy endosperm is the primary source of nutrients for use by the embryo during germination.

The oat embryo, comprised of scutellum and the embryonic axis, is foctated on the anterior sicie, near the base of the caryopsis (1"̈g. 2.11). The epidernal layer of the scutellum or epithelium is in contict with the endosperm and secretes enzymes, which digest contents of the endosperm during gemination (Bonne, 1961). The embryonic axis consists of the plumule and the radicle. The plumule 
is made up of the coleoptile, which encloses the shoot apex and two leaf primordia. The root is comprised of the radicle and two or three adventitious roots, which produce the seminal root system. Youngs (1972) determined that the embryonic axis and the scutellum comprise $1.0-1.4 \%$ and $1.7-2.6 \%$, respectively, of the groat.

\subsection{Oat Starch}

In most parts of the wortl, oats are grown and used almost exclusively on the farm as an animal feed; a very small percentage indeed linds its way into the human diet. Almost $80 \%$ of protein requirements for human is derived from cereals or cereal- based products. Although oats are well known to have both a higher protein content and better quality protcin than other cenals, their utilization for human food is still limited to a few ethnic cultures. Perhaps the principal reason for this limitation is that by itself oat flour does not make a loaf bread. However, there has been an increased interest in North America in oats as a result of the overall search for protein concentrates and isolates (Wu (t al.. 1973: Wu and Stringfellow. 1973; Cluskey et al. 197.3). High protein oat varieties have been developed and breder activity in this field remains high in an effort to further improve the crop (Patton. 1979).

About 15-20 years ago Agriculture Canada's Research Branch developed a 
Fig. 2.11 The oat caryopsis. Adopted from Leonard and Martin (196.3). 


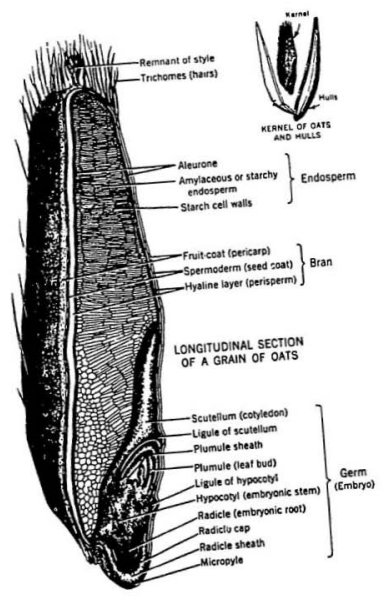


considerable interest in oats as a potential source of food protein. Cultivars containing I8$22 \%$ protein in the dehulled seed (groat) are available, and even higher values maly be obtained. Oat is a nutritious and inexpensive cereal but nevertheless is utilised mostly as feed, with $5 \%$ of the crop going to manufacture. There has been no identified specific functional property leading to an obvious market such as wheat has in bread, or barley in beer (Wood et al., 1987).

Oat starch has been shown to differ firom other cenal starches in several walys. Oat starch granules are characterized hy angular or irregular shape, the gramule sire being mostly in the range of $3 \mu \mathrm{m} 1010 \mathrm{fm}$ (Patton, 1977: Miikclii and Latakso, 1984: Gudmundsson and Eliasson, 1989; Hoover and Vasanthan. 1992). However, individual granules have a marked tendency to aggregate into bundles or clusters (Mac-Arthur and D’Appolonia, 1979; Mäkelä and Laakso, 1984; Hoover and Vasaunthan. 1992).

Oat starch is more like rice starch than wheal starch in both granule size and shape. Its amylose content (2.5-29\%) is similar to wheat starch (Mac-Masters of al.. 1947), but oat amylose is more linear and oat amylopectin is more branched than that found in wheat (MacArthur and D'Appolonia, 1979).

Traditionally, oat starch has not generated widespread commercial interest due to its functional similarity to corn and wheat starch. It can be used in composite breads, but imparts a crumb-softening effect. Recent studies have identified some nal cultivars whose 
starch pastes have unusual properties, such as the development of abnormally rapid cold viscosities. These oat starch gels are reportedly more elastic. adhesive, translucent, and show greater storage stability than corresponding wheat and corn starches (Paton, 1986). The pastes have higher cooling cycle viscosities than comparable concentrations of wheat or corn starches, and cooked oat starch granules are more sensitive to shear. The gels are inlluenced by salts, sucrose, gums, and mild acids. Industrial applications as ingredients in adhesives, paper products, and phamaceuticals have been suggested (Paton, 1977,1986; Doublier et al., 1987b).

Oat starch granules have been reported to have a relatively high lipid content, although the values reported depend on the oat varieties studied and the isolation and analysis methods used (Youngs, 1978; Karow et al., 1984; Shamekh et al., 1994). When (oat grains are ground and soaked in water most of the lipids are hydrolyzed into free fatty acids (Liukkonen and Laakso, 1992). If oat is fracrionated by a water process into fiber, protein and starch, the lipids are carried into each fraction. So, during this fractionation the amount of tree fatty acids rises in each fraction and so causes rancidity problems (Liukkonen et al., 1992). When developing good quality starch it is important to know what the contents and compositions of internal and surface lipids are. and how they do change during processing (Liukkonen and Laakso, 1992). Morrison (1988) showed that the lysophospholipid content of the starch of several oat varieties was slightly higher but 
in the same range as in normal barley starches, but clearly higher than in nomal maize and sorghum starches. The free fatty acid content of the oat starches studied was (1.3-().4\%, and the total lipid content was 1.3-1.5\% (Morrison ct al., 1984). There was a significant positive correlation between total anylose and lysophospholipid contents. According to Paton (1977) the total phosphorus content of oat starches (0.06-(0.08\%, dh) was higher than that found in other eereal starches such as wheat and maize (0.06 and $0.02 \%$, respectively), indicating a higher lysophospholipid content.

Oat starch had lower iodine affinity $(3.2-3.5 \text { at } 30)^{\prime} \mathrm{C}$ ), lower solubility $(17-26 \%$ at $95^{\circ} \mathrm{C}$ ) and slightly higher limiting viscosity than wheat and corn starches (Pattom, 1977. 1979). The gelatinization enthalpy of oat starch (9.()-.9.5 $\mathrm{J} / \mathrm{g}$ ) has been reported to be lower than that of wheat (11-12 J/g), rice (I()-14 J/g) (Paton, 1987) and of harley (10.2$10.5 \mathrm{~J} / \mathrm{g}$ ) (Tester and Morrison, 1990); Lauro of al., 194.3). On the other hand, the transition enthalpy for dissociation of the amylose-lipid complex $(3,6 \mathrm{~J} / \mathrm{g})$ was higher than that of wheat $(1.9 \mathrm{~J} / \mathrm{g}$ ) or rice $\mathrm{starch}(1.9$ or $3.2 \mathrm{~J} / \mathrm{g}$ ) (Shamekh et cl., 1994). Gudmundsson and Eliasson (1989) also reported that the endotherm of the amylose-lipid complex of oat starch $(3.7 \mathrm{~J} / \mathrm{g})$ was $2-3$ times higher than that of wheal or maize (1.6 and $1.2 \mathrm{~J} / \mathrm{g}$, respectively). At temperatures approaching 10()$^{\prime \prime C}$, oal starch granules have been shown to swell more and, therefore, to be more deformable than wheat or maize starches (Gudmundsson and Eliasson, 1989; Hoover and Vasanthan, 1992). The deformability of 
starch granules affects the rigidity of starch gels: less swollen starch particles lead to more rigid gels. Both the rigidily and the elasticity of oat and barley starch gels were shown to be greatly dependent on the proceeding heating conditions (Autio, 1990). Doublier et al. (1987a,b), Autio (1990) and Virtanen of al. (1993) have reported that the pasting bchaviour of oat starch differs substantially from that of other cereal starches, such as wheat, barley and maize, by forming during cooling a gel already at higher temperatures $\left.(80)^{\prime \prime C}\right)$.

During heating of oat starch dispersions, amylose and amylopectin are coleached from the granules, whereas in other cereal starches such as barley and wheat the amylose is solubilized first (Doublier et al., 1987a,b; Autio, 1990; Hoover and Vasanthan, 1992; Virtanen et al., 1993). Microstructural studies of oat starch pastes heated above $95^{\circ} \mathrm{C}$ showed that amylopectin formed the continuous phase (Autio, 1990). At $95^{\circ} \mathrm{C}$, when a large amount of amylopectin was liberated to the paste, the elasticity and rigidity were lowered (Virtanen $e f$ al., 1993). 


\section{CHAP'TER 3}

\section{MATERIALS AND METHODS}

\subsection{Cereal grain}

AC Stewart is a spring type oat cultivar (Avena sertiva l.) that is covered seeded. The pedigree of AC Stewart is Ogle 4/Dumont (Burrows, 1992). NO) 75.3-2 (Av'rna muda L.) is a naked or hull-free oall. The pedigree of NO 75.3-2 is as follows: CAV 2700/Gemini/2/Rodney/3/5811 al-8B/4/Gemini/3932-16/2/OA 123-3/39.32-16. CAV 2700 is an Avena byzantina selection from Bodrum Turkey. Gemini and OA 123-3 were derived from interspecific crosses (Avena strigosa $X$ the varictics Abegwert and Victory). 5811 al-8B is a winter type oat from Cornell University and 3932-16 is a naked seeded (hull-free) parent from the Ottawa program. Both cultivars were grown at the Plant Research Centre in Ottawa.

Oat grains were divided into two lots. Each lof was further subdivided into three parts and starch was extracted from them. All experiments were replicated three times.

\subsection{Starch isolation and purification}

Oat grains $(500 \mathrm{~g})$ were steeped overnight in water at reom temperature. ()ne part soaked grains was mixed with 3 parts distilled water in a Waring blender for 3 min at low speed followed by another 3 min at high speed. The resultant slurry was passed through a double layer cheese cloth and then centrifuged at 5000$) \times \mathrm{g}$ for $15 \mathrm{~min}$. The supernatant 
was discarded and the sediment suspended in excess $0.02 \% \mathrm{NaOH}$ to remove the residual proteins. After standing for th, the supernatant was removed. This procedure was repeated three times. The linal sediment was suspended in distilled water, and then subjected to sequential filtration through 70 and 20 micron polypropylene screens, neutralized to $\mathrm{pH} 7.0$, filtered on a Buchner funnel and thoroughly washed on the filter with distilled water. The filter cake was dried overnight at $30^{\circ} \mathrm{C}$ (Schoch and Maywald, 1968).

\subsection{Chemical composition of starch}

\subsubsection{Moisture content}

Moisture content was determined by drying a preweighed $(5.0 \mathrm{~g})$ amount of material in a forced air oven (Fisher scientific, isotemp 615G, USA) at $105^{\prime \prime} \mathrm{C}$ until it reached a constant weight. The moisture content was calculated as percentage of weight loss of the sample due to drying (AACC, 1983).

\subsubsection{Ash content}

Samples $(2.0 \mathrm{~g})$ were transferred into clean porcelain crucibles, charred using a flame and then placed in a temperature-controlled lumace (Lab Heat, Blue M, IL) which was preheated to $5500^{\circ} \mathrm{C}$. Simples were held at this temperature until grey ash remained 
and then transferred to a desiceator, cooled and weighed immediately. Ash was calculated as percentage weight of the remining matter (AACC, 198.3).

\subsubsection{Total protein content}

Samples $(250 \mathrm{mg})$ were weighed on nitrogen-liee papers and placed in the digestion tubes of a Buchi 430 (Buchi Laboratoriums-Technik AC, Iilavil/Schweiz) digester: The samples were cligested with two Kjeltabs catalyst pellets (Prolimo, Quebec) and $20 \mathrm{ml}$ of concentrated $\mathrm{H}_{2} \mathrm{SO}_{4}$ in the Kjeldahl digester (Buchi 4.30) until a clear solution was obtained. Digested samples were diluted with distilled water(50) ml); alkalli (150 ml of $25 \% \mathrm{NaOH}$ ) was added and the releatsed ammoniat was steam distilled (Buchi 321 ) into $4 \% \mathrm{H}_{3} \mathrm{BO}_{3}(50 \mathrm{ml})$ eontaining twelve dreps of an end posint incicator ( $\mathrm{N}$-point indicator, EM Science, Evanston, NJ) until $200 \mathrm{ml}$ distillate wats collected. 'The content of ammonia in the distillate was determined by titrating it against $0.1 \mathrm{~N} \mathrm{H}_{2} \mathrm{SO} \mathrm{O}_{4}(\wedge \wedge \mathrm{CC}$, 1983). The content of crude protein in samples was calculated by multiplying the percentage of nitrogen by a fictor of 6.25 .

\subsubsection{Lipid content}

In the determination of lipid composition, all starches were subjected to the following extraction procedures: (A) starches (5 g, dry basis) were extracted under 
vigorous agitation in a wrist action shaker with $100 \mathrm{ml}$ of chloroform-methanol $(2: 1 \mathrm{v} / \mathrm{v})$ at $25^{\mathrm{L}} \mathrm{C}$ for $\mathrm{Ih}$; (B) the residues from chloroform-methanol extraction were solvent extracted with $100 \mathrm{ml}$ of n-propanol-water $\left(3: 1 ;: \mathrm{v}^{\prime}, 90-100^{\circ} \mathrm{C}\right)$ for $7 \mathrm{~h} ;(\mathrm{C})$ lipids were also extracted, after acid hydrolysis of starches with $24 \% \mathrm{HCl}$ for 30 min at $70-80^{\circ} \mathrm{C}$, the hydrolyzate were extracted three times with n-hexane (Goshima et al., 1985).

The crude lipid extracts were then purified by further extraction with chloroform/methanol/watter $(1: 2: 0.8 \mathrm{v} / \mathrm{v} / \mathrm{v})$ and forming a biphasic system |chloroform/methanol/water $(1: 1: 0.9 \mathrm{v} / \mathrm{v} / \mathrm{v})$ | by the addition of chloroform and water (Bligh and Dyer, 1959); the chloroform layer was diluted with benzene and brought to dryness on a rotary evaporator.

\subsection{Granule morphology}

Granule morphology of native starches was studied by scanning electron microscopy (SEM). Starch samples were mounted on circular aluminum stubs with double sticky tape and then coated with $20 \mathrm{~nm}$ of gold and examined and photographed in a Hitachi (S570) scanning electron microscope at an accelerated potential of $20 \mathrm{kV}$. 


\subsection{Pasting behaviour}

Pasting characteristics of starch slurries at a concentration of $6 \%(w / v)$ and pll 5.5 were detemined using the Brabender viscoamylograph, Model VA-VI:(C.W. Brahender Instruments, Inc.. South Hackensack. N.J), e(puip)ed with a $7(1)($ cm.ge sensitivity cartridge. operating at a bowl speed of $75 \mathrm{rpm}$. The starch slurry wis heated from .30 (6) $95^{\circ} \mathrm{C}^{\circ}$ at the rate of $1.5^{\circ} \mathrm{C} / \mathrm{min}$, maintained at $95^{\circ} \mathrm{C}$ for $3(0) \mathrm{min}$, and then seonled to $50{ }^{\prime \prime} \mathrm{C}$ at the same rate. The viscosity was measured in Brabender units (BU).

\subsection{Swelling factor (SF)}

The SF of the starches, when heated to 50-80"C in excess water, wats measured according to the method ol Tester and Morrison (Jo()0). Starch samples

$(50 \mathrm{mg}, \mathrm{db}$ ) were weighed into $10 \mathrm{ml}$ serew calp tubes, $5 \mathrm{ml}$ of water was added, and the sealed tubes were incubated with constant shaking in a water bath at the reguired temperature for $30 \mathrm{~min}$. The tubes were then cooled to $20^{\prime \prime} \mathrm{C}, 0.5 \mathrm{ml}$ of blue dextran (Pharmacia, M, $2 \times 10^{6}, 5 \mathrm{mg} / \mathrm{ml}$ ) was added and the contents were mixed geally hy inverting the closed tubes several times. Alter centrifuging at $1,500 \times$ of for 5 min, the absorbence of the supernatant (A, was measured at $620 \mathrm{~nm}$. The absorbence of the reference $\left(A_{1}\right)$ sample devoid of any starch was also measured.

Calculation of SF was based on starch weight corrected Io II\% moisture, atssuming 
a density of $1 .+\mathrm{mg} / \mathrm{ml}$.

Free or interstitial plus supernatamt water (liW) is given hy

$F W=5.5\left(A_{1} / A_{S}\right)-0.5$

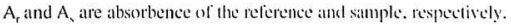

The initial volume of the starch $\left(V_{v}\right)$ of weight W (m milligrams) is

$\mathrm{V}_{\mathrm{o}}=\mathrm{W} / 1400$

and the volume of absorhed intragranular water $\left(V_{1}\right)$ is thus

$\mathrm{V}_{1}=5.0-\mathrm{FW}$

Hence the volume of the swollen starch granules $(V$,$) is$

$V_{1}=V_{10}+V_{1}$

and $\mathrm{SF}=\mathrm{V}, / \mathrm{V}_{1}$

This can also be expressed hy the single eyuation

$\left.\mathrm{SF}=1+\{, 7700 / \mathrm{W}) \times\left(\mid \mathrm{A}_{、}-\mathrm{A}_{1} / / \mathrm{A}_{、}\right)\right\}$

The coefficient of variation of the method was gencrally less than $1 \%$.

\subsection{Extent of amylose leaching}

Starch samples (15 mg) in distilied water (10 $\mathrm{ml})$ were heated $(50)-1) 5^{\circ}\left(\mathrm{C}^{\circ}\right)$ in volume calibrated sealed tubes for 30 min. The tubes were then corsled to ambient femperature and centrifuged at $3500 \mathrm{rpm}$ for 10 min. Aliquot $(0.1 \mathrm{ml})$ of the supernatant, was assiayed 
for soluhilized amylose (Chrastil, 1987). Percentage amylose leaching was calculated and represented as mg of amylose leached per $1010 \mathrm{mg}$ dry starch.

\subsection{Acid hydrolysis}

The starches were hydrolysed with $2.2 \mathrm{~N} \mathrm{HCl}$ at $35^{\circ} \mathrm{C}(100) \mathrm{mg} s t a r c h / 4 \mathrm{ml}$ acid) for 20) days. The starch slurries were shaken by hand daily to resuspend the deposited granules. At specilic time intervals, aliquots $(0.1 \mathrm{ml})$ of the reaction mixture were neutralized with $2.2 \mathrm{~N} \mathrm{NaOH}(0,1 \mathrm{ml})$ and centrifuged $(3500 \mathrm{rpm}$, for $10 \mathrm{~min})$ and the supernatant liçuid was assayed for total carbohydrates (Bruner, 1964). Controls without acid but subjected to the above experimental conditions were run concurrently. The extent of hydrolysis was determined by expressing the solubilized carbohydrates as percentage of the initial dry starch.

\subsection{Enzymatic digestibility}

Enzymatic clinestibility studies on native starehes were done using a crystalline suspension of porcine pancreatic $\alpha$-amyl Ise (EC 3.2.1.1) in $2.9 \mathrm{M}$ saturated sodium chloride containing .3 mM calcium chloride (Sigma Chemical Co.. St. Louis, Mo), in which the concentration of $\alpha$-amylase was $30.0 \mathrm{mg} / \mathrm{ml}$ and the specific activity was 790 units per milligram of protein. One unit was defined as the $\alpha$-amylase activity which 
liberated $1 \mathrm{mg}$ maltose in 3 min at $20^{\circ} \mathrm{C}$ at $\mathrm{pH}$ 6.9. The procedure used was essentially that of Knutson et al. (1982). However, a higher concentration of enryme was used in this study. Starch granules $(20 \mathrm{mg})$ were suspended in distilled water $(5 \mathrm{ml})$ and placed in a constant temperature $\left(37^{\circ} \mathrm{C}\right.$ ) shaker water bath. Then $+.0 \mathrm{ml}$ of $(0.1 \mathrm{M}$ pl osphlate buffer (pll 6.9), containing $0.006 \mathrm{M} \mathrm{NaCl}$ were added to the slurry. The mixture was gently stirred before adding $4 f \mathrm{l}$ of $\alpha$-amylase suspension. The reaction mixfures were shaken hy hand daily to resuspend the deposited granules. Then $1.0 \mathrm{ml}$ alienus were removed all specific time intervals, pipetted into $0.2 \mathrm{ml}$ of $95 \%$ ethanol, and ecutrifuged. Nliquots of the supernatant were analyod for soluble catbohydrates (Bruner. 1964). Pereentage hydrolysis was calculated as the amount (mg) of maltose released per $100 \mathrm{mg}$ of dry starch. Controls without enryme but subjected to the above experimental conditions were run concurrently. Results used for calculation were means of triplicale measurements.

For DSC analysis, the granular residues were repeatedly washed with ethanol and once with chloroform before air drying. The above experiment was replicated two times.

\subsection{Light transmittance of starch pastes}

The following procedure, adapted from Craig ef al. (1989), was used on prepare $1 \%$ (w/v) starch pastes. Starch $(50 \mathrm{mg}, \mathrm{db}$ ) was suspended in water $(5 \mathrm{ml})$ in screw cap tuhes and the $\mathrm{pH}$ adjusted by addition of $0.1 \mathrm{~N} \mathrm{HCl}$ or $\mathrm{NaOH}$ as required. The lubes were then 
heated in a boiling water bath (with occasional shaking) for 30 min. After cooling to ambient temperature, the pereenlage transmittance (\% T) at $6.50 \mathrm{~nm}$ was determined against a walter blank in a Novaspec (Model 4049, LKB Biochrom, Cambridge. England) spectrophotometer.

\subsection{Amylese content}

The apparent amylose content of native starches were determined by the method of Chrastil (1987), after complete dispersion of samples in $0.5 \mathrm{~N} \mathrm{KOH}$ solution followed by neutralization with $\mathrm{HCl}$ at room temperature. The total anylose content of starch simple was determined by the same procedure, but with prior defatting with hot npropanol-water $(3: 1$ v/v) for $7 \mathrm{~h}$.

\subsubsection{Preparation of starch dispersions}

Starch samples (20) mg, db) were dispersed in $10 \mathrm{ml}$ of $0.5 \mathrm{~N} \mathrm{KOH}$ in $20 \mathrm{ml}$ serew cap glass tubes. The dispersed samples were transferred to $100 \mathrm{ml}$ volumetric flasks and diluted to the mark with distilled water. An aliquot of the test starch solution (10) $\mathrm{ml}$ ) was pipetted into a $50 \mathrm{ml}$ volumetric flask, and $5 \mathrm{ml} 0.1 \mathrm{~N} \mathrm{HCl}$ was added prior to dilution. 
3.11.2 Chrastil's method of amỵlose determination

Sample alichots $(0.1 \mathrm{ml})$ of the neutralized solution were mixed with $5 .(0) \mathrm{ml}$ of watter and $0.05 \mathrm{ml}$ of $0.01 \mathrm{~N} \mathrm{I}_{-}-\mathrm{KI}$ solution. The ahsorbence of the blue columed complex was read at $620 \mathrm{~nm}$ (after $30 \mathrm{~min}$ at $25^{\circ} \mathrm{C}$ ), in a spectrophotomeler (1.KR Binchmom, Novaspec). The absorbence of the reation blanks wilh waler was gero. The amylose content was approximated using the following formula (ohtained through a callibration curve) and expressed as mg of amylose per $10(0)$ mg dry starch.

Absorbence $\times 32.5=m g$ of : anylose/litre in cuvette

\subsection{X-ray diffraction}

X-ray diffractograms were obtained with a Rigaku RU 20) R X-raly diffractometer connected to a data acquisition and processing station. The starel powcler was scanned through the $2 \Theta$ range of $3-35^{\prime \prime}$. Traces were obtained using ('u-K $\alpha$ radiation detector with a nickel filter and a scintillation counter operating under the following condlitions: $40 \mathrm{kV}$, $50 \mathrm{~mA}, 1^{\prime \prime} / 1^{\prime \prime}$ divergence slit/scallering slit, $0.3 \mathrm{~mm}$ receiving slit, Is time constamt and scanning rate of $3^{\circ} / \mathrm{min}$. 


\subsection{Differential scanning calorimetry (DSC)}

ISSC measurements on native and enzyme-treated starches were carried out using a Perkin-Elmer DSC-2 (Norwalk, CT) diflerential scanning calorimeter with a thermal antlysis datt-station. Water ( $(9.0 \mu \mathrm{l})$ was added with at microsyringe to starch ( $3.0 \mathrm{mg}$ ) in DSC pans, which were then seiled and allowed to stand overnight at room temperature to allow better moisture equilibrium. These pans were reweighed before the DSC experiment to ensure that water loss did not oecur during storage. The scanning temperature range and the heating rate were 20$)-120^{\circ} \mathrm{C}$ and $10^{\prime \prime} \mathrm{C} \min ^{-1}$, respectively. The thermogram was recorded with water as reference. The transition temperatures reported are the onset $\left(T_{n}\right)$, peak $\left(T_{p}\right)$ and conclusion ( $\left.T_{v}\right)$. The enthalpy $(\Delta H)$ was estimated by integrating the area between the thermogram and a baseline under the peak and was expressed in Joules per unit weight of dry $\operatorname{starch}(1 / \mathrm{g})$. Fusion of retrograded amylopectin was determined by weighing ( $3-4 \mathrm{mg}$ dry basis of the stored (at $4^{\prime \prime} \mathrm{C}$ ) gels $(50 \% \mathrm{w} / \mathrm{v}$ ) into DSC pans which were then sealed and seanned from 20 (1) $100^{\circ} \mathrm{C}$ at $10^{\circ} \mathrm{C} / \mathrm{min}$. All DSC experiments were replicated at least three limes.

\subsection{Gel preparation}

Gels $(50 \%$ w/v) were prepared as described by Krisi and Neukom (1984). Oat starches $(5 \mathrm{~g}$. $\mathrm{db})$ were carefully weighed into circular aluminum moulds (diameter 3.0 
$\mathrm{cm}$, height $3.0 \mathrm{~cm}$ ) with removable tops and bases and then mixed with $10 \mathrm{ml}$ distilled water containing $0.02 \% \mathrm{Na}_{2} \mathrm{~S}_{2} \mathrm{O}_{3}$ as preservative. The moulds were then heated in a wated bath for 35 min at $95^{\circ} \mathrm{C}$. The resulting gels were allowed to cool within the moulds for 30 min at $4^{\circ} \mathrm{C}$ prior to storage at $25^{\circ} \mathrm{C}$ for 20 (lilys.

\subsection{Gel powder preparation}

The procedure (with minor modifications) of Roulel ef al. (1988) was used to convert the stored gels $t\left(0\right.$ a powder prior $t$ examination by I)SC and $X^{\prime}$-ray diffinction. The gels were rinsed with water, cut into small pieces and mixed wilh $100 \mathrm{ml}$ acetone. After homogenization using a polytron, the mixture was felt to decant for 5 min. The liquid was discarded and the rest wats transferred to screw calp tubes. Acetone wals again added, the mixture centrifuged $(3000 \times \mathrm{g})$ and the supernat:ant discarded. This procedure was repeated three times and the remaining mass was dried in an air-oven for (bh at 30")".

\subsection{Freeze-thaw stability}

The gels (6\% w/v, db) were subjected to cold storage at 4 "C for I fh (to increase nucleation) and then firoen at $-166^{\prime} \mathrm{C}$. To measure frees-thaw stability, the gels frowen at $-16^{\circ} \mathrm{C}$ for $24 \mathrm{~h}$, were thatwed at $25^{\circ} \mathrm{C}$ for fh and then refirom at $-16^{\prime \prime} \mathrm{C}$. . Iive cyeles of freeze-thaw were performed. The excluded water was determincd by centrifuging the 
tuhes $(30 \mathrm{~mm}$ diameter $\mathrm{x} 10() \mathrm{mm}$ ) at $1000 \mathrm{xg}$ for $20 \mathrm{~min}$ after thawing. Reported values were means of three determinations.

\subsection{Gel texture determination}

The resistance to penetration of the gel, during storage (2-20 days) at $25^{\circ} \mathrm{C}$ was delermined with a model 6000R Lloyd texture testing machine (Omnitronix Instruments Ltd., Mississaltga, ON) equipped with a data acquisition and processing station. The 50 $\mathrm{N}$ load cell was used. The gels within the aluminum moulds were placed on the compression table. The cross head of the machine, fitted with the load cell and a cylindrical probe ( $5 \mathrm{~mm}$ diameter) was driven down so as to just touch the gel surface. The probe was then driven at a constant speed $(0.5 \mathrm{~mm} / \mathrm{min})$ into the gel for a distance of $6 \mathrm{~mm}$. The load at $1 \mathrm{~mm}$ compression was termed firmness. The readings were in units of load grams. The reported results were means of three determinations. 


\section{CHAPTER 4}

\section{RESULTS AND DISCUSSION}

\subsection{Morphological granular characteristies of the starch}

Starch granules tended to exist in clusters of individual granules (Iت̈gs. +.| А.B). The shape of both starch granules tested ranged from polygonal to irregular with an average granule diameter of 5 to $12 \mu \mathrm{m}$. Smooth surliaes were observed with 110 evidence of indentations lissures or pores.

\subsection{Chemical composition of the starch}

The data on composition and yield of NO 753-2 and AC' Stewart starches are presented in Table 4.1. The nitrogen content of the purilied oat starches was ().(0) I\%, (dry basis), indicating the absence of endosperm proteins and by implication most of the non-starch lipids (Morrison, 1981). The total starch lipids (TSL) obtained by acid hydrolysis were $1.6 \%$ in both starehes. These values were higher than those rejorted for AC Hill oat (1.13\%) (Hoover and Vasanthan, 1992) and wheal $(0.7 \%)$ (Vasanthan and Hoover, 1992) starches.

The solvent extracted lipids (SEL) from the combined action of chloroformmethanol 2:1 v/v (CM) and n-propanol-water 3:I v/v (PW) were 1.6.3\%. (NO) 75.3-2) and $1.67 \%$ (AC Stewart). These values were higher than those reported for wheat 


\section{1}

(0.68\%) (Vasanthan and Hoover, 1992) and AC Hill oat starches (1.12\%) (Hoover and Vasanthan, 1992), but were within the range (1.3-2.4\%) reported by Morrison $e$ al. (1984), Doublier et tl. (1987a,b), Gudmundsson and Eliasson (1989) and Sowa and White (1992) for starches isolated from other varieties of oat grains.

\subsection{Amylose content}

The total amylose contents in NO 75.3-2 and AC Stewart starches were 22.7 and $22.9 \%$, respectively (Table 4.1 ). These values are higher than those reported for AC Hill oat starch $(19.4 \%$ ) (Hoover and Vasanthan, 1992), but lower than that of wheat starch (27.3\%) (Vasanthan and Hoover, 1992) and oat starches from other cultivars (22.8-29.4\%) (Morrison et al., 1984; Gudmundsson and Eliasson, 1989; Wang and White, 1994). The amount of amylose complexed by native lipids in NO 753-2 and AC Stewart was 14.1 and $15.3 \%$, respectively,. These values were within the range (13.9-32.0\%) ieported (Morrison et al., 1984; Hoover and Vasanthan, 1992) for oat starches from other cultivars (Morrison et al., 1984; Hoover and Valsanthan, 1992), but lower than that of wheat starch $(22.7 \%)$ (Vasanthan and Hoove1, 1992). 


\subsection{X-ray diffraction}

The X-ray spectra of both oat starches examined were of the $A$ - Iype representative of cereal starches (Fig. 4.2). At approximately the same moisture content. the intensities of the major diffraction peaks were much higher in NO 7.5.3-2 than in AC Stewart (Fig. 4.2 and Table 4.2). The results suggest that crystallites of N() 753-2 are either more closely associated and/or are better orientaled to diffrict X-rays than those of AC Stewart.

\subsection{Swelling factor (SF) and amylose leaching ( $\mathrm{MML}$ )}

The SF and AML of oat starches in the temperature range of $50-80()^{\prime \prime} \mathrm{C}^{\prime}$ are presented in Table 4.3 and 4.4. The SF of both starches increased with increasing temperature. This was most marked between 50 ) and 6()$^{\prime \prime} \mathrm{C}(\mathrm{AC}$. Stewart $>$ NO $) 753-2$ ) (Table 4.3). Furthermore, at all temperatures, the SF of AC Stewart was much higher than that of NO 753-2. For instance, at $80^{\circ} \mathrm{C}$ the SF values were 22.3 and 9.5 ('Table 4.3) for AC Stewart and NO 75.3-2, respectively. The SI: of AC Stewart was comparable to that of wheat (Vasanthan and Hoover, 1992) and AC Hill (ail starches (Hoover and Vasanthan, 1992). Tester and Morrison (1990) have shown, by studies on waxy and normal starches, that swelling is a property of amylopectin, and that in 
Hig. 4.1. Scanning electron micrographs of native oat starches:

A) NO 7.5.3-2; B) AC Stewart 


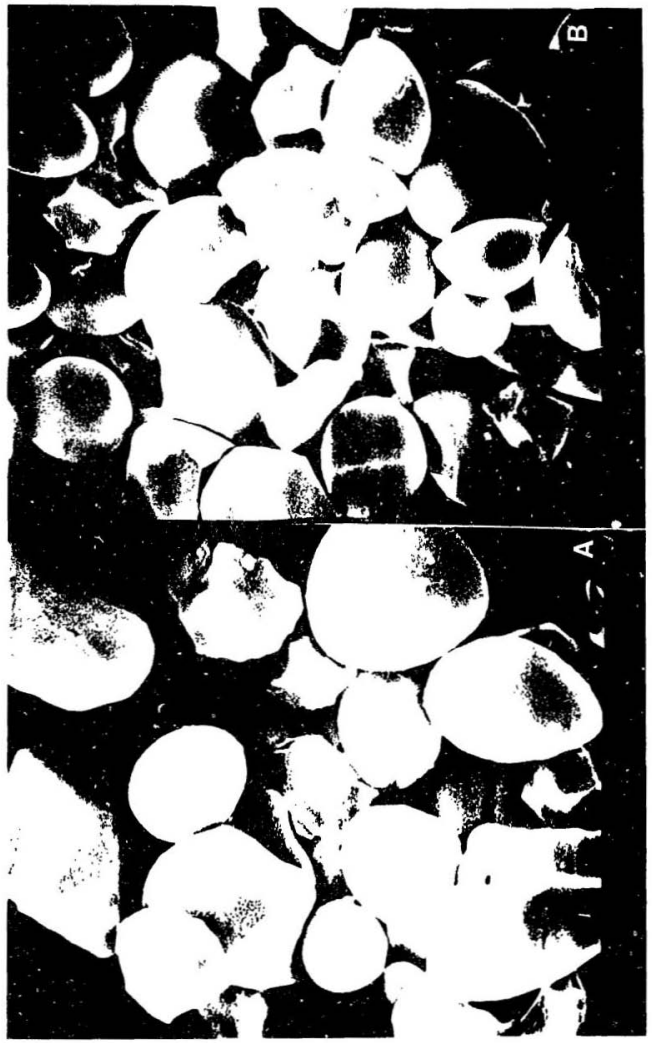


Table 4.1. Chernical composition (\%) of oat starches'.

\begin{tabular}{|c|c|c|}
\hline \multirow[b]{2}{*}{ Characteristics } & \multicolumn{2}{|c|}{ Oat cultivar } \\
\hline & NO 75.3-2 & AC Stewart \\
\hline Yield ('/ initial metlerial) & $35.8 .4 \pm 1.5$ & $34.0^{\prime \prime} \pm 1.2$ \\
\hline Muisture & $10.6^{4} \pm 0.6$ & $10.2^{\prime \prime} \pm 0.4$ \\
\hline Ash & $0.21^{a} \pm 0.01$ & $0.20^{\mathrm{n}} \pm 0.0 \mathrm{I}$ \\
\hline Nitrogen & $0.00]^{x} \pm 0.01$ & $0.001^{a} \pm 0.01$ \\
\hline \multicolumn{3}{|l|}{ Lipid } \\
\hline Acid hydrolysed ${ }^{2}$ & $1.64^{3} \pm 0.6$ & $1.67^{3} \pm 0.5$ \\
\hline \multicolumn{3}{|l|}{ Solvent extracted } \\
\hline chlorolin-methanol & $0.36 \mathrm{a} \pm 0.01$ & $0.3\left(0^{\mathrm{b}} \pm 0.01\right.$ \\
\hline n-propanol-water & $1.27^{\mathrm{b}} \pm 0.01$ & $1.37^{a} \pm 0.05$ \\
\hline \multicolumn{3}{|l|}{$\begin{array}{l}\text { Amylose content } \\
\text { (\% of total starch) }\end{array}$} \\
\hline Appurent' & $19.5^{a} \pm 0.1$ & $19.4^{n} \pm 0.4$ \\
\hline Touals & $22.7^{\mathrm{u}} \pm 0.6$ & $22.9^{\mathrm{a}} \pm 0.1$ \\
\hline $\begin{array}{l}\text { Amylose complexed with } \\
\text { native lipidf }\end{array}$ & $14.1^{b} \pm 0.1$ & $15.3^{n} \pm 0.4$ \\
\hline
\end{tabular}

'All data reporteci on dry hasis and represent means \pm standard deviation of triplicate analyses. Mean values in each low sharing the sume superseript are not significautiy different (p20.05).

I.jpids whtained by acid liydrolysis $(24 \% \mathrm{HCl}$ ) of the native starch (total lipids).

'I.ipids extrikted from native starch by chloroform-methanol $2: 1(\mathrm{v} / \mathrm{v})$ at $25^{\circ} \mathrm{C}$ (mainly unbound lipids).

"Lipids extrated hy hot propanol-water $3: 1$ ( v/v) from the residue left after chlorolorm-methanol extration (mainly bound lipies).

'Apparent and total anyylose determined by $I_{2}$-binding before and after removal of bound lipids by hot propanol-water exiraction.

"Lual amylose - apparen amylsece $\times 100$

Total amylose 
85

Fig. 4.2. X-ray diffraction patterns of native oat starches:

A) AC Stewart; B) NO 753-2 


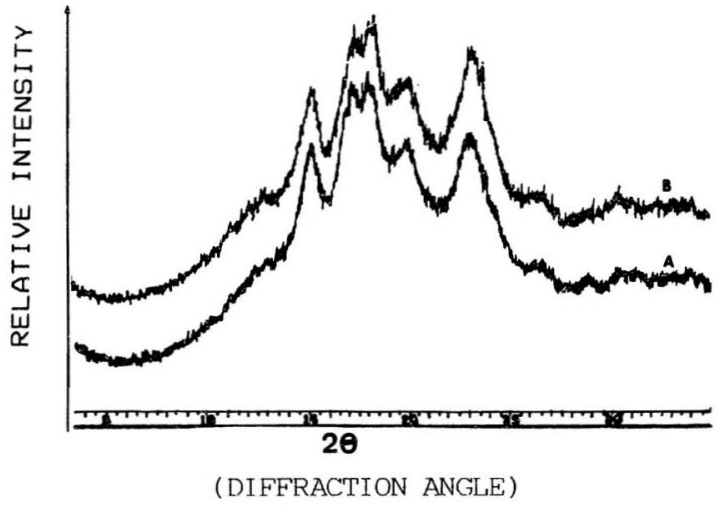


Table 4.2. X-ray diffraction spacings and intensities of the major peaks of oat starches '.

\begin{tabular}{|c|c|c|c|c|c|}
\hline Oat cultivar & Moisture & Interp & lanar spacings (d) ir & A with intensities & $(P S)^{2}$ \\
\hline NO $753-2$ & $10.6^{a}$ & $5.8(1849 \mathrm{a} \pm 0.8)$ & $5.2(257 \mid \mathrm{a} \pm 0.7)$ & $4.9\left(2698^{\mathrm{a}} \pm 0.9\right)$ & $3.8(954 \mathrm{a} \pm 1.0)$ \\
\hline AC Stewart & $10.2^{\mathrm{a}}$ & $5.9\left(1085^{b} \pm 0.7\right)$ & $5.3\left(1085^{b} \pm 0.7\right)$ & $5.2\left(1494^{b} \pm 0.7\right)$ & $3.8\left(495^{h}=1.5\right)$ \\
\hline
\end{tabular}

'Values represent means \pm standard deviation of triplicate analyses.

Mean values in each column not followed by the same superscript are significantly different ( $\mathrm{p} \leq 0.05$ ).

z Counts per second 
nomal cercal starches amylose and lipid actively inhibit swelling under conditions where amylose-lipid complexes are likely to form. The present results suggest that the Sli of both starches is probably influenced mainly by differences in the degree of association between amylopectin chains (NO 753-2 > AC Stewart).

The extent of AML in both starches was nearly similar (Table 4.4) and much lower than those reported for other oat starch cultivars (Paton, 1979; Hoover and Vasinthan, 1992). These diflerences probably reflect the lower amylose content of AC Stcwart and NO 75,3-2 starches (Table 4.1).

\subsection{Pasting properties}

The pasting properties of the oat starches are shown in Table 4.5. NO 753-2 exhibited a higher pasting temperature, a lower viseosity at $95^{\circ} \mathrm{C}$, a higher resistance to shear (during the holding cycle at $95^{\circ} \mathrm{C}$ ) than $\mathrm{AC}$ Stewart. It has been postulated (Doublier $\mathrm{cl}$ al., 1987a,b; Hoover and Vasanthan, 1992; Hoover et al., 1993; Wang and White, 1994), that pasting properties are influenced by the magnitude of associative honding fortes within the granule interior of starch. The difference in pasting properties (Tible 4.5 ) is probubly clue to stronger bonding forces within the granule interior of NO $7.5 .3-2$ starch. 
Table 4.3. Effect of temperature on swelling factor of oat starches '.

\begin{tabular}{lcccc}
\hline Oat cultivar & \multicolumn{4}{c}{ Temperature $\left({ }^{\circ} \mathrm{C}\right)$} \\
\cline { 2 - 4 } & 50 & 60 & 70 & 80 \\
\hline NO 753-2 & $3.5^{\mathrm{b}} \pm 0.2$ & $7.3^{\mathrm{b}} \pm 0.7$ & $8.6^{\mathrm{b}} \pm 0.9$ & $9.5^{\mathrm{b}} \pm 0.3$ \\
& & & & \\
AC Stewart & $6.3^{\mathrm{a}} \pm 0.4$ & $12.9^{\mathrm{a}} \pm 0.9$ & $16.7^{\mathrm{a}} \pm 0.9$ & $22.3^{\mathrm{a}} \pm 0.9$ \\
& & & & \\
\hline
\end{tabular}

'Values represent means \pm standard deviation of triplicate analyses.

Mean values in each column not followed by the same superscript are significantly different ( $\mathrm{p} \leq 0.05$ ). 
Table 4.4. Effect of temperature on amylose leaching of oat starches '.

\begin{tabular}{lcccc}
\hline & \multicolumn{4}{c}{ Temperature $\left({ }^{\circ} \mathrm{C}\right)$} \\
\cline { 2 - 5 } Oat cultivar & 50 & 60 & 70 & 80 \\
\hline NO 753-2 & - & $0.7^{\mathrm{a} \pm 0.1}$ & $1.6^{\mathrm{a} \pm 0.2}$ & $2.2^{\mathrm{a} \pm 0.2}$ \\
AC Stewart & - & $0.7^{\mathrm{a}} \pm 0.1$ & $1.8^{\mathrm{a}} \pm 0.1$ & $2.5^{\mathrm{a}} \pm 0.5$ \\
\hline
\end{tabular}

${ }^{1}$ Values represent means \pm standard deviation of triplicate analyses.

Mean values in each column sharing the same superscript are not significantly different $(\mathrm{p} \geq 0.05)$. 
Table 4.5. Pasting characteristics of oat starches'.

\begin{tabular}{|c|c|c|c|c|}
\hline Oat cultivar & $\begin{array}{l}\text { Pasting temperature } \\
\qquad\left({ }^{\circ} \mathrm{C}\right)\end{array}$ & $\begin{array}{c}\text { Viscosity at } \\
95^{\circ} \mathrm{C} \\
(\mathrm{BU})^{2}\end{array}$ & $\begin{array}{l}\text { Viscosity after } \\
30 \text { min at } 95^{\circ} \mathrm{C} \\
(\mathrm{BU})^{2}\end{array}$ & $\begin{array}{c}\text { Viscosity at } \\
50^{\circ} \mathrm{C} \\
(\mathrm{BU})^{2}\end{array}$ \\
\hline NO 753-2 & $95.7^{x} \pm 0.1$ & $139.0^{b} \pm 1.4$ & $112.5^{b} \pm 1.0$ & $445.0^{b} \pm 2.5$ \\
\hline AC Stewart & $94.7^{b} \pm 0.2$ & $162.5^{a} \pm 1.6$ & $117.5^{\circ} \pm 1.0$ & $490.0^{2} \pm 2.5$ \\
\hline
\end{tabular}

'Values represent means \pm standard deviation of triplicate analyses.

Mean values in each column not followed by the same superscript are significantly different $(p \leq 0.05)$.

'Brabender units. 


\subsection{Gelatinization temperatures}

The DSC thermograms of the two oat starches are presented in Table 4.6. The Iransition temperatures $\left(\mathrm{T}_{w}\right.$ (onset), $\mathrm{T}_{\mathrm{p}}$ (peak), $\mathrm{T}_{\mathrm{c}}$ (conclusion)) and the gelatinization enthalpy $(\Delta \mathrm{H})$ of AC Stewart were lower than those of NO $753-2$ by $8.4^{\circ} \mathrm{C}, 9.4^{\circ} \mathrm{C}$, $10.7^{\prime \prime} \mathrm{C}$ and $2.5 \mathrm{~J} / \mathrm{g}$, respectively. Furthermore, the gelatinization temperature range $\left(\mathrm{T}_{-}-\mathrm{T}_{\mathrm{v}}\right)$ of NO 753-2 was higher than that of AC' Stewart by $2.3^{\prime \prime} \mathrm{C}$ (Table 4.6). The $\mathrm{T}_{\mathrm{e}}$, $\mathrm{T}_{\mathrm{p}}$ and $\mathrm{T}_{\mathrm{c}}$ of the above starches were within the range reported for other oat cultivars. However, $\Delta \mathrm{H}$ values were lower than the reported range (9.4-10.6 J/g) (Paton, 1987; Gudmundsson and Eliasson. 1989; Hoover and Vasanthan, 1992; Sowa and White, 1992: Wang and Whitc. 1994). The higher $T_{n}, T_{p}$ and $T_{c}$ of NO 753-2 suggest that the crystallite size and/or crystallite association within its granules are of a higher order of magnitude than AC Stewart.

Kugimiya et al. (1980) showed that lysolecithin complexed potato starch exhibited a lower $\Delta \mathrm{H}$ value than did native potato starch. Biliaderis et al. (1986) noted that waxy rice starches (devoid of lipids) exhibited higher $\Delta \mathrm{H}$ values than those of their non-waxy counterparts. The latter authors postulated that the lower $\Delta H$ values for nonwaxy starches were the net result of two competing processes: melting of starch crystallites (endothermic) and crystallization (exothermic) of amylose-lipid complexes. 
Table 4.6. Differential scanning calorimetry of oat starches'.

\begin{tabular}{lccccccc}
\hline Oat cultivar & $\mathrm{T}_{\mathrm{o}}{ }^{2}$ & $\mathrm{~T}_{\mathrm{p}}{ }^{2}$ & $\mathrm{~T}_{\mathrm{c}}{ }^{2}$ & $\mathrm{~T}_{\mathrm{c}}-\mathrm{T}_{\mathrm{o}}{ }^{3}$ & $\Delta \mathrm{H}^{4}$ & $\mathrm{~T}_{\mathrm{cx}}{ }^{\mathrm{S}}$ & $\Delta \mathrm{H}_{\mathrm{cs}}{ }^{0}$ \\
& $\left({ }^{\circ} \mathrm{c}\right)$ & $\left({ }^{\circ} \mathrm{c}\right)$ & $\left({ }^{\circ} \mathrm{c}\right)$ & $\left({ }^{\circ} \mathrm{c}\right)$ & $(\mathrm{J} / \mathrm{g})$ & $\left({ }^{\circ}\right)$ & $(\mathrm{J} / \mathrm{g})$ \\
\hline
\end{tabular}

NO 753-2 $\quad 60.4^{\mathrm{a}} \pm 0.1 \quad 67.0^{\mathrm{a}} \pm 0.2 \quad 74.2^{\mathrm{a}} \pm 0.1 \quad 13.8^{\mathrm{a}} \pm 0.1 \quad 8.4^{\mathrm{a}} \pm 0.2 \quad 98.5^{\mathrm{b}} \pm 0.3 \quad 3.0^{\mathrm{b}} \pm 0.1$

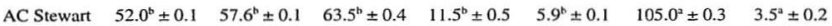

'Starch:water ratio 1:3, Values represent means \pm standard deviation of triplicate analyses.

${ }^{2} \mathrm{~T}_{\mathrm{o}}, \mathrm{T}_{\mathrm{p}}$ and $\mathrm{T}_{\mathrm{c}}$ indicate the temperatures of the onset, midpoint and end of gelatinization.

${ }^{3}$ Gelatinization temperature range.

Enthalpy of gelatinization.

${ }^{5}$ Amylose-lipid complex transition temperature.

'Amylose-lipid complex transition enthalpy.

Mean values in each column not followed by the same superscript are significantly different $(\mathrm{p} \leq 0.05)$. 
Biliaderis et al. (1986) also showed that $\Delta \mathrm{H}$ values decrease with increase in bound lipid content for 8 cultivars of rice starch. Thus, the difference in $\Delta \mathrm{H}$ values between NO 753-2 and AC Stewart starches (Table 4.6) is probably due to the higher bound lipid content of the latter (Table 4.1).

The transition enthalpy for the melting of the amylose-lipid complex $\left(\Delta \mathrm{H}_{\mathrm{cr}}\right)$ was 3.0) and $3.5 \mathrm{~J} / \mathrm{g}$ in NO 75.3-2 and AC Stewart starches, respectively (Table 4.6). These values were within the range $(0.84-3.70 \mathrm{~J} / \mathrm{g})$ reported for other oat starch cultivars (Paton, 1987; Gudmundsson and Eliasson, 1989; Hoover and Vasanthan, 1992; Sowa and White, 1992). Furthermore, the $\Delta \mathrm{H}_{\mathrm{cx}}$ of both starches werc higher than those reported for wheat starch $(1.30 \mathrm{~J} / \mathrm{g})$ (Hoover and Vasanthan, 1992). This suggests that $\Delta \mathrm{H}_{\mathrm{cr}}$ is influenced by the amount of amylose complexed lipids (AC Stewart > NO 753$2>$ wheat). It was interesting to observe that although the amount of lipid complexed amylose in NO 753-2 $(14.1 \%)$ and AC Stewart (15.5\%) starches was only slightly higher than the value reported for AC Hill oat starch (13.1\%) (Hoover and Vasanthan, 1992), the $\Delta \mathrm{H}_{\mathrm{sr}}$ of the latter $(0.8 \mathrm{~J} / \mathrm{g})$ was much lower than those of NO $753-2(3.1 \mathrm{~J} / \mathrm{g})$ and AC Stewart $(3.5 \mathrm{~J} / \mathrm{g})$ starches. This indicates that lipids of AC Hill oat starch are probably less strongly bound to the amylose helix than those of NO 753-2 and AC Stewart starches. 


\subsection{Light transmittance}

The percentage light transmittance ( $\% \mathbf{T}$ ) of the oat starches at different pll values are presented in Table 4.7. Above $\mathrm{pH}$ 6, the clarily of the starch paste was higher in $\mathrm{AC}$ Stewart. This difference was most pronounced at pH values between 6 and 9. At pH 12. the \% $\mathrm{T}$ was 91 and $83 \%$ in AC Stewart and NO 753-2 starehes, respectively. The $\% \mathrm{~T}$ of $\mathrm{AC}$ Stewart at $\mathrm{pH} 12$ was comparable to that reported for AC Hill out starch (90) and wheat starch (94) (Hoover and Vasanthan, 1992).

Swinkels (1985) and Craig ot al. (1989) showed that amylose-lipid complexes decrease the \% $\mathrm{T}$ of starch paste. The latter authors also reported that \% ' $\mathrm{T}$ increases with the degree of swelling. Our results showed that the difference in "\% 'l' between the two oat starches (Table 4.7) is probably influenced by dillierences in swelling lactor (Table 4.3) (AC Stewart > NO 753-2).

\subsection{In vitro digestibility of native starches by porcine pancreatic $\alpha$-amylase}

The extent of $\alpha$-amylase hydrolysis of the oat starches is presented in Table 4.8 . During the first $12 \mathrm{~h}, \mathrm{AC}$ Stewart was more extensively hydrolysed than N() 7.53-2. Thereafter, differences in hydrolysis were only marginal (Table 4.8). For instance, after 12h of hydrolysis AC Stewart and NO 7.53-2 starches were hydrolysed hy 3.5 and $28 \%$, respectively. However, the corresponding values after 48 h of hydrolysis 
Table 4.7 Effect of $\mathrm{pH}$ on light transmittance (\%) of native oat starches '.

\begin{tabular}{|c|c|c|c|c|c|c|c|c|}
\hline \multirow{3}{*}{ Oat cultivar } & \multicolumn{8}{|c|}{$\mathrm{pH}$} \\
\hline & 2 & 3 & 4 & 6 & 7 & 8 & 9 & 12 \\
\hline & \multicolumn{8}{|c|}{ Transmittance $(\%)$} \\
\hline NO 753-2 & $2.5 \cdot \pm 0.4$ & $6.1 \pm 0.4$ & $11.8 \pm 0.5$ & $20.0^{\infty} \pm 0.3$ & $22.4^{\circ} \pm 0.2$ & $27.6^{6} \pm 0.3$ & $40.0^{b} \pm 0.2$ & $83.2^{b} \pm 0.3$ \\
\hline AC Stewart & $2.2^{a} \pm 0.3$ & $5.5^{*} \pm 0.7$ & $10.7 \because 0.4$ & $24.2 \pm 0.4$ & $34.9= \pm 0.4$ & $39.4 \pm 0.7$ & $49.1 \pm 0.3$ & $91.2 \pm 0.2$ \\
\hline
\end{tabular}

\footnotetext{
'Values represent means \pm standard deviation of triplicate analyses.
}

Mean values in each column not followed by the same superscript are significantly different ( $\leq \leq 0.05$ ) 
were 43 and $41 \%$. respectively. The above values were comparable to that of wheat starch (42\% after 24h) (Hoover and Vasanthan, 1992), but higher that that of $A C$ Ilill oat starch (31.6\% in 24h) (Hoover and Vasanthan. 1992). Studies have shown that amylose helices complexed with mono:acyl lipids (Van Lonkhuysen and Blankiestijn. 1976; Larrson and Meizis, 1979): Holm et al., 1983) are resistant to hydrolysis by $\alpha$ amylase, probably die to a decreased solubility of the complex. In addition, fictors such as degree of crystallinity (Dreher ef al., 1984: Ring et al., 1988: Lauro ct al., 1993), amylose/amylopectin ratio (Dreher et al., 1984: Holm and Bjürck, 1988), and particle size (Ring et al., 1988) have also been shown to influence starch digestibility. Marsden and Gray (1986) and Franco et al. (1988) postulated that $\alpha$-imlinye initially hydrolyses the amorphous regions of the granule. Furthermorc, Williamson ef al. ( 1492$)$ showed by means of DSC and X-ray diffraction studies that in $\Lambda$-type granules, hydrolysis occurs predominantly in the amorphous regions of the gramule. The differences in the degree of susceptibility of the two starches towards $\alpha$-amylase hydrolysis suggest that starch chain associations within the amorjhous regions of the granule are probably more extensive in NO 75.3-2 than in AC: Stcwart. This secms plausible, since difference in granule size (Fig. 4.1), between the (wo slarches is only marginal. 
Table 4.8 Time course of hydrolysis of native oat starches by porcine pancreatic $\alpha$-amylase '

\begin{tabular}{|c|c|c|c|c|c|c|}
\hline \multirow{3}{*}{ Oat cultivar } & \multicolumn{6}{|c|}{ Hydrolysis time (h) } \\
\hline & 3 & 6 & 9 & 12 & 24 & 48 \\
\hline & \multicolumn{6}{|c|}{ Hydrolysis (\%) } \\
\hline NO 753-2 & $14.6^{\circ} \pm 0.1$ & $20.0^{\circ} \pm 0.7$ & $25.4^{\mathrm{h}} \pm 0.3$ & $28.3^{3} \pm 0.2$ & $40.0^{0} \pm 0.9$ & $41.3 \cdot \pm 1.5$ \\
\hline AC Stewart & $21.0^{2} \pm 0.1$ & $27.2 \pm 0.2$ & $30.9 \pm 0.5$ & $35.3^{2} \pm 0.6$ & $42.5^{2} \pm 0.8$ & $42.6^{a} \pm 1.2$ \\
\hline
\end{tabular}

'Values represent means \pm standard deviation of triplicate analyses.

Mean values in each column not followed by the same superscript are significantly different ( $\mathrm{p} \leq 0.05)$. 
The granular residues left after enzyme hydrolysis (2 2(0h) were antal ad by 1 DSC

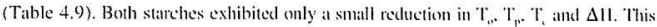
suggests that the perfecting and ordering of the amylopectin crystallites in the gramular residues are very nearly the same as in the native granule.

\subsection{Acid hydrolysis}

The solubilization patterns of the two oat starches are presented in Tathle t.10. A relatively higher rate of solubilization was observed during the first 9 and 12 days for AC Stewart and NO 753-2 starches, respectively. followed by a slower rate thereatier (Table 4.10). After 20) days, the extent ol hydrolysis was $86.5\left(A C^{\circ}\right.$ Stewart) and $79 .(1 \% \%$ (NO 753-2). During the same period, corn. wheall, and $\wedge C^{\prime}$ llill oal starches were hydrolysed by 76 (unpublished results), 82 (Hoover and V:IsanthatI, J9(4) and $80 \% \%$ (Hoover and Vasanthan, 1992), respectively. The fister rate during the early stages of hydrolysis (9 days (AC Stewart), 12 days (NO 75,3-2)) corresponded to the destruction of the amorphous regions of the granule. During the final stage, the crystalline region is slowly degraded (Kainuma and Irench, 1971; Rohin at al., 1974; French, 1984). It is evident from the results presented in Tahle 4. 10, that the anorphous and erystalline region: are more highly ordered in NO 75.3-2 than in $\Lambda C^{\circ}$ S Stewart. 
Table 4.9. DSC gelatinization parameters of enzyme treated granular residues following hydrolysis with porcine pancreatic $\alpha$-amylase'.

\begin{tabular}{lccccc}
\hline & & \multicolumn{4}{c}{ Hydrolysis time $(\mathrm{h})$} \\
\cline { 3 - 5 } Starch source & DSC parameter & \multicolumn{1}{c}{2} & 4 & 10 & 20 \\
\hline NO 753-2 & $\mathrm{Tp}^{2}$ & $69.0^{\mathrm{a}} \pm 0.2$ & $68.0^{\mathrm{a}} \pm 0.1$ & $69.0^{\mathrm{a}} \pm 0.2$ & $70.0^{\mathrm{a}} \pm 0.1$ \\
& $\Delta \mathrm{H}^{\mathrm{3}}$ & $6.7^{\mathrm{c}} \pm 1.0$ & $5.9^{\mathrm{c}} \pm 1.0$ & $5.9^{\mathrm{c}} \pm 1.0$ & $5.5^{\mathrm{c}} \pm 1.0$ \\
AC Stewart & $\mathrm{Tp}^{2}$ & $65.0^{\mathrm{b}} \pm 0.2$ & $63.0^{\mathrm{b}} \pm 0.2$ & $65.0^{\mathrm{b}} \pm 0.1$ & $67.0^{\mathrm{b}} \pm 0.1$ \\
& $\Delta \mathrm{H}^{3}$ & $5.9^{\mathrm{c}} \pm 0.1$ & $5.9^{\mathrm{c}} \pm 0.1$ & $5.8^{\mathrm{c}} \pm 0.1$ & $5.7^{\mathrm{c}} \pm 0.1$ \\
\hline
\end{tabular}

'Values represent means \pm standard deviation of traplicate analyses.

Mean values in each column sharing the same superscript are not significantly different $(\mathrm{p} \geq 0.05)$.

${ }^{2}$ Peak temperature $\left({ }^{\circ} \mathrm{C}\right)$

${ }^{3}$ Enthalpy of gelatinization $(\mathrm{J} / \mathrm{g})$ 
Table 4.10 Heterogenous acid hydrolysis of native oat starches in $2.2 \mathrm{~N} \mathrm{HCl}$ at $35^{\circ} \mathrm{C}{ }^{\prime}$.

\begin{tabular}{|c|c|c|c|c|c|c|c|c|c|c|}
\hline \multirow{3}{*}{ Oat cultivar } & \multicolumn{10}{|c|}{ Hydrolysis time (days) } \\
\hline & 1 & 3 & 5 & 7 & 9 & 12 & 13 & 15 & 17 & 20 \\
\hline & \multicolumn{10}{|c|}{ Hydrolysis (\%) } \\
\hline
\end{tabular}

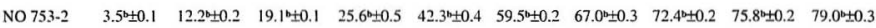

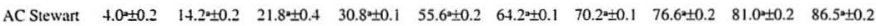

${ }^{1}$ Values represent the means \pm standard deviation of triplicate analyses.

Mean values in each column not followed by the same superscript are significantly different ( $\mathrm{p} \leq 0.05)$. 


\subsection{Retrogradation of oat starch gels}

The extent of retrogradation during gel storage was monitored by determining changes in free\%-thaw stability, gel strength, retrogradation enthalpy and X-ray intensitics.

\subsubsection{Jreeze-thaw stability}

The frece-thaw stability of a starch gel is evaluated by the amount (\%) of water released (syneresis) when starch chains retrograde (reassociate) during the freeze-thaw cycle. The degree of syneresis of the starch gels are presented in Fig. 4.3. The extent of syneresis has been shown to be influenced by the amount of amylose complexed by native lipids (Hoover and Vasanthan, 1992), and by the degree of polymerization of the A chains of amylopectin (Wu and Seib, 1990). The results showed that more starch chains (which separated out as individual units during gelatinization) reassociate during frozen storage in AC Stewart than in NO 753-2 starch. This is probably due to more extensive interaction between starch chains within native granules of NO 753-2 (since differences in the extent of amylose leaching (Table 4.4) and lipid content (Table 4.1) between the starches are only marginal). Both oat starches showed a higher degree of syneresis than AC Hill oat starch (Hoover and Vasanthan, 1992). However, in comparison with wheat starch (Hoover and Vasanthan, 1992), the \% syneresis was 
lower in NO 753-2. but higher in AC Stewart. For instance, at the same concentration $(6 \% \mathrm{w} / \mathrm{v})$ and storage temperature $\left(-16^{\circ} \mathrm{C}\right)$, the \% syneresis were $62.2,65.3,52.0$ and $60.1 \%$ respectively, in NO 753-2. AC Stewart. AC Hill and wheat starches.

\subsubsection{Differential scanning calorimetry}

In both starches, the retrogradation endotherm was ohserved alter the 16 datys of storage (at $\left.4^{\circ} \mathrm{C}\right)$. The transition temperatures $\left(\mathrm{T}_{1,}, \mathrm{~T}_{1,}, \mathrm{~T}_{2}\right)$ of the retrogradation endotherm of NO 753-2 $\left(45,48,54^{\circ} \mathrm{C}\right)$ and AC Stewart $\left(42,44,55^{\circ} \mathrm{C}\right)$ starch gels showed only marginal changes during the time course of retrogradition. Furthermore, $T_{c}-T_{s}$ for retrogradation |NO 75.3-2 $\left(17^{\prime \prime} \mathrm{C}\right)$. AC Stewart $\left(1.3 .5^{\prime \prime}\left(^{\prime}\right) \mid\right.$ were broader than for gelatinization [NO 753-2 (13.8"C). AC Stewart (5.9"C)|. In both out starch gels, the enthalpy of retrogradation $\left(\Delta \mathrm{H}_{\mathrm{R}}\right)$ increased gradually until the $24^{\text {th }}$ day

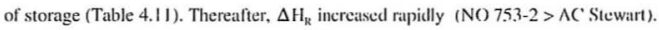
At the end of the storage period (32 days), the increase in $\Delta \mathrm{II}_{\mathrm{k}}$ was 6.7 and $5.0 \mathrm{~J} / \mathrm{g}$ in NO 753-2 and AC Stewart starch gels, respectively.

The broadening of the crystallite melting endotherm on retrogradation, probably reflects melting of crystallites of different stability, size or perfection formed by different types of starch chain associations (amylose-amylopectin and/or amylopectin- 
Fig. 4.3. Freeze-thaw stability of native oat starches. CY1-CY5 represent the number of freeze-thaw cycles. The data are presented as means of three determinations. 


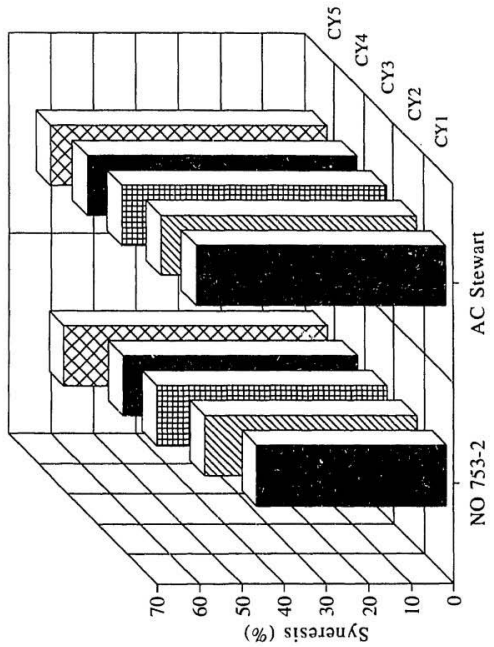


amblopectin) during gel storuge. Gudmundsson and Eliasson (1989) showed that maize starch exhibited higher $\Delta \mathrm{H}_{\mathrm{B}}$ values on storage than oat starches (which had higher lipid contents). However, the oat starch cultivar Chicauhua, when defatted with $75 \%$ isopropanol, showed a higher increase in $\Delta \mathrm{H}_{\mathrm{R}}$ when compared with its native counterpart. Furthermore, in the oat cultivar Svea, the difference in $\Delta \mathrm{H}_{\mathrm{R}}$ between native and defatted starches was only marginal (Gudmundsson and Eliasson, 1989). Wang and White (1994) reported that in three oat cultivars (E 77, Dal, L 996), the percentage retrogradation (\% R) decreased with decreased starch lipid content. The E 77 starch, with the least starch lipid content had the lowest \% R, whereas L 996 starch with the highest starch-lipid content, had the highest \% R. Our results showed that $\Delta H_{R}$ values are not influenced by the lipid content, since both NO 753-2 and AC Stewart starches with identical total lipid contents (Table 4.1) showed wide differences in their $\Delta H_{R}$ (Table 4.11). The differences in $\Delta \mathrm{H}_{\mathrm{R}}$ observed by Gudmundsson and Eliasson (1989) between native and defatted oat starches probably reflect structural changes on defatting (Vasanthan and Hoover. 1992), rather than lipid removal. Yuan et al. (1993) reported that the chain length and chain length distribution of amylopectin could intluence the extent of retrogradation of maize starch by forming a mixture of crystallites of different sizes, with longer chain lengths forming longer double helices. Wang and White (1994) showed that in out starch cultivars, a close relationship exists 
Table 4.11 The enthalpy of retrogradation of native oat starch gels ${ }^{1}$.

\begin{tabular}{|c|c|c|c|c|c|}
\hline \multirow{3}{*}{ Oat cultivar } & \multicolumn{5}{|c|}{ Time (days) } \\
\hline & 16 & 20 & 24 & 28 & 32 \\
\hline & & & Enthalpy $(\mathrm{J} / \mathrm{g}$ & & \\
\hline NO $753-2$ & $2.3 \pm 0.05$ & $2.6^{3} \pm 0.04$ & $3.2^{2} \pm 0.02$ & $5.0^{\mathrm{a}} \pm 0.01$ & $6.7 \div 0.02$ \\
\hline AC Stewart & $1 .+40.02$ & $1.8^{\circ} \pm 0.05$ & $2.5^{\circ} \pm 0.04$ & $3.5^{\circ} \pm 0.05$ & $5.0^{\circ} \pm 0.05$ \\
\hline
\end{tabular}

${ }^{1}$ Values represent means \pm standard deviation of triplicate analyses.

Mean values in each column not foliowed by the same superscript are significantly differe9nt ( $p \leq 0.05)$. 
between the pereentage retrogradation, weight average chain length and the degree of multiple branching. Since $\Delta \mathrm{H}_{\mathrm{R}}$ values reflect the r.elting of amylopectin crystallites formed (hy association between idjacent double helices) during gel storage, the difference in the extent of retrogradation between the oat starches (NO 753-2 > AC Stewart), suggest that amylopectin chains of NO 753-2 are probably less branched and/or are of a longer chain length than those of AC Stewart.

\subsubsection{X-ray diffraction}

The X-ray intensity patterns of NO 753-2 starch gels stored for periods ranging from 2-20 days (at $25^{\circ} \mathrm{C}$ ) are presented in Fig. 4.4. The X-ray intensities of the major peaks of the two oat starch gels stored for 6 and 10 days (at $25^{\circ} \mathrm{C}$ ) are presented in Table 4.12.

The intensitics of the peaks gradually increased (AC Stewart $>$ NO 753-2) during storage (Fig. 4.4, Table 4.12). This suggests that more crystallites form during retrogradation in AC Stewart than in NO 753-2. This seems to contradict the data oltained by DSC (Table 4.11) which showed that NO 753-2 retrograded faster than AC Stewart. This is not surprising, since DSC selectively examines only the crystallization of amylopectin, whereas $\mathrm{X}$-ray diffraction examines crystallization between amyloseamylose, amylose-amylopectin and amylopectin-amylopectin. Interaction between amylose chains can extend over many more residues (due to its linearity) than those 
between amylopectin chains. Consequently, amylose crystallites would be thermally more stable than amylopectin erystallites. Thus, it would not he possible to monitor anylose crystallization by DSC, since pan failure is eommon at temperatures exceeding $1+4()^{\circ} \mathrm{C}$. The X-ray data suggests that the amylose chains of AC Stewart are probably longer (leading to the formation of more crystallites during storage) than thusc of N() 75.3-2. A comparison of the data obtained by X-ray (Table 4.12) and DSC (Table 4.11), suggests that crystallization between chains of amylose (AC Stewalt > NO 75.3-2) are more extensive than between amylopectin chains (NO 753-2 > AC S(Lwarl).

\subsubsection{Gel firmness}

The gel firmness of the starch pastes alter storage at $25^{\prime \prime} \mathrm{C}$ for periods ranging from 2-20 days are presented in Fig.4.5. The magnitude and the extent of increase in gel firmness during storage were more pronounced in AC Stewart. Gudmundsson and Eliasson (1989) and Takahashi and Seib (1988) have shown that statrch lipids influence gel firmness. The former authors reported that among oal cultivars, the starch which gave the stiffest gel had the highest lipid content. Whereas, the latter authors 
108

Hïg.4. 4. X-ray diffraction patterns of retrograded NO 753-2 starch gels as a function of storage time (at $25^{\circ} \mathrm{C}$ ) 


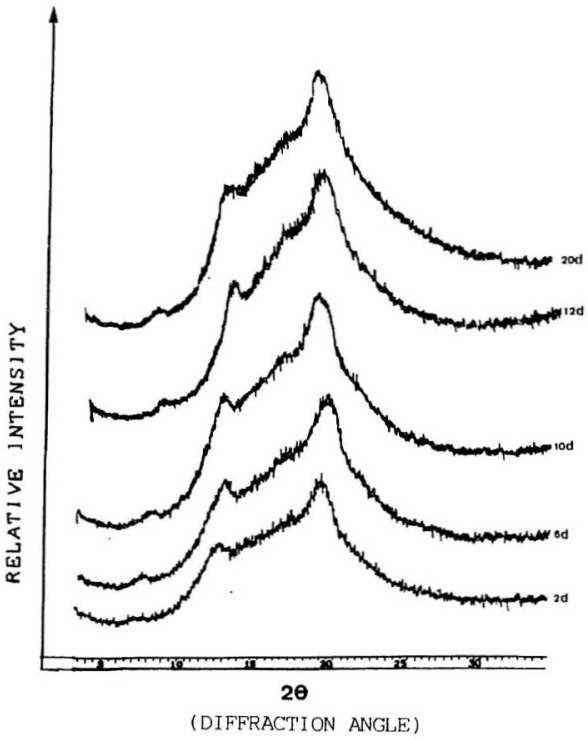


Table 4.12. X-ray diffraction spacings and intensities of the major peaks of retrograded oat starch gels !

\begin{tabular}{|c|c|c|c|c|c|}
\hline \multirow{2}{*}{$\begin{array}{l}\text { Oat cultivar } \\
\text { NO } 753-2\end{array}$} & \multirow{2}{*}{$\begin{array}{c}\text { Time of } \\
\text { storage } \\
\text { at } 25^{\circ} \mathrm{C}\end{array}$} & \multicolumn{4}{|c|}{ Interplanar spacings (d) in Angstroms ( $\AA$ ) with intensities (CPS) 2} \\
\hline & & $6.5\left(1166^{b} \pm 0.8\right)$ & $5.0\left(1724^{b} \pm 0.5\right)$ & $4.6\left(1764^{b} \pm 0.5\right)$ & $4.4(2597 \mathrm{~b} \pm 0.8)$ \\
\hline \multirow{3}{*}{ AC Stewart } & 10 & $6.6(1226 a \pm 0.7)$ & $5.5(1769 a \pm 0.6)$ & $5.2(2206 \mathrm{a} \pm 0.4)$ & $4.4\left(2839^{a} \pm 0.7\right)$ \\
\hline & 6 & $6.9\left(608^{d} \pm 0.9\right)$ & $5.0(734 d \pm 0.7)$ & $4.1(1171 \mathrm{~d} \pm 0.8)$ & $4.3(1880 \mathrm{~d} \pm 0.8)$ \\
\hline & 10 & $6.5(1092 \mathrm{c} \pm 1.0)$ & $5.5(1526 c \pm 0.6)$ & $5.2(169 ?= \pm 0.7)$ & $4.9\left(\left.196\right|^{\mathrm{C}} \pm 0.4\right)$ \\
\hline
\end{tabular}

${ }^{1}$ Values represent means \pm standard deviation of triplicate analyses.

Mean values in each column not followed by the same superscript are significantly different $(p \leq 0.05)$.

${ }_{2}^{2}$ Counts per second. 
reported that stareh lipids in native corn and wheat starehes showed redued gel strength $(\sim 50 \%)$ in comparison with defatted starches. This wiss attribuled to al decrease in amylose concentration in the continuous phase (resulting frum amylese-lipid interactions during gelatinization).

In the starches examined, the differences in total lipid content (Table +.1 ) and amylose leaching (Table 4.4 ) were only marginal. Therefore, the diflerence in gel firmness (Fig. 4.5) is probably a reflection of the extent of amyluse crystallization (AC' Stewart > NO 753-2) in the continuous phase. 


\section{III}

Fig. 4.5 Gel strength of oat starches as a function of storage time (at $25^{\circ} \mathrm{C}$ ). The data are presented as means of three determinations. 


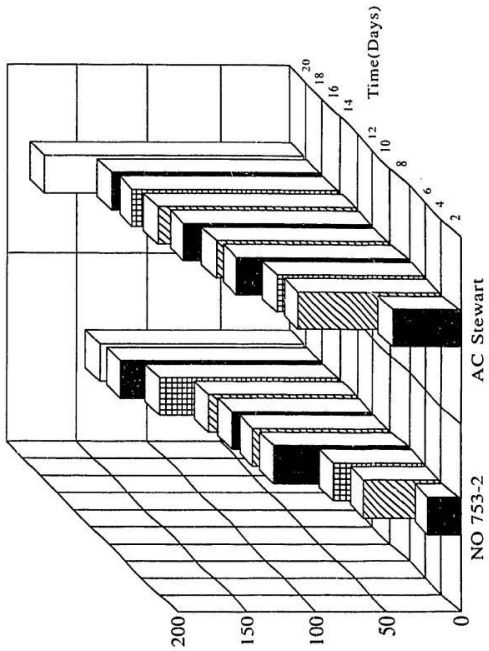

(8) บเชินวกา 1 อD 


\section{CONCLUSIONS}

This study has demonstrated that starches from two new oat varieties. NO 753 2 and $A C$ Stewart, cliffer widely in their composition and physicochemical properties. AC Stewart had a higher swelling factor than that of NO 753-2. The X-ray spectra of both oat starches examined had A-type pattern representative of cereal starches. However, intensities of major diffraction peaks were higher in NO 753-2 than in AC Stewart. The pasting temperature and shear resistance of NO 753-2 were higher than thuse of AC Stewart. The transition temperatures and the gelatinization enthalpy of AC Stewart were lower than those of NO 753-2. The AC Stewart had a higher clarity of starch paste than NO 75:3-2.

The susceptibility of AC Stewart towards hydrolysis by $\alpha$-amylase and acid was higher than that of NO 753-2. Thus, the present results show that the amorphous and crystalline regions of NO 753-2 are ordered to a much greater extent than AC Stewart. The extent of retrogradation during storage was more pronounced in AC Stewart than in NO 753-2. These differences are probably inlluenced by existing differences in the magnitude of interaction between and among starch chains within the amorphous and crystalline regions of the native granule, and by the chain lengths of amylose and amylopectin. However, further studies are needed to characterize the structure and propertics of starch components fractionated from these two starches in order to 
obtain a more precise insight into their granular structures. An undersianding of the variation in physicochemical properties among oat starches would form the basis for future investigations on chemical modifications to improve functionality of ant starches. 


\section{REFERENCES}

AACC (1983). Approved Methods of the AACC. (8th edition). American Association of Cercal Chemists. St. Paul, MN, 08-18,41-60, 46-50.

Atwell, W.A., Hood, L.F., Lineback, D.R., Varriano Marston, E., and Zobel, H.F. (1988). The terminology and methodology associated with basic starch phenomena. Cereal Foods World, 33, 306-I1.

Autio, K. (1990). Rheological and microstructural changes of oat and barley starches during heating and cooling. Food Structure, 9, 297-304.

Badenhuizen, N.P.( 1965). Occurrence and development of starch in plants. In Starch: Chemistry and Technology. (eds. Whistler, R.L. and Paschall, E.F.) Vol.1. Academic Press, NY. pp. 65-103.

Banks, W., Greenwood, C.T. and Khan, K.M. (1970). Studies on starch degrading cnzymes. Part XII. The initial stages of the action on amylose of the $\alpha$-imylases from B. subtilis, human saliva, malted rye and porcine pancreas. Carbohydr. Res., 12, 79-87.

Banks, W. and Greenwood. C.T. (1975). The structure and biosynthesis of the starch granule. In Starch and its Components. (eds. Banks, W. and Greenwood, C.T.). Edinburgh University Press. pp. 242-73.

Batres, L.V. and White, P.J. (1986). Interaction of amylopectin with monoglycerides in model systems. J. Am. Oil Chem. Soc., 63, 1537-40.

Bean, M.M. and Yamazaki, W.T. (1978a). Wheat starch gelatinization in sugar solutions. I. Sucrose: microscopy and viscosity effects. Cereal Chem., 55, 936-44.

Bean. M.M. and Yamazaki, W.T. (1978b). Wheat starch gelatinization in sugar solutions. II. Fructose, glucose, and sucrose: cake performance. Cereal Che'm., 55, 945-52. 
Bello-Pérez. L. A. and Paredes-Lopez. O. (1995). Eflects of solutes on retrogradation of stored starches and amylopectins: A calorimetric study. Starch/Stärke, 47, 8.3-6.

Biliaderis, C.G., Page. C.M.. Slade. L. and Sirett, R.R. (1985). Thermal behuviour of amylose-lipid complexes. Carbohydr: Polymers, 5. 367-89).

Biliaderis, C.G., Page, C.M., Maurice, T.J., and Juliano, B.O. (1986). Thermal characterization of rice starches: a polymeric approach to phase transitions of granular starch. J. Astic: Food Chem., 34, 6-14.

Biliaderis, C.G. and Zawistowski, J. (1990). Viscoelastic hehavior of anging starch gels: Effects of concentration, temperature, and starch hydrolysaltes on network properties. Cereal Chem., 67, 24()-46.

Biliaderis, C.G. (1991). The structure and interactions of starch with food constituents. Can. J. Physiol. Pharmacol., 69, 60-78.

Birnbaum. H. (1977). Interactions of surfactants in bread making. Belker's Dig.. $51,17-24$.

Björck, I., Asp, N.-G., Birkhed, D. and Lundquist, I. (1984). Itflects of processing on availability of starch for digestion in vitro and in viro. I. I Extrusion conking of wheat flours and starch. J. Cereal Sci., 2, 91-103.

Björck, 1., Gunnarsson, A. and Ostergard, K. (1989). A study of native and chemically modified potato starch. Part II. Digestibility in the rat intestinal tract. Starch/Stärke, 41, 128-34.

Blanshard, J.M.V. (1978). Physicochemical aspects of starch gelatinization. In Polysaccharides in food. (eds. Blanshard, J.M.V. and Mitchell, J.R.). Butterworths, London. pp. 139-52.

Bligh, E.G. and Dyer, W.J. (1959). A rapid method of total lipid extraction and purification. Can. J. Biechem. Phys., 37,911-7. 
Bonne, O.T. (1961). Morphology and development. In Oats and Oat Improvement, (ed. Colfman, F.A.). American Society of Agronomy. Madison, WI. pp. $41-74$.

Bornet, F. (1993). Technological treatments of cereals. Repercussions on the physiological properties of starch. Carbohydr: Polymers, 21, 195-203.

Botlan, D. Le and Desbois, P. (1 995). Starch retrogradation study in the presence of sucruse by low-resolution Nuclear Magnetic Resonance. Cereal Chem., 72, $191-93$.

Braga, D., Ferracini, E., Ferrero, A., Ripamonti, A., Brant, D.A., Bulga, G.S. and Cesaro, A. (1985). Amylose conformation in aqueous solution: a small angle X-ray scattering study, Int. J. Biol. Macromol., 7, 161-65.

Bruner, R.L. (1964). Determination of reducing value. In Methods in Carbohydrate Chemistry, Vol. 4 (cd. Whistler. R.L.) Academic Press, NY. pp. 67-71.

Burrows, V.D. (1992). AC Stewart oat. Cen.J. Plant Sci., 72, 447-49.

Burt. D.J. and Russell, P.L. (1983). Gelatinization of low water content wheat starch-water mixtures. A combined study by differential scanning calorimetry and light microscopy. Starch/Stäirke, 35, 354-60.

Camire. M.E. and Camire, A.L. (1994). Enzymatic starch hydrolysis of extruded potato pecls. Starch/Stärke, 46, 308-11.

Camire, M.E. Camire, A. and Krumhar, K. (1990). Chemical and nutritional changes in foods during extrusion. CRC Crit. Rev. Food Sci. Nutr., 29, 35-55.

Cameron, R.E., Durrani, C.M.. and Donald, A.M. (1994). Gelation of amylopectin without long range order. Starch/Stärke, 46, 285-7.

Cameron, R.E. and Donald, A.M. (1992). A small-angle x-ray scattering study of the annealing and gelatinization of starch. Polymer, 33, 2628-35. 
Carlson, T.L.-G., Larsson, K., Dinh-Nguyen. N. and King. N. (1979). A study of the amylose-monoglyceride complex by Ramtim spectroseopy. Starch/Stiöke. 31. $222-4$.

Chandrashekar, A. and Kirleis. A.W. (1988). Influence of protein on starch gelatinization in sorghum. Cereal Chem., 65, 457-62.

Chungcharoen, A. and Lund, D.B. (1987). Influence of solutes and water in rice starch gelatinization. Cereal Chem., 64, 24()-3.

Chrastil, J. (1987). Improved calorimetric determination of anyinse in starches or flours. Carbohydr. Res., 15\%, 154-8.

Ciacco, C.F. and Fernandes, J.L.A. (1979). Effect of various ions m the kinetics of retrogradation of concentrated wheat starch gels. Starch/Stiriter, 31, 51-5.

Cluskey, J.E., Wu, Y.V., Wall, J.S. and Ingletl, G.E. (1973). Oal protein concentrates from a wet-milling process: Preparation. Cereell Chem.. 50, 475-81.

Collison, R. and Chilton, W.G. (1974). Starch gelation ats at lunction of watter content. J. Food Te'dmol., 9. 309-15.

Colwell, K.H., Axford, D.W.E., Chumberlain, N. and Elton. (i.A.II. (1969)). IEffed of storage temperature on the ageing of concentrated wheat starch gels. J. St $i$. Food Agric., 20, 550-5.

Coma, V., Copinet, A., Couturier, Y. and Prudhomme. J. (1995). Biofragmentation of acetylated starch by the $\alpha$-amylase of Aspergillus oryzare. Stcurch/Stärke, 47. $100-7$.

Craig, S.A.S., Maningat, C.C., Seih, P.A. and Hoseney, R.C. (1989). Starch paste clarity. Cereal Chem., 66, 173-82.

Curà, J.A. and Krisman, C.R. (1990). Cereal grains: a study of their $\alpha-1,4-\alpha-1,6$ glucopolysaccharide composition. Starch/Stärke. 42, 171-5. 
D'Appolsnia, B.L. (1972). Effect of bread ingredients on starch-gelatinization propertics as measured by the amylograph. Cereal Chem., 49, 532-43.

Derby, R.I., Miller, B.S., Miller, B.F. and Trimbo, H.B. (1975). Visual observations of wheat-starch gelatinization in limited water systems. Cereal Chem., 52, 7()2-13.

Donovan, J.W. (1979). Phase transitions of the starch-water system. Biopolymers, 18. 26.3-7.5.

Doublier, I.L. (1981). Rheological studies on starch -Flow behaviour of wheat starch pastes. Starch/Stärke, 33, 415-20.

Doublier, J.L., Llamas. G.L. and LeMeur, M. (1987a). A rheological investigation of cereal starch pastes and gels. Effect of pasting procedure. Carbohydr.

Polymers, 7, 251-75.

Doublier, J.L., Paton, D. and Llamas, G. (1987b). A rheological investigation of oat starch pastes. Cereal Chem., 64, 21-6.

Dreher, M.L.. Dreher, C.J. and Berry, J.W. (1984). Starch digestibility of foods: a nutritional perspective. CRC Crit. Rev. Food Sci. Nutr., 20, 47-71.

Eherstein. K., Hüpcke, R., Koniecyny-Janda, G. and Stute, R. (1980). DSCUntersuchungen an Stärken. I. Möglichkeiten thermoanalytischer Methoden zur Stärke-charakterisierung. Starch/Stärke, 12, 397-404.

Eerlingen, R.C.. Van Den Broeck, I.. Delcour, J.A., Slade, L. and Levine, H. (1994). Enzyme-resistant starch. VI. Influence of sugars on resistant starch formation. Cereal Chem., 71, 472-6.

Fliasson. A.-C. (1980)). Effect of water content on the gelatinization of wheat starch. Starh/Staikke, 32, 270-2. 
Eliasson, A.-C. (1983). Differential stanning calorimetry studies on wheat starchgluten mixtures. II. Effects of gluten and sodium stearoyl lactylate on starch crystallization during angeing of wheat statch gels. I. Cereal Sici., 1, 2(17-1,3.

Eliasson, A.-C. (1985). Retrogradation of starelt as measured by differetitial seatmning calorimetry. In New Approaches to Research on C'ercal ('arbolydrates. (ed. Hill, R.D. and Munck. L.). Elsevier Science, Inc., Antsterdam. p1, 9.3-98.

Eliasson, A.-C. (1986a). Viscoelastic behaviour during the gelatinization of starch. J. Texture Stud., 17, 253-65.

Eliasson, A.-C. (1986b). On the effects of surfice active agents on the gelatinization of starch -a calorimetric investigation. Cathohydr: Polymess, 6, t6,3-76.

Eliasson, A.-C. and Krog, N. (1985). Physical properties of amylesse-monoglyecride complexes. J. Cereal Sit., 3, 239-48.

Eliasson, A.-C. and Ljunger, G. (1988). Interactions between amylopectin and lipid additives during retrogradation in a model system. . . Sci. Fond Agric.. 44. 353-61.

Eliasson, A. -C. (1988). On the thermal transitions of the amylesecetyltrimethylammonium bromide complex. Cantohydr. Res., 172, 83-95.

Ellis, H.S. and Ring. S.G. (1985). A study of some factors influencing anylose gelation. Carbolydr: Polymers, 5, 201-13.

Evans, I.D. (1986). An investigation of starch/surlactant interactions using viscometry and differential scanning calorimetry. Starch/Stärke, 38, 227-35.

Franco, C.M.L.. Preto, S.J. doR. Ciacco, C.F. and Tavares, i).(2. ( I (988). Studies on the susceptibility of granular cassavat and corn starches on enzymattic attack. Part 2. Study of the granular structure of starch. Sturchsiairke, 40, 29--32. 
Freeman, J.E. and Verr, W.J. (1972). A rapid procedure for measuring starch paste development and its application to corn and sorghum starches. Cereal Sci. Today, 17, 46-53.

French, D.(1972). Fine structure of stirch and its relationship to the organization of the granules. J. Jph. Sox. Starch Sci., 19, 8-33.

French, D. (1975). Chemistry and biochemistry of starch. In Biochemistry of Carbehydretes. Vol. 5, (ed. Whelan. W.J.). Butterworth and Co. Ltd., London. pр. 267-335.

French, A. D. and Murphy, V.G. (1977). Computer modelling in the study of starch. Cereal Foods World. 22, 61-70.

French. D. (1984). Organisation of starch granules. In Starch: Chemistry and Te'hnology (II). (eds. Whistler, D.M., BeMiller, J.N., and Paschall, E.F.) Academic Press, NY. pp. 188-200.

Fulcher, R.G. (1986). Morphological and chemical organization of the oat kemel. In Oats: Chemistry and Technology. (ed. Webster, F.H.). AACC, Sc. Paul, MN. pp. 47-74.

Gialliard, T. and Bowler, P. (1987). Morphology and composition of starch. In Starch: properties and potential. (ed. Galliard, T.). John Wiley and Sons, NY. pp. $55-78$.

Germani, R., Ciacco, C.F., and Rodriguez-Amaya, D.B. (1983). Effect of sugars, lipids, and type of starch on the mode and kineties of retrogradation of concentrated corn starch gels. Starch/Stärke, 35, 377-81.

Ghiasi, K., Hoseney, R.C. and Varriano-Marston, E. (1982). Gelatinization of wheat starch. IV. Amylograph viscosity. Cereal Chem., 59, 262-5.

Gibinski. M., Palasinski, M. and Tomesik. P. (1993). Physicochemical properties of delatted oat starch. Starch/Stärke, 45, 354-7. 
Gidley, M.J. (1987). Factors affecting the crystalline type (A-C') (1) mative standes and model compounds: a rationalization of observed effets in terms of polymorphic structures. Carbohiver. Re's., 161. 301--4.

Gidley, M.J. and Bulpin. P.V. (1987). Crystallization of millon-oligosatcharides as models of the crystalline forms of starch: minimun chain-lenght repuirement for the formation of double helices. Carbohydr. Res., 161, 2)1-30)(.

Gorinstein. S. (1993). Kinetic studies during enzyme hydrolysis of putalto and cassava starches. Starch/Stärke, 45, 91-95.

Goshima, G., Abe, M., Sato, N., Ohashi, K. and Tsuge, 11. (1985). Amylographic reproducibility of defatted potato starch by the reintrodetion of lipid. Starch/Stärke, 37, 101-14.

Gough, B.M. Greenwell. P. and Russell, P.L. (1985). (On the interation of sodium dodecyl sulphate with starch granules. In New Approuches al Research on Cereal Carbohydrates. (eds. Hill, R.D. and Munck, L.). Ilsevior Sience, Inc.. Amsterdam. pp. 99-105.

Gracza. R. (1965). Minor constituents of starch. In Starch : ('/n'mistry and Technology; Vol.I. Fundamental Aspects (eds. R. L. Whisiler and Paschill, E.F.). Academic Press. NY. pp. 1()5-31.

Gray, V.M. and Schoch, T.J.(1962). Effect of surfactants and fatly adjuncts on the swelling and solubilization of granular starches. Stenc/h/Staitke, 14, 230-46.

Greenwood, C.T. and Milne, E.A. (1968a). Starch degrading and symhesizing enzymes: A discussion of their properties and action pattern. Ads. ('arbohlyalr. Chein., 23, 281-366.

Greenwood, C.T. and Milne, E.A. (1968h). Studies on starch degrading enzymes. Part VII. Properties and action pattern of the $\alpha$-imylises from harley, wats. rye and wheat. Starch/Stärke, 20, I()1-7. 
Giudmundssun. M. and Fliasson. A.-C. (1989). Some physico-chemical properties of aat starches extracted from varieties with different oil content. Acta Agric. Srand.. 39. 101-11.

(iudmundsson. M. and Eliasson. A.-C. (1991). Thermal and viscous properties of rye starch extracted from different varieties. Cereal Chem., 68, 172-7.

Gudmundsson. M. and Eliasson. A.-C. (1992). Comparison of thermal and viscoelastic propertics of four waxy starches and the effect of added surfactant. Starch/stiorke. 44, 379-85.

Hahu, 1).F.. and Hood, L.F. (1987). Factors influencing corn starch-lipid complexing. cirecal chem., 64, 8:-5.

Hansen, L.M., Sester. C.S., and Paukstelis, J.V. (1989). Investigation of sugarstarch interactions using carbon-13 nuclear magnetic resonance. I. Sucrose. Cereal Chem., 66. $411-15$.

Hasc. S.. Kawamura. U. and Yasui. T. (1981). Effects of sugars and sugar alcohols on the gelatinization and retrogradation of starch. Rept. Natl. Food Res. Inst.(Tsukuba. Japan). 38, 73-84.

Hashim. D.B.M.. Moorthy. S.N., Mitchell, J.R., Hill, S.E., Linfont, K.J. and Blanshard, J.M.V. (1992). The effect of low levels of antioxidants on the swelling and solubility of cassava starch. Starch/Stärke, 44, 471-5.

Hellman. N.N., Fairchild, B. and Senti. F.R. (1954). The bread staling problem. Molecular organization of starch upon aging of concentrated starch gels at rarious moisture levels. Cereal Chem., 31, 495-505.

Ilill. R.D. and MatGregor, A.W. (1987). Cereal $\alpha$-amylases in grain research and technology. In Adrances in Coreal Science and Technology. Vol. IX. (ed. Pomeram\%. Y.). AACC, St. Paul, MN. pp. 217-61. 
Hizukuri. S., Kaneko. T. and Takeda, Y. (1983). Measurement of the chain length of amylopectin and its relevance to the origin of erystalline polymorphism of starch granules. Biochim. Biophlys. Acta, 760, I88-91.

Hizukuri, S., Takeda. Y. and Yasuda, M. (1981). Multi-branched nature of anylose and the action of debranching enzymes. Carbohych. Res., 94. 205-1.3.

Hizukuri. S. (1985). Relationship between the distribution of the chatis length of amylopectin and the erystalline structure of statch granules. Carbohrdr: Res., 141. 295-306.

Hizukuri, S. (1986). Polymodal distribution of the chain lengths of amylopectins, and its significance. Carbolnydr: Res., 147, 342-47.

Holm, J., Björck, I. and Eliasson, A.-C. (1988). Effects of themal processing of wheat on starch. I. Physico-chemical and functional properties. I. C'real Sri., 8, 249-60.

Holm, J., Björck, I, Ostrowska, S., Eliasson, A.C., Asp, N.G., Larrson, K. and Lundquist, 1. (1983). Digestibility of anylose-lipid complexes in vifro and in vivo. Starch/Stairke, 35, 294-7.

Holm, J. and Björck, I. (1988). Effect of thermal processing of wheilt on starch. II. Enzymic availability. J. Cereal Sci., 8, 261-8.

Hoover, R. (1995). Starch retrogradation. Foud Reviows Intermational, 1 1, 331-46.

Hoover, R. and Vasanthan, T. (1992), Studies on isolation and characterization of starch from oat (Avena meda) grains. Carbohydr. Polymers, 19. 285-97.

Hoover, R., Swamidas, G. and Vasanthan, T. (1993). Studies on the physicochemical

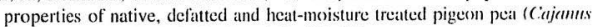
cajan L) starch. Carbolivelr. Res., 246, 18.5-203. 
Hoover, R. and Vasanthan, T. (1994). Effect of heat-moisture treatment on the structure and physicochemical properties of cereal, legume, and tuber starches. Carbohydr. Res., 252, 33-53.

Hoover, R. and Vasanthan, T. (1994). The effect of annealing on the physicochemical propertics of wheat, oat, potato and lentil starches. J. Ford Biochem., 17. 303-25.

Hoover, R., and Hadriyev, D. (1981). Characterization of potato starch and its monoglyceride complexes. Starch/Stärke, 33, 290-300).

Hoover, R. and Sosulski, F.W. (1985). Studies on the functional characteristics and digestibility of starches from Phaseolus vulgaris biotypes. Starch/Stärke, 37, $181-91$.

Hosency, R.C., Atwell, W.A., and Lineback, D.R. (1977). Scanning electron microscopy of starch isolated from baked products. Cereal Foods world, 22, $56-60$.

Huang, R., Chang, W., Chang, Y. and Lii, C. (1994). Phase transitions of rice starch and flour gels. Cereal Chem., 71, 202-7.

I'anson, K.J., Miles, M.J., Morris, V.J., Besford, L.S., Jarvis, D.A. and Marsh, R.A. (1990). The effects of added sugars on the retrogradation of wheat starch gels. J. Cereal Sci.. 11. 243-8.

Imbrty. A., Chumzy. H., Perez, S., Buleon, A. and Tran, V. (1987). Three-dimensional structure analysis of the crystalline moiety of A-starch. Food Hydrocolloids, 1, $4.55-9$.

Imberty. A., Bulćon. A.. Tran, V. and Pérez, S. (1991). Recent advances in knowledge of starch structure. Starch/Stärke, 43, 375-84.

Jenkins, P.J., Cameron, R.E., and Donald, A.M. (1993). A universal feature in the structure of starch granules from different botanical sources. Starch/Stärke, 45, 4I7-20. 
Johnson, J.M., Davis, E.A. and Gordon, J. (190(a). Lipid hinding of modified eorn starches by electron spin resonance. Cereal Chem., 67, 236-40).

Johnson, J.M., Davis, E.A. and Gordon. J. (199()b). Interactions of stiuch and sugatr water measured by electron spin resonance and diflerential scamning salorimetry. Cereal Chem., 67, 286-91.

Kainuma, K. and French, D. (1971). Nageli amylodextrin and its rutationship to starch granule structure I. Preparation and properties of amylodextrins fiom various starch types. Biopelymors. 10. 1673-7.

Kalichevsky, M.T. Orford, P.D. and Ring. S.G. (199()). The retrogradation and gelation of amylopectins from various botanical sources. Carbohydr. Re's., $198,49-55$

Karow, R.S., Forsberg. R.A. and Peterson. D.M. (1984). A comparison of Iwo rapid oat-lipid extraction procedures in terms of latty-acid profile. Cereal chem, 61, 196-7.

Katsuta, K., Miura, M. and Nishimura, A. (1992a). Kinetic treatment for rheological properties and effects of saccharides on retrogradation of rice starch gels. Food Hydrocollovids. 6, 187-98.

Katsuta, K., Nishimura, A. and Miura, M. (1992h). Effects of sacebaricles on stabilities of rice starch gets. I. Mono- and disilccharides. Fond Hyrfocollesids, 6. 387-98.

Katsuta, K.. Nishimura, A. and Miura, M. (1992c). Eflects of salceharides on stabilities of rice starch gels. 2. Oligosaccharides. Fond Hrdrocollowids, 6, 399-408.

Katz, J.R. and Van Itallie, T.B. (1930). Abhandlungen zuv physikalischen chemie der stärke und eler brotbereitung. V. Alle starkearten haben das gleiche. Retrogradations spektrum. Z. Phys. Chem., 150, 9()-1()(). 
Knutson, C.A., Khoo, U., Cluskey, J.E. and Inglett, G.E. (1982). Variation in enzyme digestibility and gelatinization behavior of corn starch granule fractions. Cereal Chem., 59, 512-5.

Koepsel, K.M. and Hosency, R.C. (1980). Effects of corn syrups in layer cakes. Cereal Chem., 57, 49-53.

Konik, C.M., Miskelly, D.M. and Gras, P.W. (1993). Starch swelling power, grain hardncss and protein: Relationship to sensory properties of japanese noodles. Starch/Stärke, 45, 136-39.

Kowblansky, M. (1985). Calorimetric investigation of inclusion complexes of amylose with long-chain aliphatic compounds containing different functional groups. Macromolecules, 18, 1776-79.

Krog, N. and Jensen, N. B. (1970). Interaction of monoglycerides in different physical states with amylose and their anti-firming effects in bread. J. Food Techolmol., 5, 77-87.

Krog. N. (1971). Amylose complexing effect of food grade emulsifiers. Starch/Stärke, 23, 206-10.

Krog, N. and Lauridsen, J.B. (1976). Food cmulsifiers and their associations with water. In Fond Emulsioms. (ed. Friberg, S.). Marcel Dekker, Inc., NY. pp. 67135.

Krog. N., Olesen. S.K.. Toernaes, H. and Joensson. T. (1989). Retrogradation of the starch fraction in wheat bread. Cereal Foods World, 34, 281-5.

Krïsi, Von H. and Neukom, H. (1984). Untersuch unger über die retrogradation der stärke in konzentrierten weizestärkegelen. Teil. I. Herstellung konzentrierter gele, einflub der stärke koncentration and herstellungsbedingungen auf die retrogradution der stibie. Starch/Stärke, 36, 40-5.

Kugimiya. M., Donovan. J.W. and Wong. R.Y. (1980). Phase transitions of amyloselipid complexes in starches: a calorimetric study. Starch/Stärke, 32. 265-70. 
Kulp, K. and Lorenz, K. $(1981)$. Heat-moisture treatment of starches. 1. Physicochemical properties. Cereal Chem.. 58. th-8.

Kulp, K. and Ponte, Jr.. J.G. (1981). Staling of white pan bread: fundamental causes. Crit. Rev, Food Sici. Nutr., 15, 1-48.

Lagendijk, J. and Pennings, H.J. (1970). Relation between complex formation of starch with monoglyeerides and the fimmess of bread. C'ereal Si.i. Toda!n. 15. 354-70.

Larsson, K. and Miezis, Y. (1979). On the possibility of dietary fiher formation by interaction in the intestine between starch and lipids. Sturch/Stärke, 31, 301-2.

Launay, B., Doublier, J.L. and Cuvelier. G.( 1986). Flow properties of anueous solutions and dispersions of polysaccharides. In linnctienal propertices of food macromolecules. (eds. Mitchell, J.R., and Ledward, D.A.), Iilsevier Applied Sci. Publ., NY. pp. 56-78.

Lauro, M., Suorti, T., Autio, K., Linko, P. and Poutanen, K. (1993). Accessibility of barley starch granules to $\alpha$-amylase during diflerent phasus of gelatinization. J. Cercal Sci.,17, 125-36.

Leach, H.W., McCowen, L.D. and Schoch, T.I. (1959). Structure of the starch granule. 1. Swelling and solubility patteins of various starclies. C'ereal Cheni., 36, 534-44.

Lee, S.-J., Yoo, S.H., Kim, M.J., Kim, J.W., Seok, H.M. and Park, K.H. (I9)5). Production and characterization of branched oligosaccharides from liquefied starch by the action of B. licheniformis amylase starch. Starch/Stiorke, 47 , 127-34.

Leegwater, D.C., Zeist, and Luten, J.B. (1971). A study on the in vitro digestibility of hydroxypropyl starches by pancreatin. Siar:h/Stärke, 23, 4.3()-2. 
Leloup, V. M., Colonna, P., Ring, S.G., Roberts, K. and Wells, B. (1992). Microstructure of amylose gels. Carbohydr. Polymers, 18, 189-97.

Lineback, D.R. (1984). The starch granule organization and properties. Baker's Dig., 58, 16-8.

Linchack, D.R. and Rasper, V.F. (1988). Wheat carbohydrates. In Wheat: Chemistry and Techology. (cd. Pomeran\%, Y.). AACC, St. Paul, MN. pp. 277-372.

Liukkonen, K. and Laakso, S. (1992). Characterization of internal and surface lipids of oat starches from two isolation processes. Starch/Stärke. 44, 128-32.

Liukkonen, K.H., Montfoort, A., Laakso. S.V. (1992). Water-induced lipid changes in (at processing. J. Agric. Food Chem., 40, 126-30.

Longton, J. and LeGrys, G.A. (198I). Differential scanning calorimetry studies on the crystallization of ageing wheat starch gels. Starch/Stärke, 33, 410-4.

Lund, D.(1984). Influence of time, temperature, moisture, ingredients, and processing conditions on starch gelatinization. CRC Crit. Rev. Food Sci. Nutr., 20, 249-72.

MacArthur, L.A. and D'Appolonia, B.L. (1979). Comparison of oat and wheat carbohydrates. II. Starch. Cereal Chem., 56, 458-61.

MacMasters, M.M., Wolf, M.J. and Seckinger, H.L. (1947). The possible use of oat and other cereal grains for starch production. Am. Miller Process, 75, 82-83.

Mäkelii. M.J. and Laakso. S. (1984). Studies on oat starch with celloscope: granule size and distribution. Starch/Stärke, 36, 159-63.

Manley, R.S.J. (1946). Chain folding in amylose crystals. J. Polym. Sci., 2, 4503-6.

Manners, D.J. (1962). Enzymic synthesis and degdradation of starch and glycogen. Adv: Carbolydir: Chem. 17, 371-430. 
Manners, D.J. (1974). Some aspects of the enzymic degradation of starch. In I'lamt Carbohydrate Chemistry. (ed. Pridham. I.B.). Actidemic Press, NY. pp. I()9-25.

Manners, D.J. and Matheson. N.K. (1981). The line structure of amylopectin. Carbohydr: Res., 90, 99-110.

Manners, D.J. (1985a). Some aspects of the structure of starch. C're'al liosds World, 30, 461-7.

Manners, D.J. (1985b). Some aspects of the metabolism of starch. C'ereal Fouds World, 30. 722-7.

Manners, D.J. (1985c). Starch. In Biochemistry of Storage Carbohychates in (ire'n Plants. (eds. Dey, P.M. and Dixon, R.A.). Acidemic Press, NY. pp. 149-2(03.

Manners, D.J. (1989). Recent deveiopments in our understanding of amylopectin structure. Carbohydi: Polymers, 11, 87-112.

Marchant, J.L. and Blanshard, J.M.V. (1978). Studies of the dymimics of the gelatinization of starch granules employing a small angle light scittering system, Starch/Stärke, 30, 257-64.

Marsden, W.L. and Gray, P.P. (1986). Enzymatic hydrolysis of cellulose in lignocellulosic materials. CRC Crit. Rev. Biolectmol., 3, 235-76.

Maurice, T.J., Slade, L., Page, C.M. and Sirett, R.R. (1985). Polysactharide-water interactions-Thermal behavior of rice starch. In Propertices of Woter in Foods, (eds. Simatos, D. and Multon, J.L.). Martinus Nijhofl, Dordrecht, The Netherlands. pp. 211-27.

Maxwell, J.L. and Zobel, H.F. (1978). Model studies on cake staling. Cereerl fionds World, 23, 124-8.

McBurney, M.I. (1991). Passage of starch into the colon of humans: quantitation and implications. Can. J. Physiol. Pharmacol., 69, 130)-36. 
McMullen, M.S. (1991). Oats. In Handbook of Cereal Science and Technology. (eds. Lorenz, K.J. and Kulp. K.) Mareel Dekker, Inc. NY. pp. 199-232.

Medcall, D. G. and Gilles, K. A. (1965). Wheat starches. I. Comparison of physicochemical properties. Cereal Chem., 42, 558-68.

Meyer, K.H. and Bernfeld, P. (1940). Recherches sur l'amidon. V.L'Amylopectine. Hels. Chim. Actu, 23. 875-85.

Mikus, F.F., Hixon, R.M. and Rundle, R.E. (1946). The complex of fatty acids with amylose. J. Am. Chem. Soc, 68, 1115-23.

Miles, M.J., Morris, V.J., and Ring, S.G. (1984). Some recent observations on the retrogradation of amylose. Carbohydr. Polymers, 4, 73-7.

Miles, M.J., Morris, V.J., Orford, P.D., and Ring, S.D. (1985a). The roles of amylose and amylopectin in the gelation and retrogradation of starch.

Carbolycdr. Res., 135, 271-81.

Miles, M.J.. Morris, V.J., and Ring. S.G. (1985b). Gelation of amylose. Carboluydr. Res., 135, 257-69.

Minitab. Inc. (1991). Minitab computer supplement: Statistics for business and economics. 5th. edition. Minitab, Inc., State College, PA. pp. 299-319.

Miara, M., Nishimura, A. and Katsuta, K. (1992). Influence of addition of polyols and food emulsifiers on the retrogradation rate of starch. Food Structure, 11, 225-36.

Motris, V.J. (1990). Starch gelation and retrogradation. Trends in Food Science and Tochnology, July. 2-6.

Morrison. W.R.. Mann. D.L.. Wong. S. and Conventry, A.M. (1975). Selective extraction and quantitative analysis of non-starch and starch lipids from wheat llour. J. Sci. Food Agric.. 26, 507-21. 
Morrison, W.R. (1981). Starch lipids: a reappraisal. Star(h/Stärke', 33, 4(1)-10.

Morrison, W.R., Milligan. T.P. and Azudin, M.N. (1984). A relationship between the amylose and lipid contents of starches from diploid cereils. J. C'reral Siti., 2, 257-71.

Morrison, W.R. (1988). Lipids in cercal starches: a review. I. C're'al Sici., 8, 1-15.

Muhrbeck, P. and Eliasson, A.-C. (1987). Influenee of pH and ionic strength on the viscoelastic properties of starch gels. A comparisen of potato and eissava starches. Carbohydr: Polymers, 7, 29)-6.

Myrbäck, K. and Neumuller, G. (1950). Amylases and the hydrolysis of starch and glycogen. In The Enzymes, Chemistry and Morhamism of Action. Ist ed. (eds. Sumner, J.B. and Myrbäck, K.). Academic Press, NY. pp. 65.3-724.

Olkku, J. and Rha, C. (1978). Gelatinization of starch and wheall flour starch.- $\Lambda$ review. Food Chem., 3, 293-317.

Oosten, B.J. (1984). Effects of organic molecules on the gelatinization temperature of starch. Starch/Stärke, 36, 18-23.

Orford, P.D., Ring, S.G., Carroll. V., Miles, M.J., and Morris, V.J. (|987). The effect of concentration and botanical source on the gelation and retrogradation of starch. J. Sci. Food Agric., 39, 169-77.

Osman, E.M., Leith, S.J. and Fles, M. (1961). Complexes of amylose with surfitctants. Cereal Chem, 38, 449-53.

Paredes-Lope\%, O. and Hernànde\%-Lope\%, D. (|99|). Application of differential scanning calorimetry to amaranth starch gelatinization -lnfluence of water, solutes and annealing. Starch/Stärke, 43, 57-61.

Paton, D. (1977). Oat Starch. I. Extraction, purification and pasting propertics. Starch/Stäirke, 29, 149-53. 
Palton, D. (1979). (at Starch. Some recent developments. Starch/Stärke, 31, 184-7.

Paton, D. (1986). Oat Starch: Physical, chemical and structural properties. In Outs: Chemistry and Technology: (ed. Webster, F.H.). AACC, St. Paul, MN. pp. 93-120.

Paton, D. (1987). Differential scanning calorimetry of oat starch pastes. Cereal Chem., (64, 394-9.

Pizzur, J.H. (1965). Enzymes in synthesis and hydrolysis of starch. In Starch Chemistry and Ter/molegy. Vol. I. Fumedanemtal Aspects. (eds. Whistler, R.L. and Piaschall, E.F.). Academic Press, NY. pp. 133-75.

Preiss, J. and Levi, C. (1980). Starch biosynthesis and degradation. In The Biochemistry of Plants: a comprehensive treatise. Vol. 3. (ed. Preiss, J.). Aciddemic Press, NY. pp. 371-423.

Raphaclides, S. and Karkalas, J. (1988). Thermal dissociation of amylose-fatty acid complexes. Carbohydr. Res.. 172. 65-8.

Riisom, T., Krog. N. and Eriksen, J. (1984). Amylose complexing capacities of cisand trans-unsaturated monoglycerides in relation to their functionality in hread. J. Cereal Sci.. 2. 105-18.

Ring. S.G. (1985). Some studies on starch gelation. Starch/Stärke, 37, 80-3.

Ring. S.G.. I'Anson, J. and Morris, V.J. (1985). Static and dynamic light scattering studies of amylose solutions. Macromolecules, 18, 182-5.

Ring. S.G. (1987). Molecularm interactions in aqueous solutions of the starch polysaccharides: a review. Fond Hydrocolloids, 1, 449-54.

Ring, S.G., Colonna, P., l'Anson, K.J., Kalichevsky, M.T., Miles, M.J., Morris, V.J., and Orford, P.D. (1987). The gelation and crystallization of amylopectin. Carbolndedr: Res.. 162. 277-93. 
Ring. S.G.. Gee. J.M.. Whittam, M., Orford, P. and Johnson, I.T. (1988). Resistant starch: its chemical form in foodstuffs and effect on digestibility in vitro. Food Chem., 28, 97-109.

Robin. J.P.. Mercier, C.. Charbonniere, R., and Guilhot, A. (1974). Lintnerized starches. Gel filtration and enzymatic studies of insoluble residuss from prolonged acid treatment of potato starch. Cercal (\%'m., 51, 389-4)(3.

Robin. J.P., Mercier. C. Duprat. F.. Charbonniere, R. and Gitullsot, A. (1975). Amidons lintnérisés. Etudes chromatographique el emzymatiçue des risidus insolubles provenant de l'hydrolyse chlorhydrique d'amidons de cercess, en particulier de maïs cireux. Starch/Stärke, 27, 36-45.

Robyt, J.F. and French, D. (1967). Multiple attack hypothesis of $\alpha$-imylase action: Action of porcine pancreatic, human salivary and Asprergillus oryan $\alpha$-amylases. Arch. Biochem. Biophys., 122, 8-16.

Robyt, J.F. and Whelan, W.J. (1968a). The $\alpha$-imylases. In Stare/h and lts / Trritutiles. (ed. Radley, J.A.). Chapman and Hall Ltd. London. pp. 430-76.

Robyt, J.F. and Whelan, W.J. (1968b). The $\beta$-amylases. In Starr/h and It.s I Derivatiles. (ed. Radley, J.A.). Chapman and Hall Ltd. London. pp. 477-97.

Robyt, J.F. (1984). Enzymes in the hydrolysis and synthesis of starch. In Starrh: Chemistry and Technology. (eds. Whistler, R.L.. BeMiller. J.N. and Paschall. E.F.). Academic Press, Orlando, FL. pp. 87-123.

Roos, Y.H. (1992). Phase transitions and transfirmations in food systems. In Handbook of Food Engineering. (eds. Heldman, D.R. and L.und, I).B.). Marcel Dekker, Inc., NY. pp. 145-97.

Rosario, R.R. del and Pontiveros, C.R. (1983). Retrogradation of some starch mixtures. Starch/Stärke, 35, 86-92. 
Roulet, P.H., MacInnes, W.M., Wursch, P., Sanchez, R.M. and Raemy, A. (1988). A comparative study of the retrogradation kinetics of gelatinized wheat starch in gel and powder form using $x$-rays, differential scanning calorimetry and dynamic mechanical analysis. Fond Hydrocollosids, 2, 381-96.

Russell, P.L. (1983). A kinetic study of bread staling by differential scanning calorimetry and compressibility measurements. The effect of added monoglyceride. J. Cereal Sci.. 1, 297-303.

Russell, P.L. and Oliver, G. (1989). The effect of $\mathrm{pH}$ and $\mathrm{NaCl}$ content on starch gel ageing. A study by differential scanning calorimetry and rheology. J. Cereal Sici. 10, 123-38.

Strko, A. and Wu, H.C.H. (1978). The crystal structures of A-, B- and C-polymorphs of amylose and starch. Starch/Stärke, 30, 73-78.

Savinge, H.L. and Osman, E.M. (1978). Effects of certain sugars and sugar alcohols on the swelling of corn starch granules. Cereal Chem., 55, 447-54.

Schuch, T.J. and Maywald, E.C. (1968). Preparation and properties of various legume starches, Cereal Chem., 45, 564-73.

Shamekh, S., Forssell, P. and Poutanen, K. (1994). Solubility pattern and recrystallization behavior of oat starch. Starch/Stätke, 46, 129-33.

Shamnon, J. C. and Garwood, D.L.(1984). Genetics and physiology of starch development. In Starch Chemistry and Techmology.(eds. Whistler, R.L., BeMiller, J. N. and Paschall, E. F.), Academic Press Inc. NY. pp. 26-86.

Sievert, D. and Wursch, P. (1993). Amylose chain association based on differential scanning calorimetry. J. Food Sci.. 58, 1332-35.

Slade, L. and Levine. H.(1987). Recent Advances in Starch Retrogradation. In Industrial Polysactharides: The Impact of Biotechmology and Advanced Methodologies.(eds. Stivala. S.S., Crescenzi, V. and Dea, I.C.M.) Gordon and Breach Science Publishers, NY. pp.387-430. 
Slade, L. and Levine, H. (1988). Non-equilibrium melting of native gramular statch. P'ar! I. Temperature location of the glass transition associalled with gelatinization of A-type cereal starches, Carbohydr: Polymers. 8. 18.3-2()s.

Sollars, W.F. (1973). Water-retention properties of wheat flour frations. C'ereul Chem.. 50. 717-22.

Soni, P.L. Sharma. H., Dun, D. and Gharia. M.M. (1943). Physicenchemical properties of Quercus leucotrichophora (oak) starch. Sturch/Stätke, 45. I21-7.

Sowa, S.M. and White, P.J. (1992). Characterization of starch isolated from oal groats with different amounts of lipids. Cereal ('hem.. (6). 521-7.

Spies, R.D. and Hoseney, R.C. (1982). Effect of sugars on starch gelatinization. Cereal Chem., 59, 128-31.

Sreenath, H.K. (1992). Studics on starch grantes digestion hy $\alpha$-imylase. Starch/Stairke, 44, 61-3.

Svegmark, K. and Hermansson. A.-M. (1993). Microstrature and rheohgical properties of composites of potato starch granules and amylose: $\wedge$ comparison of observed and predicted structures. Fond Siruchure, 12. 181-19)3.

Swinkles, J.J.M. (1985). Composition and properties of commercial mative starches. Starch/Stärke, 37, 1-5.

Takahashi, S. and Seib, P.A. (1988). Paste and gel properties of prime corn and wheat starches with and without native lipids. Cereal ('/e'm., 65. 474-83.

Tester, R.F. and Morrison, W.R. (1990)). Swelling and gelatinization of curcal starches. I. Effects of amylopectin, amylose and lipids. ('W'al ('/n'm., 67. 551-7.

Thoma, J.A., Spradlin, J.E. and Dygert, S. (1971). Plant and animial amylases. In The Enzymes. 3rd Ed., Vol.5. (cd. Boyer, P.D.). Academic Press, NY. pp.115-89. 
Thema. . .А. (1976). Models fir depolymerizing enzymes. Application to $\alpha$-amylases. Birpolimers, 15, 729-40.

Tomasik, P.. Wang, Y.-I. and Jane, J.L. (1995). Complexes of starch with lowmolecular saceh harides. Starch/Stärke, 47, 185-9].

Tsuge. H., Tatsumi, E., Ohtani, N. and Nakazima, A. (1992). Screening of $\alpha$-amylase for evaluating the degrec of starch re rogradation. Starch/Stairke, 44, 29-32.

Vitiler. S., Hanssen, K.F., and Aligenaes, O. (1984). The effect of cooking upon the blood glucose response to ingested carrots and potatoes. Diabetes Care. 7 . $221-3$.

Van L.onkhuysen. H. and Blankestijn. I. (1976). Influence of monoglycerides on the gelatinization and enzymatic breakdown of wheat and cassava starch. Siarch/siäke. 28. 227-31.

Vissinthan. T. and Hoover. R. (1992). Effect of defatting on starch structure and physicothemical properties. Food Chem.. 45, 337-47.

Wang. L.\%.. and White. P.J. (1994). Functional propertie: of oat starches and relationships among lunctional and structural characteristics. Cereal Chem.. $71,+51-58$.

Ward, K.F.J.. Hoseney, R.C. and Seib, P.A. (1994). Retrogradation of amylopectin from maize and wheat starches. Cereal Chem., 71, 150-5.

Williams. P.C.. Kuzinat. F.D. and Hlynka. I. (1970). A rapid colorimetric procedure for estimating the amylose content of starches and flours. Cereal Chem., 47. $411-20$.

Williamson. G.. Belshaw. N.J.. Self, D.J., Noel, T.R., Ring, S.G., Cairns, P., Morris, V.I.. Clark, S.A. and Parker, M.L. (1992). Hydrolysis of A- and Btype crystalline polymorphs of starch by $\alpha$-amylase, $\beta$-amylase and glucoamylase 1. Carbolndi: Polymers, 19, 179-87. 
Wolever. T.M.S. (1991). Small intestinal effects of starchy foods. (im. I. Ihixiol. Pharmacol.. 69, 93-99.

Wolters, M.G.E. and Cone. J.W. (1992). Prediction of degradability of starch by gelatinization enthalpy as measured by differential scanning calorimetry. Starch/Stärke. 44. 14-8.

Wood. P.J.. Weisz. J. and Fedec. P. (1987). ()at beta glucan-Potential value as

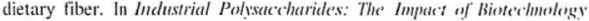
and Advenced Methodoleggies.(eds. Stivala. S.S.. Crescenzi. V. and Deil. I.C.M.) Gordon Breach Science Publishers. NY, pp. 215-27.

Wootton, M. and Bamunuarachehi, A. (1979). Application of differential scanning calorimetry to starch gelatinization. II. Effect of heating rate and moisture level. Starch/Starke, 31, 262-4.

Wootton. M. and Bamunuarachchi, A. (1980). Application of differential scamning calorimetry to starch gelatinization. III. Fiffects of sucrose and sodium chloricle. Starch/Stärke. 32, 126-9.

Wootton, M. and Chaudhry, M.A. (1979). Enzymic digestibility of modified starches. Sturch/Stärke. 31, 224-8.

Wootton, M. and Chaudhry, M.A. (1980). Gelatinization and in vitro digestihility of slarch in baked products. J. Food Sci., 45, 1783-4.

Wootton. M. and Mahdar, D. (1993). Properties of starches from atustralian wheats. Part 3: In vitro digestibility and hydroxypropyl derivatives. Sturth/Stïrke, 45. $337-41$.

Wu, Y.V., Cluskey, J.E., Wall, J.S. and Inglell, (i.J:. (1973). ()at protein concentrates from a wet milling process: Composition and propertics. ('ereerl Chem.. 50, 481-88.

Wu, Y.V. and Stringfellow, A.C. (1973). Protein concentrates from calt flours by air classification of normal and high-protein varieties. Cereal ('hr'm., 50. 489)-96. 
Wu, H.C.H. and Sarko, A. (1978a). The double-helical molecular structure of crystalline B-amylose. Carbohydr. Res., 61, 7-26.

Wu, H.C.H. and Sarko, A. (1978b). The double-helical molecular structure of Aamylose. Carbolịdr. Res., 61, 27-40.

Wu. Y. and Seib. P.A. (1990). Acetylated and hydroxypropylated distarch phosphates from waxy barley, paste properties and freeze-thaw stability. Cereal Chem., 67, 2()2-8.

Yamishita, Y.-H., Ryugo, J. and Monobe, K. (1973). An electron microscopic study on crystals of amylose V complexes. J. Electron Microscopy, 22, 19-23.

Youngs, V.L. (1972). Protein distribution in the oat kernel. Cereal Chem.,49, $407-11$.

Youngs. V.L. (1978). Oat lipids. Cereal Chem.. 55. 591-7.

Yuan. R.C.. Thompson. D.B. and Boyer, C.D. (1993). Fine structure of amylopectin in relation to gelatinization and retrogradation behavior of maize starches from thre wx-containing genotypes in two inbred lines. Cereal Chem., $\mathbf{7 0 ,}$ 81-9.

\%eleznak, K.J. and Hoseney, R.C. (1986). The role of water in the retrogradation of wheat starch gels and bread crumb. Cereal Chem.. 63. 407-11.

Zeleznak. K.J. and Hoseney. R.C. (1987). Characterization of starch from bread aged at different temperature. Starch/Stärke, 39, 231-5.

Zohel, H.F., French, A.D. and Hinkle, M.E. (1967). X-ray diffraction of oriented amylose fibers. II. Structure of V-amyloses. Biopolymers. 5. 837-45.

\%obel. H.F. (1984). Gelatinization of starch and mechanical properties of starch pastes. In "Starch Chemistry and Techmology. (eds. Whistler, R.L., Paschall, E.1. and BeMiller. J.N.). Academic Press, NY. pp. 285-309. 
Zobel, H.F. (1988a). Starch crystal transformations and their industrial importance. Starch/Stärke, 40. 1-7.

Zobel, H.F. (1988b). Molecules to granules: a comprehensive starch review. Starh/Stärke, 40, 44-50. 


\section{PUBLICATIONS}

Hoover, R., Vasanthan, T., Senanayake, N. J. and Martin, A.M. (1994). The effects of defatting and heat-moisture treatment on the retrogradation of starch gels from wheat, oat, potato, and lentil. Carbohydr. Res., 261, 13-24.

Hoover, R. and Senanayake, S.P.J.N. (1995). Composition and physicochemical properties of oat starches. Food Research International (Accepted for publication, August 9, 1995). 


